HERMES FRANCISCO DE BARROS SANTOS LA MACCHIA

ANÁLISE DO CURTO-CIRCUITO TRIFÁSICO EM GERADORES DE INDUÇÃO DUPLAMENTE ALIMENTADOS 
HERMES FRANCISCO DE BARROS SANTOS LA MACCHIA

\section{ANÁLISE DO CURTO-CIRCUITO TRIFÁSICO EM GERADORES DE INDUÇÃO DUPLAMENTE ALIMENTADOS}

Dissertação apresentada à Escola Politécnica da Universidade de São Paulo para obtenção do título de Mestre em Engenharia 
HERMES FRANCISCO DE BARROS SANTOS LA MACCHIA

\section{ANÁLISE DO CURTO-CIRCUITO TRIFÁSICO EM GERADORES DE INDUÇÃO DUPLAMENTE ALIMENTADOS}

Dissertação apresentada à Escola Politécnica da Universidade de São Paulo para obtenção do título de Mestre em Engenharia

Área de concentração:

Engenharia Elétrica - Sistemas de Potência

Orientador: Professor Doutor Silvio Ikuyo Nabeta 
Este exemplar foi revisado e alterado em relação à versão original, sob responsabilidade única do autor e com a anuência de seu orientador.

São Paulo, de de 2013.

Assinatura do autor

Assinatura do orientador

La Macchia, Hermes Francisco de Barros Santos

Análise do curto-circuito trifásico em geradores de indução duplamente alimentados / H.F.B.S. La Macchia. - versão corr. -São Paulo, 2013.

$90 \mathrm{p}$.

Dissertação (Mestrado) - Escola Politécnica da Universidade de São Paulo. Departamento de Engenharia de Energia e Automação Elétricas.

1.Máquinas elétricas I.Universidade de São Paulo. Escola Politécnica. Departamento de Engenharia de Energia e Automação Elétricas II.t. 


\section{RESUMO}

Este trabalho propõe a análise de curtos-circuitos trifásicos em geradores de indução duplamente alimentados (DFIG - Doubly Fed Induction Generator).

Os DFIGs voltam à pauta de hidrogeração devido aos recentes investimentos em usinas hidrelétricas reversíveis com velocidade variáveis empregando DFIGs. Esta configuração de geração, que permite velocidade do eixo diferente da frequência da rede, também é uma opção para usinas hidrelétricas convencionais, trazendo benefícios em termos de eficiência energética, estabilidade e otimização do sistema de potência.

As pesquisas envolvendo este tipo de gerador tem se concentrado em aplicações para energia eólica. Os estudos são focados em aspectos de controle e otimização da geração não havendo muitos trabalhos voltados ao estudo de curto-circuito do ponto de vista da máquina principalmente relativos à solução analítica.

Os trabalhos voltados a transitórios tratam em geral de afundamentos de tensão na linha de transmissão e metodologias para manter o gerador conectado ao sistema durante estes transitórios. $\mathrm{Na}$ área de hidrogeração, na maioria dos casos, os estudos tratam de aspectos de controle, de otimização da operação e de ganhos para o sistema de potência quando do uso do DFIG. Assim, faz-se necessário aumentar a gama de estudos do comportamento desses geradores frente a transientes elétricos, mais especificamente a curtos-circuitos.

Para o estudo de transientes do curto-circuito trifásico foi desenvolvida a solução analítica e um modelo baseado no proposto por Krause (KRAUSE, 2002) para simulação em Simulink do Matlab para comparação de resultados.

Palavras-Chave: Usinas Reversíveis, Máquinas elétricas, DFIG. 


\begin{abstract}
This work proposes the analysis of three-phase short circuit on doubly fed induction generator, DFIG.

This generator is again a subject of study for hydrogeneration as per recent investments on variable-speed Pumped Storage Power Plants. This configuration, which allows asynchronous shaft speed, is also an alternative for conventional hydro power plants, providing improvements on energy efficiency and stability and optimization of power system.

Current studies on this subject are focused on wind power applications, covering mostly control and generation optimization aspects while there aren't so many studies on short-circuit especially with analytical solution.

Electrical transient studies are usually covering voltage dips or sags on transmission line and associated methods to maintain power unit connected to power system during such. The researches on hydro power are also about control, operational optimization and power system improvements when DFIGs are installed. Thus, it is necessary to contribute to research regarding behavior of such generators under electrical transient conditions, more specifically under short circuits.

The analytical equation for three-phase short circuit was developed as well the electric model based on the one proposed by Krause (KRAUSE, 2002) for simulations on Simulink of Matlab.
\end{abstract}

Keywords: Pumped Storage Power Plants, Electrical machines, DFIG. 


\section{AGRADECIMENTOS}

A Deus pela oportunidade de aprender e evoluir, sempre.

Ao meu pai Cláudio, minha mãe Denise e familiares pelos princípios e valores ensinados. Vocês me ensinaram o que é importante na vida.

Ao professor Doutor Silvio Ikuyo Nabeta pela orientação, suporte, motivação e por ajudar a manter o foco.

A Voith Hydro, em especial Jiri Koutnik, Masato Yano, e Thomas Hildinger pelo suporte profissional e informações essenciais para a elaboração deste trabalho.

Aos amigos e todos os que colaboram de uma forma ou de outra para a conclusão deste trabalho.

Em especial a Thaysa Laudari Giovannetti, minha companheira de jornada, pela paciência e incansável incentivo. 


\section{DEDICATÓRIA}




\section{LISTA DE SÍMBOLOS}

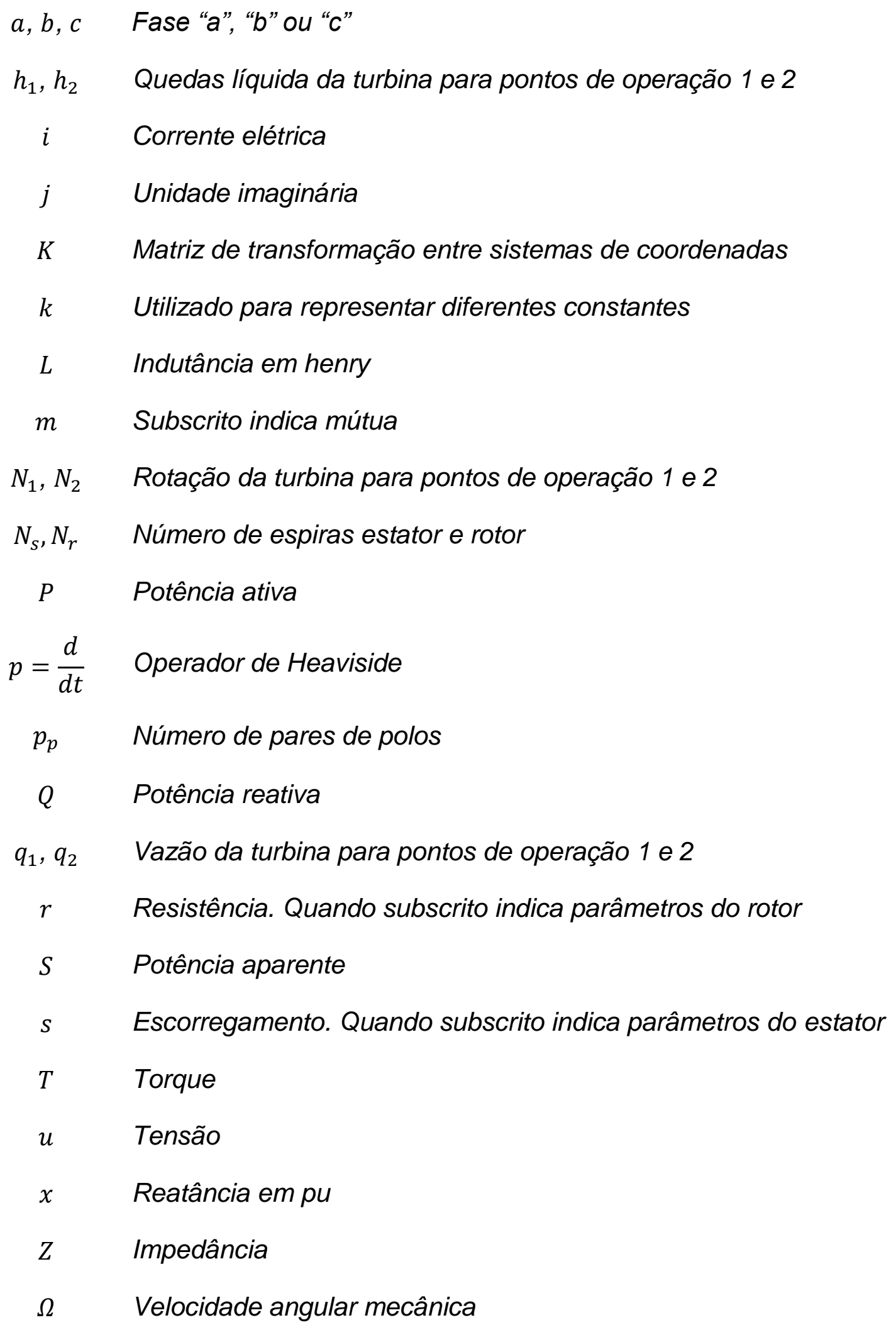




\begin{tabular}{|c|c|}
\hline$\delta$ & Ângulo de carga \\
\hline$\eta$ & Rendimento ou eficiência \\
\hline$\theta, \varphi$ & Ângulos de defasagem \\
\hline$\theta_{e}$ & $\begin{array}{l}\text { Ângulo elétrico da tensão de excitação em relação aos enrolamentos } \\
\text { do rotor }\end{array}$ \\
\hline$\theta_{r}$ & Ângulo elétrico entre enrolamentos do estator e rotor \\
\hline$\theta_{s}$ & Ângulo da tensão da fase "as" \\
\hline$\lambda$ & Fluxo magnético concatenado \\
\hline$\psi$ & Fluxo magnético em pu \\
\hline$\omega_{b}$ & Frequência angular de base \\
\hline$\omega_{e}$ & $\begin{array}{l}\text { Frequência angular da tensão de excitação do rotor em relação aos } \\
\text { enrolamentos do rotor }\end{array}$ \\
\hline$\omega_{r}$ & Velocidade angular elétrica do eixo da unidade geradora \\
\hline$\omega_{s}$ & Frequência angular síncrona \\
\hline$\phi$ & Fluxo magnético \\
\hline
\end{tabular}




\section{SUMÁRIO}

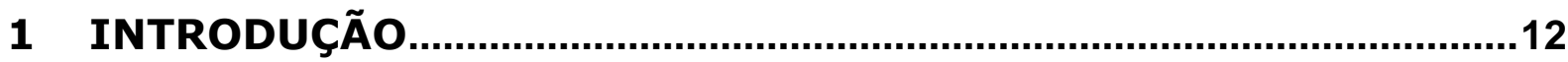

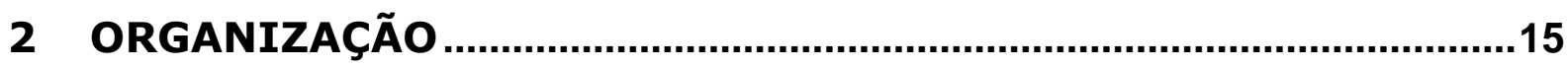

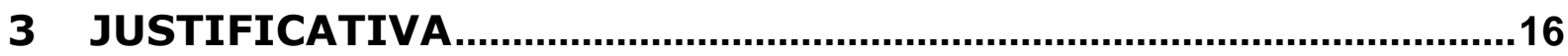

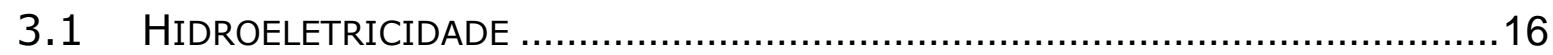

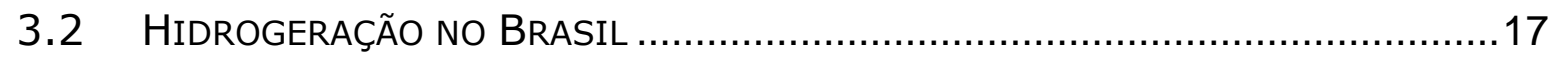

3.3 HidROGERAÇÃO COM VELOCIDADE VARIÁVEL ................................................. 19

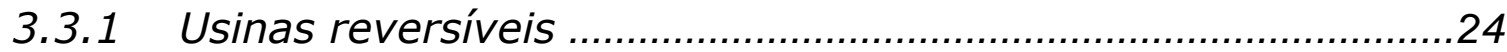

4 ESTADO DA ARTE

5 METODOLOGIA

5.1 MODELAGEM DAS MÁQUINAS DE INDUÇÃO DUPLAMENTE ALIMENTADAS …........32

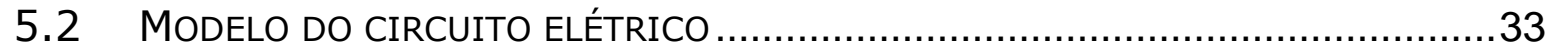

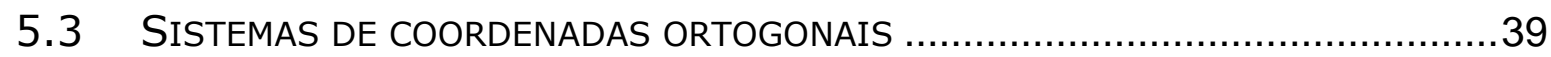

5.4 MÁQUINA DE INDUÇÃO NAS COORDENADAS DQ0 ........................................

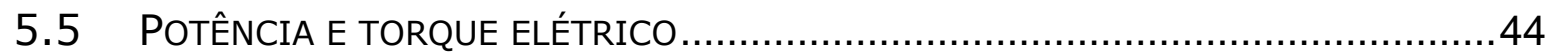

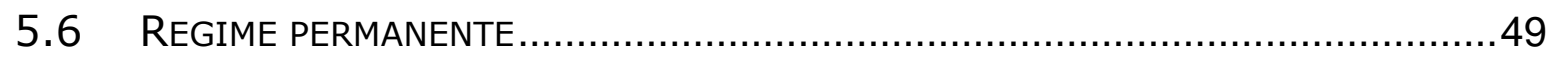

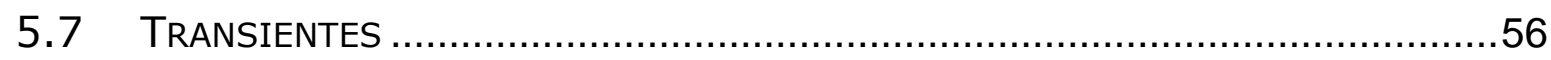

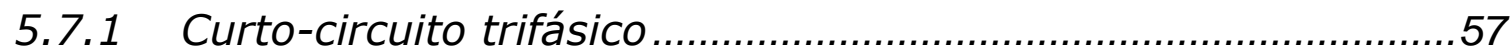

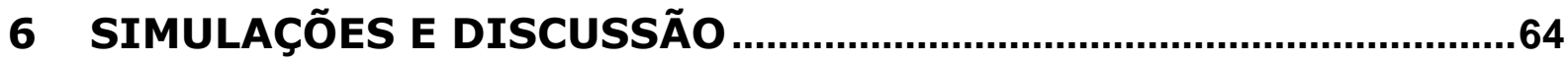

7 CONCLUSÃO

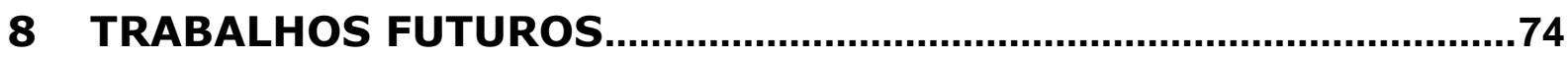

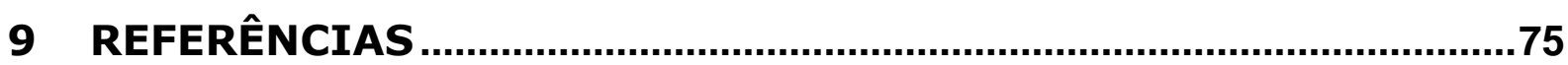

ANEXO A RESOLUÇÃO DO CURTO-CIRCUITO TRIFÁSICO..................79

ANEXO B CIRCUITOS MAGNÉTICOS..................................................88 


\section{INTRODUÇÃO}

A busca por formas de obtenção de energia para reduzir a dependência das adversidades naturais acompanha a história do ser humano. Poder gerar a energia necessária para as suas atividades firmou a estrutura da sociedade.

Com o passar do tempo, o desenvolvimento tecnológico da humanidade deu à energia elétrica diversos usos. Hoje, existem diversas tecnologias para geração que disponibilizam energia para um sem número de aplicações. De motores elétricos nas indústrias aos modernos equipamentos hospitalares, a energia elétrica proporciona mais qualidade de vida para o ser humano.

Esta relação entre os diferentes tipos de energia e qualidade de vida é tal que a evolução das formas de sua obtenção está intimamente relacionada com o desenvolvimento tecnológico-social. Os primeiros moinhos de vento e rodas d'água ocasionaram o aperfeiçoamento da agricultura e aumento de produção de alimentos; o desenvolvimento das turbinas a vapor revolucionou a indústria no século XVIII na Primeira Revolução Industrial; e a inserção da energia elétrica no meio industrial veio novamente trazer profundas modificações nos processos industriais e na sociedade em meados do século XIX na Segunda Revolução Industrial.

É impensável atender a demanda de energia elétrica para as necessidades atuais do ser humano atual sem o presente estado da arte das formas de geração de energia elétrica. Existem diversas opções para sua produção. As centrais hidrelétricas ofertam grandes pacotes de energia necessária aos processos de larga escala; parques eólicos têm aerogeradores de capacidade cada vez maiores; painéis fotoelétricos estão cada vez mais eficientes e mais próximos da viabilidade econômica em larga escala e novas opções são constantemente pesquisadas.

Esta variedade de tecnologias para geração de energia elétrica só foi possível através da pesquisa por melhores métodos e busca por formas alternativas de produção, que proporcionam meios cada vez mais eficazes e menos degradantes ao meioambiente, traduzindo-se na elevação da oferta de energia elétrica. 
Apesar da tendência mundial para redução do consumo de energia elétrica, a utilização de energia elétrica está de tal forma enraizada nas necessidades da sociedade que o desenvolvimento de um país pode ser relacionado, entre outros fatores, com o nível de consumo desta energia por habitante. A figura 1 relaciona o índice de desenvolvimento humano (IDH) e o consumo anual de energia elétrica per capita no qual é possível perceber que pelo menos para um nível inicial de desenvolvimento é necessária certa quantidade de consumo de energia elétrica por habitante.

Os dados foram obtidos da Organização das Nações Unidas (ONU) e da Energy Information Administration (EIA). O IDH é o principal fator para se medir o desenvolvimento humano em determinado país e é apresentando anualmente no relatório do programa de desenvolvimento da ONU, varia entre zero e um, sendo, quanto mais próximo de um, melhor é a qualidade de vida no país.

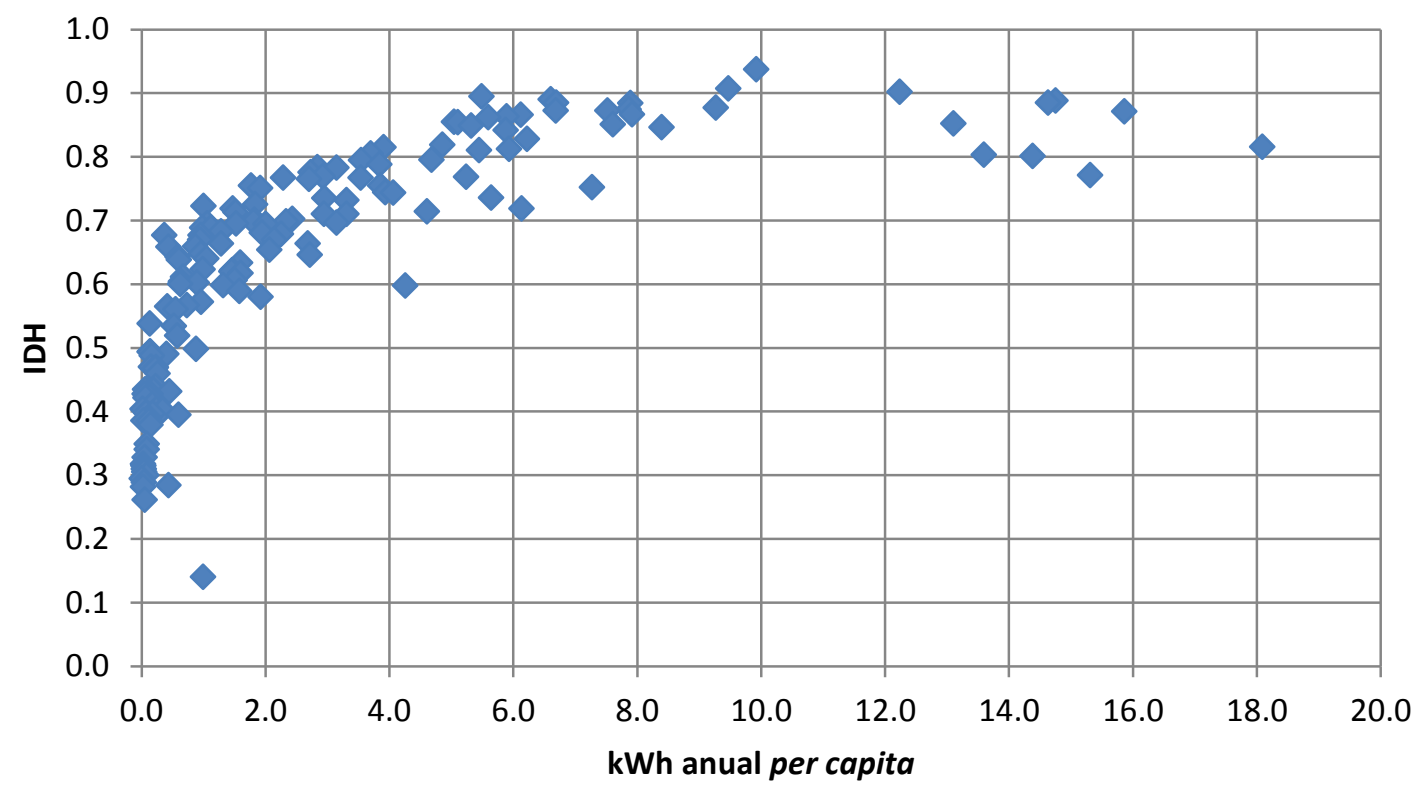

Figura 1 - Consumo anual de energia elétrica per capita por país e respectivo índice de desenvolvimento humano (IEA, ONU, 2010).

Cada ponto no gráfico representa um país. Noruega e Islândia foram removidas do gráfico, pois a escala do gráfico resultante dificultaria a visualização da tendência. Observa-se que o IDH de determinado país tende a ser mais elevado quanto maior o consumo de energia elétrica por habitante. 
Com a conscientização ambiental, o atendimento às necessidades energéticas da sociedade tende a empregar formas renováveis e mais limpas para obtenção de energia, impulsionando pesquisas por novas opções de geração e uma revisão das formas tradicionais.

Repensar as formas tradicionais de geração significa procurar alternativas mais eficientes e limpas para utilização das mesmas fontes utilizadas hoje para atender a crescente demanda.

A aplicação de velocidade variável em geradores eólicos e em usinas hidrelétricas reversíveis representa esta iniciativa. Neste sentido, este trabalho pretende contribuir para o desenvolvimento do conhecimento em novas tecnologias para a área de geração de energia, mais especificamente, estudando o comportamento dos geradores de indução duplamente alimentados (DFIGs - Doubly Fed Induction Generators) frente a curtos-circuitos trifásicos, apresentando seu o equacionamento retomando assim este importante aspecto do estudo de transientes em máquinas elétricas. 


\section{ORGANIZAÇÃO}

Esta dissertação de mestrado está organizada da seguinte maneira:

Introdução: Apresenta o trabalho, discorre sobre a importância da energia para o ser humano bem como a importância da pesquisa por formas alternativas de geração. Situa o trabalho dentro da área da energia

Organização: Especifica a organização do trabalho com o conteúdo resumido de cada capítulo.

Justificativa: Apresenta a utilização das DFIGs e situa o tema na área de hidrogeração. É contextualizado o trabalho e o motivo da pesquisa.

Estado da arte: Discorre acerca das pesquisas envolvendo transitórios nas DFIGs.

Metodologia : Apresenta a metodologia utilizada para o modelamento, com as premissas, breve introdução teórica descrevendo o equacionamento da máquina.

Simulações e discussão: Neste capítulo as expressões analíticas obtidas são comparadas com resultados de simulação em software com o modelo elétrico do gerador.

Conclusão: Apresenta as conclusões do trabalho. 


\section{JUSTIFICATIVA}

\subsection{Hidroeletricidade}

A energia mecânica obtida a partir do movimento de rodas d'águas instaladas em cursos de rios é utilizada desde a Grécia antiga para tarefas simples, como moagem de grãos. Com o desenvolvimento ${ }^{1}$ de geradores elétricos por Tesla e Edson e outros equipamentos elétricos, a energia elétrica foi ganhando cada vez mais importância. Não tardou até que surgissem as primeiras associações de rodas d'águas e estes geradores para a produção de energia elétrica.

A primeira grande central hidroelétrica, em Niágara Falls nos Estados Unidos, utilizava geradores de corrente contínua de Edson em 1881. Foram substituídos, em 1893, pelos geradores de corrente alternada, transformador elevador e sistema de transmissão associado de Tesla e Westinghouse, pois possibilitavam transmitir energias a distâncias maiores.

As centrais hidrelétricas modernas permitem geração de energia elétrica em grandes quantidades necessária às indústrias de base ou às de grande porte. Essas potências são ainda inalcançáveis pelas outras formas de energia limpa, como parques eólicos ou usinas térmicas a biomassa.

A tabela 1 mostra um panorama da situação da energia hidroelétrica no mundo, sua participação nas dez maiores matrizes energéticas elétricas em potência instalada. Observa-se a relativa baixa representação percentual deste tipo de geração na matriz energética da maioria desses países. As exceções são Canadá e Brasil. No caso do Brasil esta grande participação se deve à abundância de recursos hídricos que direcionaram o desenvolvimento energético do país.

\footnotetext{
${ }^{1}$ Aperfeiçoando inventos já existentes e baseados nas contribuições de inúmeros pesquisadores, como Faraday, Ampère, Volta, Galvani, Henry, Oersted e outros
} 
Tabela 1 - Hidrelétricas nas dez maiores matrizes energéticas em potência instalada em 2008 (EIA).

\begin{tabular}{|c|c|c|c|c|}
\hline & País & $\begin{array}{l}\text { Total } \\
\text { [GW] }\end{array}$ & $\begin{array}{c}\text { Hídrica } \\
\text { Convencional } \\
\text { [GW] }\end{array}$ & Representação \\
\hline 1 & Estados Unidos & 1010,2 & 77,9 & $7,7 \%$ \\
\hline 2 & China & 797,1 & 171,5 & $21,5 \%$ \\
\hline 3 & Japão & 280,5 & 21,9 & $7,8 \%$ \\
\hline 4 & Rússia & 224,2 & 47,0 & $21,0 \%$ \\
\hline 5 & Índia & 177,4 & 39,3 & $22,2 \%$ \\
\hline 6 & Alemanha & 139,3 & 3,5 & $2,5 \%$ \\
\hline 7 & Canadá & 127,6 & 74,4 & $58,3 \%$ \\
\hline 8 & África & 122,6 & 22,1 & $18,0 \%$ \\
\hline 9 & França & 117,8 & 20,9 & $17,7 \%$ \\
\hline \multirow[t]{2}{*}{10} & Brasil $^{3}$ & 89,1 & 74,4 & $83,5 \%$ \\
\hline & Mundo & 4624,8 & 857,3 & $18,5 \%$ \\
\hline
\end{tabular}

\subsection{Hidrogeração no Brasil}

No Brasil, a matriz energética elétrica é majoritariamente renovável, devido à grande quantidade de usinas hidrelétricas (UHEs) instaladas no país, como mostra a figura 2. A primeira usina hidrelétrica comercial instalada no Brasil foi a UHE Paraibuna, Minas Gerais, em 1889. Nas décadas seguintes, foram criados órgãos para promover novos empreendimentos e atrativos foram oferecidos para que empresas estran-

\footnotetext{
${ }^{2}$ Hidrelétricas convencionais são a fio d'água ou com reservatório, não reversíveis

${ }^{3}$ Dados provenientes do ONS, no resumo da operação de 2008.
} 
geiras viessem impulsionar estes novos projetos para atender a crescente demanda de energia.

Devido às questões geográficas, as grandes centrais hidrelétricas brasileiras ficam geralmente longe dos grandes centros consumidores. Além disso, o crescimento do consumo e geração, além da necessidade de aumentar a segurança e estabilidade do fornecimento de energia exigiu que o sistema de transmissão fosse mais integrado. Essa integração permitiu a melhor coordenação entre geração e consumo da energia elétrica produzida, possibilitando a otimização do despacho de energia. $\mathrm{O}$ sistema interligado nacional (SIN) é controlado pelo operador nacional do sistema (ONS), criado em 1998 em substituição ao grupo de controle das operações integradas (GCOI). Em 2009, mais de 93\% da energia produzida conectada ao Sistema Interligado Nacional (SIN) foi de origem hidráulica.

A figura 2 apresenta a distribuição de fontes de geração conectadas ao SIN por potência instalada.

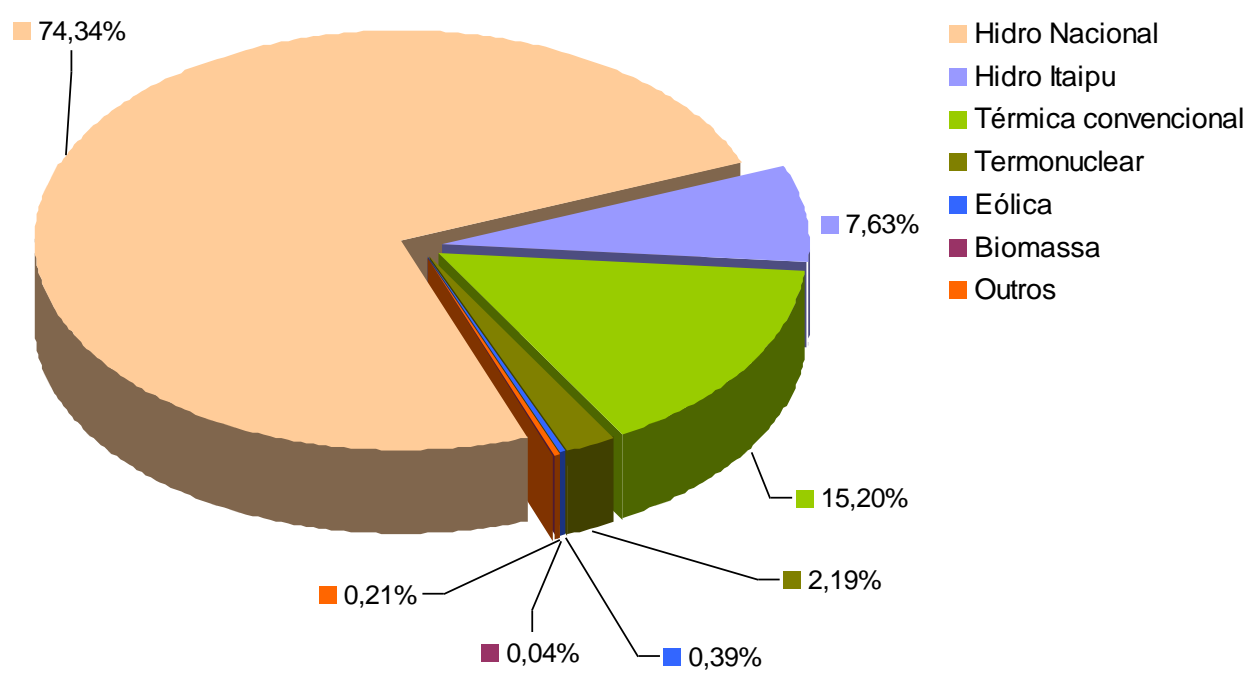

Figura 2 - Proporções por potência instalada conectada ao SIN em 2009. (ONS) 
A capacidade instalada conectada ao SIN em 2009 ficou em 91.727,4 MW, sendo $82 \%$ de origem hídrica. A previsão de consumo de energia elétrica é de 1.056 .796 MWh em $2030^{4}$, vide a figura 3.

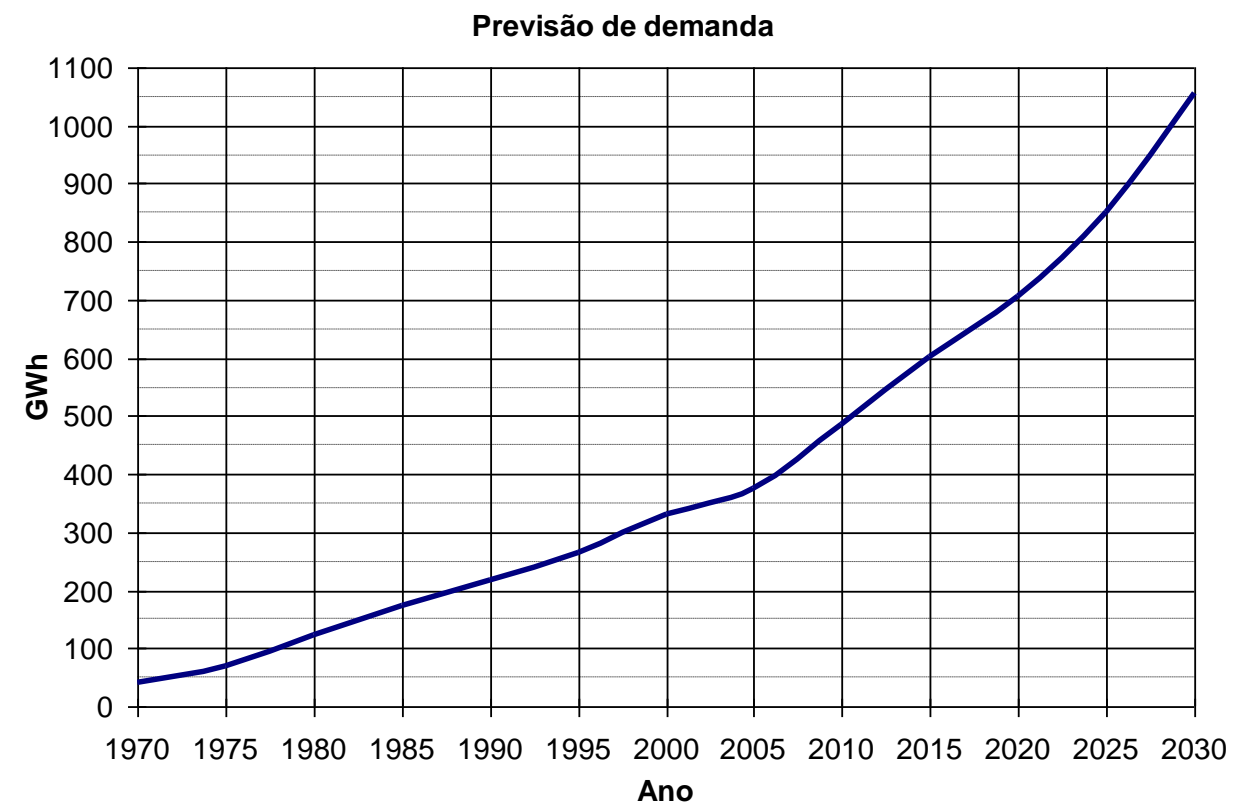

Figura 3 - Previsão de demanda de energia elétrica para o Brasil (Plano Nacional de Energia 2030, 2007).

Para atender a demanda prevista, estão planejados novos empreendimentos hidrelétricos nas próximas décadas, essenciais para atender fornecimento de energia esperado.

\subsection{Hidrogeração com velocidade variável}

\footnotetext{
${ }^{4}$ Projeção segundo Ministério de Minas e Energia no Plano Nacional de Energia 2030
} 
As fontes primárias limpas, por dependerem em sua maior parte dos fatores naturais, ofertam energia de maneira inconstante. Para aproveitá-las ao máximo, ou são elaboradas formas de acumular e canalizar esta energia, como nas hidrelétricas, ou procura-se alinhar a geração com a oferta de energia como no caso dos parques eólicos modernos, nos quais, devido à impossibilidade de canalizar a energia, esta estratégia vingou como a solução para a geração de energia a partir dos ventos.

A utilização de geração com velocidade variável (também encontrada sob o nome de velocidade ajustável na literatura) vem no sentido de proporcionar uma opção para a melhoria da eficiência da cadeia geração de energia elétrica, buscando a velocidade ótima do conjunto em função da força motriz. Das possibilidades de geração com velocidade variável, a utilização de geradores de indução duplamente alimentados vem superando todas as outras disponíveis no mercado para máquinas de grande porte.

Aplicar os geradores de indução duplamente alimentados para possibilitar a geração com velocidade variável em usinas hidrelétricas não é uma ideia recente. Unidades Reversíveis com DFIGs deste tipo estão em operação há cerca de vinte anos no Japão (Usina Narude Okawachi) e, na última década, foi instalada a primeira grande unidade hidroelétrica com esta configuração fora do Japão na usina reversível Golsdisthal, localizada na Alemanha. A aplicação comercial ainda está em fase inicial.

Usinas hidrelétricas utilizam tradicionalmente geradores síncronos. Por adotar máquinas deste tipo, a máquina elétrica e a máquina hidráulica trabalham em velocidade fixada pelo sistema de potência. Devido à turbina hidráulica ser uma máquina de eficiência variável em função da vazão, velocidade de operação e queda líquida, a operação com velocidade fixa reduz a máxima eficiência em determinadas condições de operação.

A figura 4 mostra uma curva de colina típica de uma turbina hidráulica. A curva de colina relaciona normalmente as grandezas queda $\left(h_{1}\right)$, vazão $(q)$ e rendimento $(\eta)$. 


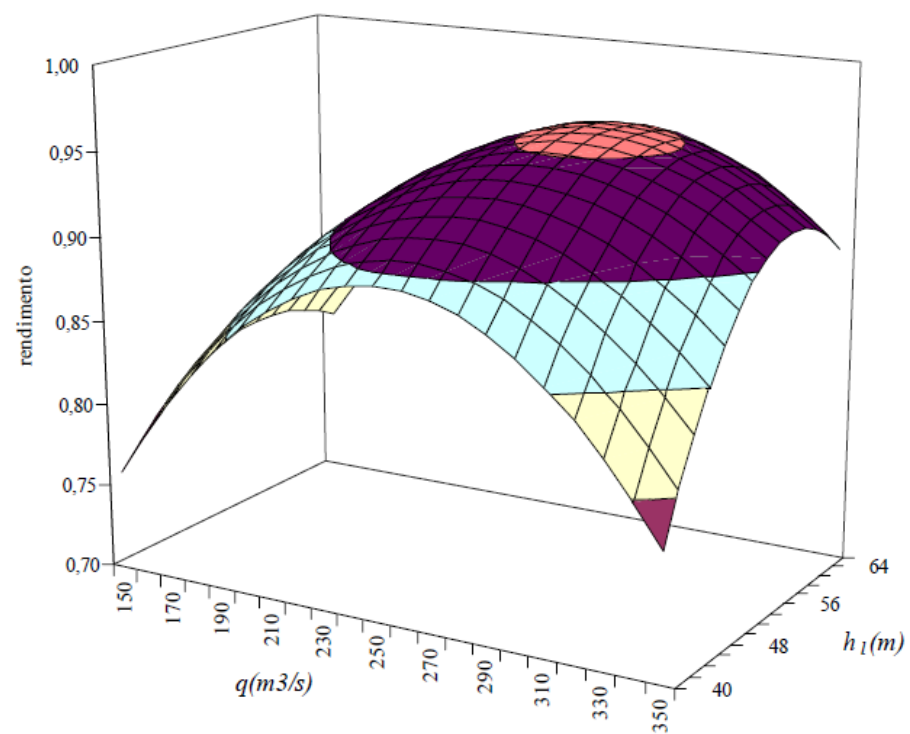

Figura 4 - Curva de colina típica de uma turbina hidráulica (ENCINA, 2006).

A curva de colina é determinada para uma turbina modelo por meio de ensaios em laboratório. Obtém-se a eficiência desta turbina para diferentes pontos de vazão e queda. A curva pode então ser escalonada para uma turbina (protótipo) semelhante, ou seja, com características geométricas e dinâmicas similares, utilizando as leis de semelhanças de acordo com a teoria de mecânica dos fluídos (ÇENGEL, 2006).

As leis de semelhanças também podem ser utilizadas para comparar dois pontos de operação distintos da mesma turbina:

$$
\begin{aligned}
& \frac{q_{1}}{q_{2}}=\frac{N_{1}}{N_{2}} \\
& \frac{h_{1}}{h_{2}}=\left(\frac{N_{1}}{N_{2}}\right)^{2}
\end{aligned}
$$

Onde $q$ é a vazão para uma abertura de distribuidor, $N$ a rotação e $h$ a queda líquida. Portanto, ao variar a rotação, pode-se mudar o ponto de operação da turbina, buscando otimizar a eficiência.

O projeto da turbina é realizado com base em séries históricas de vazões, portanto pode-se esperar que a eficiência real varie consideravelmente durante a operação. Essas variações das condições às quais a turbina está sujeita são ainda mais evidentes em usinas a fio d'água ou nas que possuem reservatórios pequenos. Nesses dois tipos de usina, a utilização da velocidade variável traria maior benefício, pois o ponto de operação da turbina varia consideravelmente em sua curva de colina. 
Nos trabalhos de Saidel (SAIDEL, 1995) e Ardanuy (ARDANUY, 2006) é avaliado o ganho energético com a utilização de velocidade variável para usinas hidrelétricas. Saidel concluiu principalmente que o ganho é maior em reservatórios pequenos, pois a grande variação de nível característica desses reservatórios influencia consideravelmente no ponto de operação da turbina, especialmente em turbinas Francis. Ardanuy concluiu que usinas a fio d'água podem apresentar aumento significativo de faixa operativa além do aumento de eficiência.

Utilizar velocidade variável na hidrogeração pode trazer os seguintes benefícios (SPORILD; 2000; GJENGEDAL, 2001):

Estabilidade do sistema - A utilização de aerogeradores e painéis fotovoltaicos aumentam a cada ano. Apesar de serem energias renováveis, podem prejudicar a estabilidade do sistema, já que a geração obedece à disponibilidade da fonte primária. Além disto, estas fontes de energia apresentam massas girantes pequenas ou nulas, que devido à estratégia de controle normalmente utilizada, não conseguem contribuir para a rigidez da frequência do sistema como hidrogeradores com máquinas síncronas, que geralmente apresentam momentos de inércia muito maiores. A utilização da hidrogeração com velocidade variável permite rápida resposta frente às variações de potência ativa, melhorando a resposta do sistema frente às variações bruscas de consumo.

Eficiência energética - A geração com velocidade variável permite colocar a turbina na velocidade ótima de operação dentro dos limites de dimensionamento do conversor e do gerador.

A escolha da geração com velocidade variável em hidrogeradores deve considerar que a potência nominal pode ser dezenas e até centenas de vezes maior que os geradores eólicos, ou seja, a aplicação hidráulica tem a gama de soluções reduzidas quanto maior for a potência da máquina.

As principais formas de geração com velocidade variável são listadas a seguir.

- Gerador síncrono acoplado à rede via retificador e transmissão em corrente contínua - conexão unitária;

- Gerador de indução gaiola de esquilo ou síncrono acoplado a um retificador e inversor em configuração back-to-back; 
- Gerador de indução gaiola de esquilo acoplada diretamente à rede e um compensador estático;

- Gerador de indução duplamente alimentado;

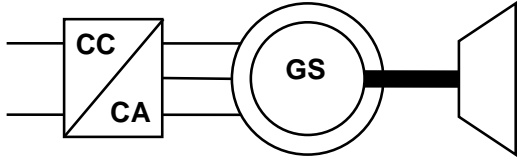

Figura 5 - Gerador síncrono acoplado à retificador para transmissão em corrente contínua.

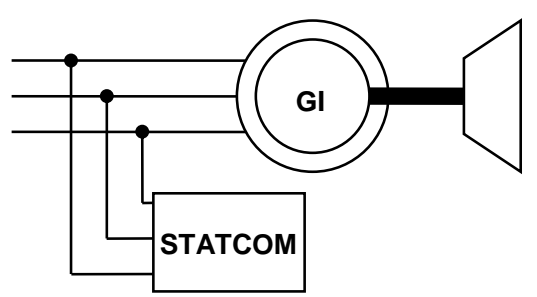

Figura 7 - Gerador gaiola de esquilo e compensador estático.

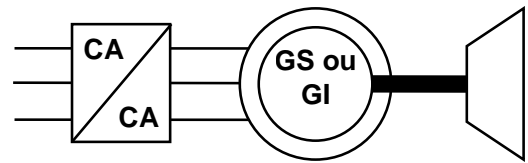

Figura 6 - Gerador síncrono ou de indução do tipo gaiola de esquilo e conversor backto-back.

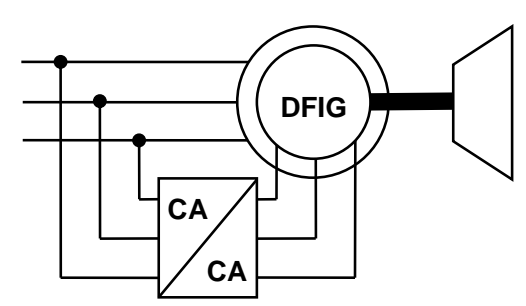

Figura 8 - Gerador de indução duplamente alimentado e conversor back-to-back.

Utilizar conversores acoplados diretamente às máquinas síncronas ou máquinas de indução gaiola de esquilo implica num dimensionamento dos conversores para a potência nominal da máquina. Além disso, é necessário outro conversor, também de potência nominal da máquina, para conversão em corrente alternada e posterior conexão à rede e a transmissão em corrente contínua para usinas hidrelétricas fica economicamente viável apenas para grandes distâncias.

A utilização de máquinas de gaiola de esquilo em conjunto com compensadores estáticos (STATCOM em inglês) são estudadas como alternativas para micro centrais hidrelétricas já que apresentam baixo custo e alta disponibilidade no mercado devido à produção em escala. As dificuldades de controle de tensão e estabilidade são problemas que inviabilizam a sua utilização para geradores de grande potência.

No caso das máquinas de indução duplamente alimentadas, utiliza-se um conversor CA-CA conectado ao rotor. O rotor possui enrolamento trifásico o que permite criar um campo magnético girante controlado por seus conversores. O dimensionamento do conversor deve ser feito apenas para a parcela de potência proporcional a diferença velocidade do eixo do gerador e frequência da rede, denominada potência de 
escorregamento. Assim, a potência do conversor é menor quando comparada com conversores das outras opções com geradores de mesma potência. Para aplicações em hidrogeradores, devido às grandes potências envolvidas, o escorregamento fica entre 5 e $15 \%$ de modo que os conversores não devem suportar potências elevadas.

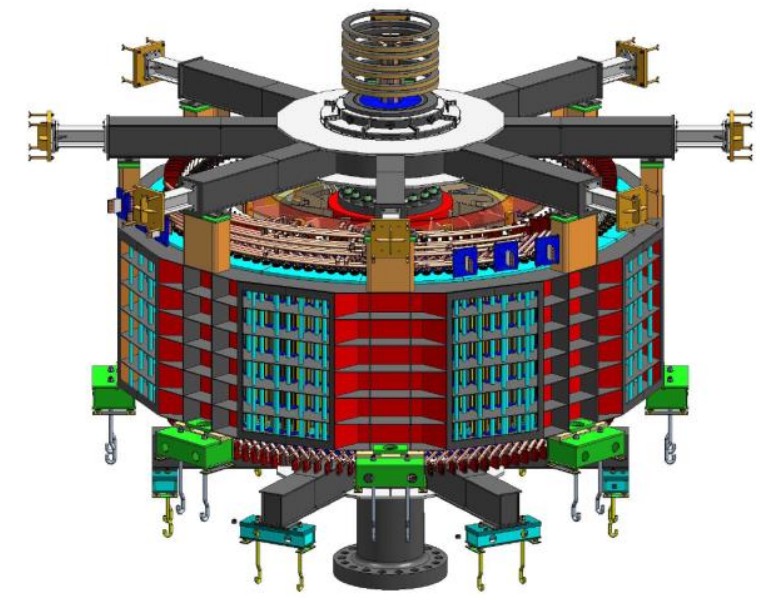

Figura 9 - Rotor e estator do gerador de indução duplamente alimentado.

(Fonte: @ VOITH Hydro)

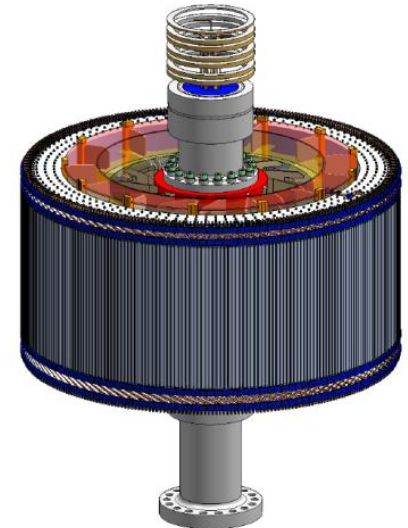

Figura 10 - Rotor do gerador de indução duplamente alimentado. Rotor

(Fonte: @ VOITH Hydro)

Nas usinas hidrelétricas mais recentes que utilizam DFIGs, a tensão trifásica necessária para produzir o campo girante no rotor é gerada pelo conversor do lado do rotor (RSC - Rotor Side Converter). Para fornecer tensão contínua para o RSC, utilizase um conversor conectado à rede, o conversor do lado da rede (GSC - Grid Side Converter) conforme exemplificado na figura 18. Além de ser o responsável por fornecer tensão contínua para o RSC, o GSC pode fornecer uma parcela de reativos, trabalhando da mesma forma que um compensador estático.

\subsubsection{Usinas reversíveis}

A curva diária de carga de um sistema de potência apresenta picos de alto consumo e períodos de baixo consumo. Tradicionalmente criada para nivelar esta variação e para otimizar o uso das térmicas, a usina reversível consome energia elétrica no pe- 
ríodo de baixa demanda, bombeando água, e a produz no período de ponta, turbinando.

A primeira usina reversível foi construída com este intuito na Suíça em 1890 (FISHER et al., 2012), com um gerador acoplado a turbina e um motor acoplado a bomba. Na década de 1930, foram desenvolvidas as primeiras unidades com turbina e bomba na mesma máquina hidráulica. Em 1937, foi instalada a primeira máquina hidráulica com função turbina-bomba do mundo na Usina Reversível de Pedreira, em São Paulo. A figura 11 apresenta um esquema simplificado de uma usina reversível.

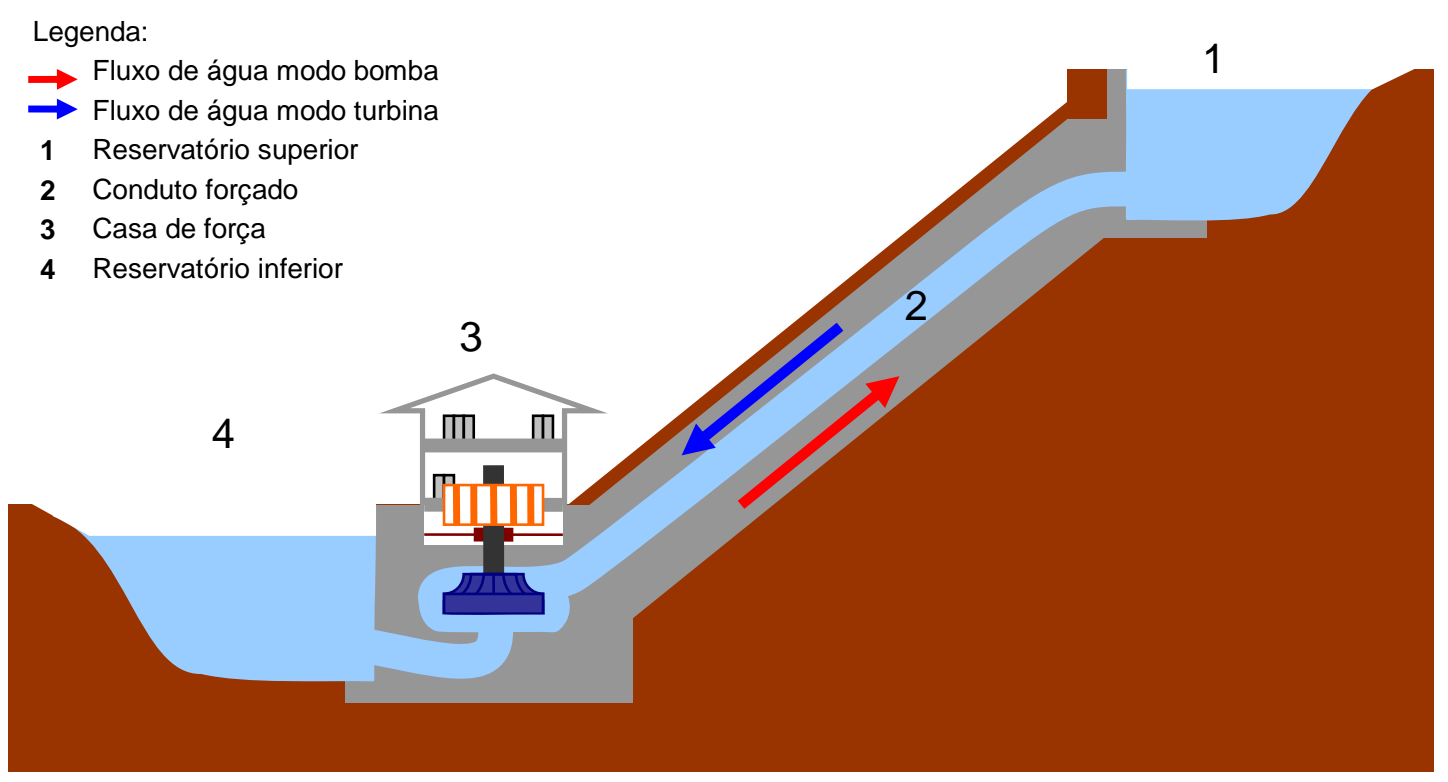

Figura 11 - Esquema simplificado de Usina Reversível.

Hoje, as usinas reversíveis vêm sendo instaladas em países como Portugal, Alemanha, Suíça e Áustria para permitir o aumento da potência instalada de energia renovável nos sistemas de transmissão desses países.

Como a energia gerada por fontes eólicas ou solares variam ao longo do dia devido às características da força motriz primária, vide figura 12, o aumento destas fontes de energia pode ser prejudicial à qualidade de energia do sistema de potência.

Entretanto essas fontes de energia são uma realidade e há poucas opções para compensar esta intermitência. A Alemanha é o membro da União Europeia com maior avanço em termos do cumprimento da meta dos $20 \%$ de geração por fontes renováveis até 2020. A maior parte é produzida por fontes eólicas que devido à 
questão previamente mencionada, junto com a elevada representatividade desta fonte conectada à rede, está trazendo problemas de instabilidade no sistema de potência do país [26], [27] e [28].

Novas estratégias para armazenamento de energia proveniente das usinas eólicas e solares estão sendo apresentadas para contrabalancear a intermitência da geração nos países europeus citados anteriormente. A utilização de usinas reversíveis é a solução mais promissora devido à maturidade da tecnologia, densidade de energia, custo e eficiência total do processo.

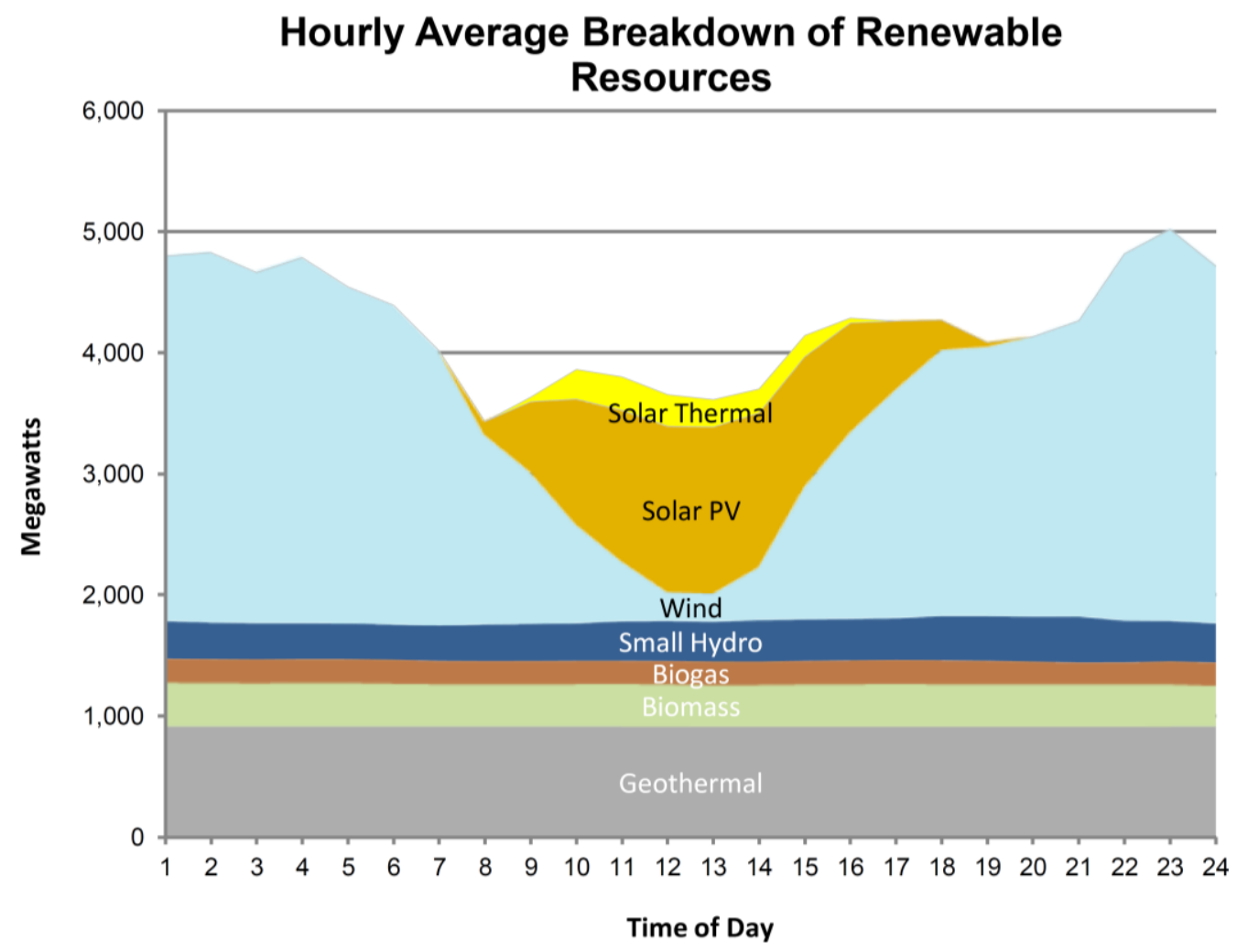

Figura 12 - Curva de produção em 2013-03-18 para várias fontes de energia elétrica renovável na rede elétrica da Califórnia, EUA. (Califórnia ISO)

A utilização de turbina e bomba na mesma máquina hidráulica acoplada a máquinas síncronas ainda é a solução principal em usinas reversíveis, (FISHER et al., 2012). Entretanto, a utilização de DFIGs como máquina elétrica, permitindo flexibilização da operação tanto no modo bomba como no modo turbina, está começando a ser viabilizada comercialmente para grandes potências.

As turbinas-bombas são projetadas para ter a eficiência ótima no modo bomba. Como a velocidade de eficiência ótima é diferente entre este e o modo turbina, a velo- 
cidade fixa ocasiona redução da eficiência no modo turbina. Além disso, restrições hidráulicas para operação em carga parcial no modo bomba, impossibilitando variar a potência consumida são reduzidas se a velocidade puder ser variada.

A figura 13 ilustra este ganho de eficiência $\left(\eta_{p}\right)$ de forma qualitativa em função da vazão $\left(Q_{p}\right)$ para diferentes curvas de velocidade. A curva em verde claro é a velocidade nominal da bomba. É possível também observar o ganho de faixa operativa para diferentes valores de queda $\left(H_{p}\right)$ e possibilidade te operação e carga parcial $\left(P_{p}\right)$.

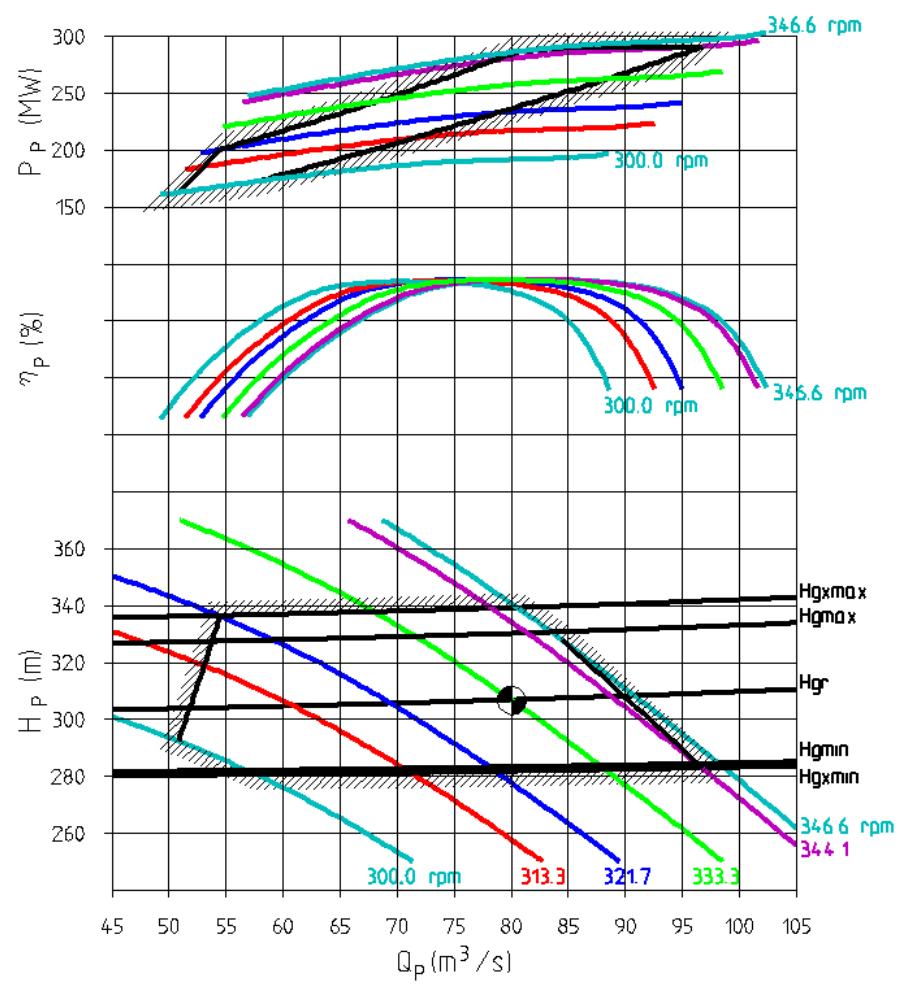

Figura 13 - Curva de colina uma turbina-bomba para operação em velocidade variável em modo bomba. (Fonte: @ VOITH Hydro)

Apesar da principal motivação discutida na literatura para a eventual instalação de DFIGs em usinas hidrelétricas convencionais ser a eficiência energética, as novas instalações em usinas reversíveis tem permitido reavaliar o tópico. As principais vantagens para estes empreendimentos têm sido a melhoria na resposta às variações de potências ativa consumida pela rede, e flexibilização da operação (regulação da potência ativa gerada no modo bomba pelo aumento da faixa operativa). 
Como exemplos atuais desta tecnologia, encontram-se as usinas de Golsdisthal na Alemanha (duas DFIGs de 380MVA em operação) e Venda Nova III em Portugal (duas DFIGs de 420MVA com previsão de entrada em operação em 2015).

$\mathrm{Na}$ tabela 2, são apresentados os países líderes em potência instalada de usinas reversíveis.

Tabela 2 - Principais países em potência instalada de Usinas Reversíveis em 2008 [21].

\begin{tabular}{|c|c|c|c|c|}
\hline & País & $\begin{array}{l}\text { Total } \\
\text { [GW] }\end{array}$ & $\begin{array}{c}\text { Reversível } \\
\text { [GW] }\end{array}$ & Representação \\
\hline 1 & Japão & 280,5 & 25,5 & $9,1 \%$ \\
\hline 2 & Estados Unidos & 1010,2 & 21,9 & $2,2 \%$ \\
\hline 3 & China & 797,1 & $11,2^{5}$ & $1,4 \%$ \\
\hline 4 & Itália & 98,6 & 7,5 & $7,6 \%$ \\
\hline 5 & Alemanha & 139,3 & 6,5 & $4,7 \%$ \\
\hline 6 & Espanha & 93,5 & 5,3 & $5,7 \%$ \\
\hline 7 & Índia & 177,4 & $4,8^{6}$ & $2,7 \%$ \\
\hline 8 & França & 117,8 & 4,3 & $3,7 \%$ \\
\hline 9 & Áustria & 20,8 & 4,3 & $20,6 \%$ \\
\hline \multirow[t]{2}{*}{10} & Coréia do Sul & 79,9 & 3,9 & $4,9 \%$ \\
\hline & Mundo & 4624,8 & 104,0 & $2,2 \%$ \\
\hline
\end{tabular}

5 China Pumped Storage Plant Network "http://www.psp.org.cn:8080/upload/news/ n2008101309103489.pdf", excluindo dados de 2009

${ }^{6}$ Central Electricity Authority "http://www.cea.nic.in/reports/yearly/annual_rep/2008-09/ar_08_09.pdf" 


\section{ESTADO DA ARTE}

Condições anormais nos elementos constituintes dos sistemas de potência devem ser estudadas para o entendimento do fenômeno possibilitando correto dimensionamento das proteções, que são as responsáveis pela segurança e confiabilidade do sistema como um todo.

Faltas nos terminais de geradores ou nos barramentos que conectam o gerador e o transformador elevador são bem menos frequentes do que as faltas nas linhas de transmissão e distribuição. Entretanto, a proteção deve estar devidamente ajustada para atuar caso estas ocorram, pois são de grave impacto sobre a segurança e podem trazem grandes danos aos equipamentos atingidos. Para correta proteção do gerador, é necessário o conhecimento de seu comportamento durante estas condições anormais de operação.

Os trabalhos existentes na literatura se concentram em aplicação do DFIG em aerogeradores e analisam principalmente faltas no sistema de potência, após o transformador elevador, sem se preocupar com o entendimento físico do problema por trás do curto-circuito.

Os transientes estudados (faltas trifásicas, afundamentos de tensão na rede, etc.) têm em vista encontrar métodos para atender requisitos mínimos de interconexão da DFIG durante curtos-circuitos que são determinados pelos operados dos sistemas de potência em cada país. Por exemplo, nos novos requisitos de interconexão à rede da Alemanha, os DFIGs devem permanecer conectados ao sistema e contribuir com reativos na ocorrência de faltas, já que parcela de geração proveniente dos ventos cresce a cada ano, de modo que a desconexão dos geradores no evento de um transitório severo não pode ser mais permitida, visando manter a estabilidade no sistema.

Para a proteção do DFIG em aerogeradores no caso de curtos-circuitos, são propostas na literatura algumas soluções:

- Crowbar no circuito rotórico

- Chopper no ramo CC 
- Restaurador dinâmico de tensão

- Estratégia de controle com corrente desmagnetizante

- Resistor-série no estator

O crowbar constitui de um dispositivo limitador de corrente através da inserção de resistores colocados em série para limitar a corrente. Ele é ativado caso a corrente ultrapasse limites pré-determinados.

O chopper do ramo CC é responsável pela proteção em caso de sobretensão no ramo CC entre GSC e RSC (vide figura 18). Resistores são chaveados absorvendo a energia em excesso, trazendo a tensão a níveis seguros.

Essas duas soluções são utilizadas normalmente combinadas. A proteção crowbar é a mais disseminada, entretanto seu problema está no fato levar o gerador a consumir reativos quando ativa, pois com o crowbar ativo, o DFIG se comporta como uma máquina de gaiola de esquilo. Além disso, o gerador não pode ser controlado enquanto está ativo já que o RSC deve ser bloqueado durante a utilização da proteção. Mais recentemente, foram propostos outros dispositivos, como o restaurador dinâmico de tensão (DVR - Dynamic Voltage Restorer), para corrigir os afundamentos de tensão, injeção de corrente desmagnetizante por estratégia de controle do RSC para amenizar os fluxos transitórios responsáveis pelo surgimento de correntes no rotor e resistor em série no estator para limitar corrente de curto.

O DVR é um conversor estático em série com o estator, podendo impor uma tensão adicional caso seja necessário. A injeção de corrente desmagnetizante constitui de estratégia de controle para filtrar, e impor uma corrente que possa contrabalancear as componentes induzidas devido ao curto-circuito. O resistor em série no estator é similar ao Crowbar: quando a corrente atinge um determinado nível, resistores são inseridos limitando-a.

Em (FOSTER, 2009) é estudado a influência do valor da resistência do crowbar e do escorregamento no instante do curto-circuito na forma de onda da corrente do rotor. Esses parâmetros influenciam na qualidade da resposta da máquina frente a esse tipo de distúrbio da rede já que o conversor deve ficar bloqueado até que a corrente no resistor do crowbar se anule. Quanto maior o valor da resistência e quanto menos próximo da velocidade síncrona o gerador estiver, menos tempo demora o RSC re- 
tomar o controle. Entretanto, o valor da resistência do crowbar não deve ser elevado demais para que a tensão resultante não chegue a níveis destrutivos de isolação.

Em (WESSELS, 2011) é estudada a utilização de restaurador dinâmico de tensão (DVR - Dynamic Voltage Restorer) para melhorar o comportamento da máquina. O DVR é colocado em série com o estator, visando manter a estabilidade de tensão da rede e melhorar o comportamento frente à faltas (Fault Ride Through) do DFIG.

Na pesquisa de Gong (GONG, 2010) é proposta a utilização de chopper no ramo CC em conjunto com injeção de corrente desmagnetizante via estratégia de controle e resistor limitador de corrente em série com o estator.

As pesquisas para aerogeradores descritas acima apontam uma direção para as prováveis soluções para aplicação em hidrogeradores. Enquanto nos trabalhos descritos anteriormente as DFIGs são da ordem de alguns megawatts, o hidrogerador em estudo é da ordem de 400MVA, o que impossibilita a utilização de determinadas soluções, devido tanto às limitações de custo quanto às de caráter técnico.

Vicatos e Tegopoulos (VICATOS, 1991) estudaram analiticamente o curto-circuito trifásico no DFIG em carga nominal operando com excitação e escorregamento constantes durante o curto para definir um indutância transitória e obter um circuito elétrico para simplificar e modelar o comportamento elétrico do gerador durante o curto-circuito trifásico. No trabalho deles não foi realizada simulação e o equacionamento encontrado por eles não possibilita entender o fenômeno físico facilmente, pois as equações são deduzidas diretamente da relação entre tensão e corrente, tornando o entendimento mais difícil.

No trabalho de Heising (HEISING, 2010), simulações são realizadas para estudo da falta fase-terra no estator da máquina. Tanto a velocidade mecânica quanto a tensão imposta pelos conversores são consideradas constantes. Porém não é apresentada solução analítica do problema. 


\section{METODOLOGIA}

\subsection{Modelagem das máquinas de indução duplamente alimentadas}

As máquinas de indução de rotor bobinado possuem um enrolamento trifásico em seu rotor com acesso aos seus terminais por meio de anéis coletores. É possível utilizar essa conexão para alterar características da máquina, por exemplo, adicionando resistências ao circuito do rotor para alterar a curva de torque.

A curva de torque em função da velocidade do rotor foi construída para o gerador em estudo com resistência nominal $r_{r}^{\prime}$ e valores crescentes de resistência total do rotor $r_{2}>r_{1}>r_{r}^{\prime}$. É interessante notar que, como a máquina é projetada com resistência rotórica baixa para reduzir perdas no cobre, o torque de partida para rotor curto-circuitado é bastante reduzido.

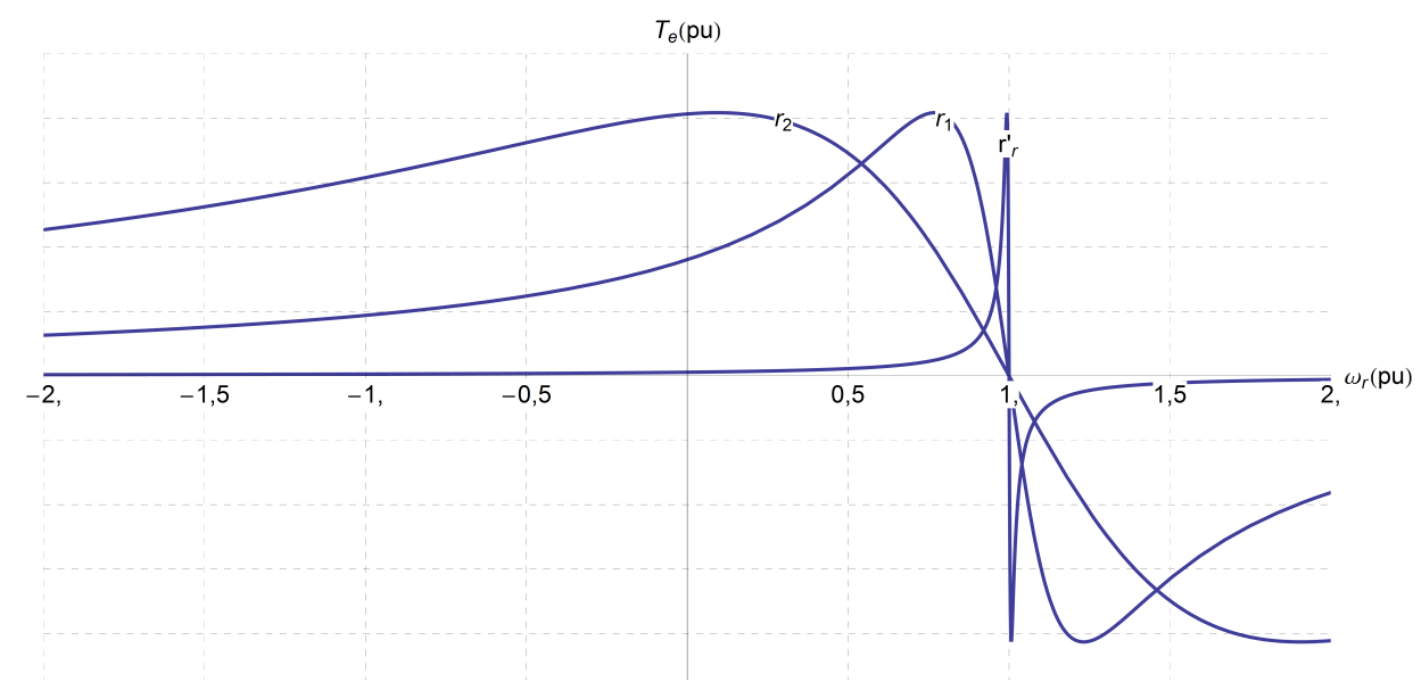

Figura 14 - Curva torque em função da velocidade do rotor da máquina em estudo para diferentes resistências do circuito do rotor. 
A configuração de dupla alimentação é caracterizada pela alimentação simultânea dos circuitos do rotor e do estator. Devido às interações entre os dois fluxos resultantes da dupla alimentação, a velocidade angular do eixo pode ser alterada em função da potência absorvida ou fornecida ao circuito rotórico.

Assim, diferente das máquinas síncronas, é possível desacoplar a velocidade do eixo e a frequência elétrica da tensão do estator. Esta vantagem é de interesse em sistemas de geração de energia que necessitam entregar energia à carga com frequência constante, porém necessitam variar a velocidade angular conforme a força motriz para otimização da utilização da força motriz.

\subsection{Modelo do circuito elétrico}

Para o modelo do circuito elétrico do gerador, são adotadas as seguintes premissas:

- A máquina de indução tem enrolamentos simétricos, igualmente distribuídos pelas três fases;

- Não há saturação magnética do material ferromagnético;

- Apenas a componente fundamental da força magneto motriz (FMM) é considerada nas deduções.

A figura 15 mostra um corte transversal da máquina de um par de polos. 


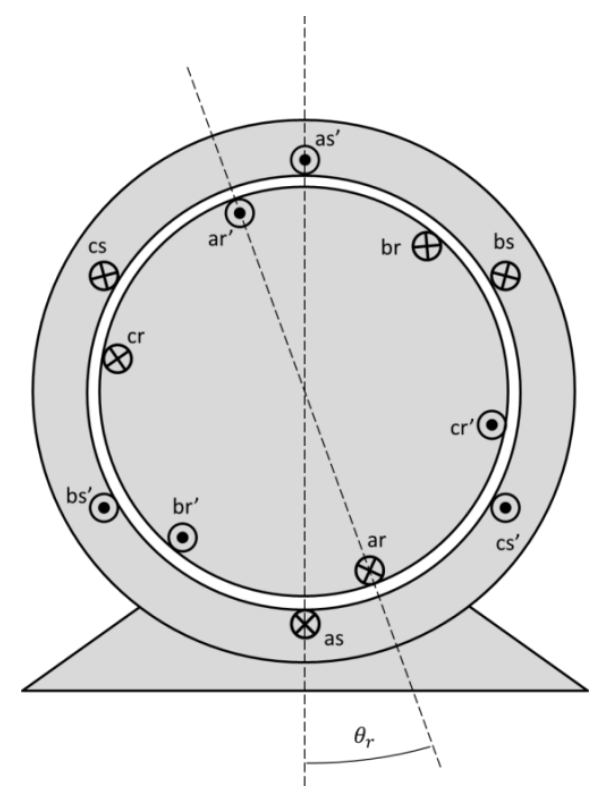

Figura 15 - Máquina elétrica equivalente com um par de pólos

Da teoria clássica de máquinas, o fluxo total visto pelo enrolamento de uma fase do estator é o fluxo próprio somado com os fluxos concatenados gerados por outros enrolamentos. Pode-se escrever, portanto que o fluxo visto pelo enrolamento da fase "a" do estator "as" é:

$$
\phi_{a s}=\phi_{a s a s}+\phi_{b s a s}+\phi_{c s a s}+\phi_{\text {aras }}+\phi_{\text {bras }}+\phi_{\text {cras }}
$$

O fluxo próprio produzido por uma fase da máquina possui duas parcelas, uma que concatena com outros enrolamentos, subscrito "m", e outra que fecha apenas em seu próprio enrolamento, subscrito "l". A esta última dá-se o nome de fluxo de dispersão. Para a fase "as" então:

$$
\phi_{a s a s}=\phi_{l s}+\phi_{m s}
$$

Os enrolamentos trifásicos do estator são iguais entre si (mesmo número de espiras, mesma seção de condutor, mesmo passo de enrolamento) e os do rotor entre eles, assim, o fluxo próprio deve ter o mesmo valor para cada enrolamento do estator e o mesmo valor para cada enrolamento do rotor. Ou seja (Anexo B):

$$
\begin{aligned}
& \phi_{a s a s}=\phi_{b s b s}=\phi_{c s c s}=\phi_{l s}+\phi_{m s} \\
& \phi_{\text {arar }}=\phi_{b r b r}=\phi_{c r c r}=\phi_{l r}+\phi_{m r}
\end{aligned}
$$


De acordo com a premissa de simetria e distribuição de $120^{\circ}$ elétricos adotada para os enrolamentos, o fluxo gerado pelo enrolamento "as" concatenando em "bs" e "cs" é função do cosseno de $120^{\circ}$ e $240^{\circ}$, assim (Anexo B):

$$
\phi_{b s a s}=\phi_{c s a s}=-\frac{1}{2} \phi_{m s}
$$

De maneira similar, temos a interação entre enrolamentos do rotor e do estator, entretanto esta dependerá da posição angular do rotor. Na posição angular zero, na qual fase "ar" está alinhada com "as", "br" com "bs" e "cr" com "cs", demonstra-se por analogia ao caso anterior que o fluxo mútuo entre os enrolamentos "as" e "br" ou "cr" é equivalente à metade do fluxo concatenado entre "ar" e "as". Ou seja, incluindo a variação da posição angular relativa entre os enrolamentos do rotor e estator:

$$
\begin{gathered}
\phi_{\text {aras }}=\phi_{m s r} \cos \left(\theta_{r}\right) \\
\phi_{\text {bras }}=\phi_{m s r} \cos \left(\theta_{r}+\frac{2 \pi}{3}\right) \\
\phi_{\text {cras }}=\phi_{m s r} \cos \left(\theta_{r}-\frac{2 \pi}{3}\right)
\end{gathered}
$$

É possível através das equações (10) e (9) relacionar o fluxo concatenado no enrolamento com a corrente e indutância (Vide Anexo B).

$$
\lambda=L i \quad(9) \quad \lambda=N \phi
$$

Ou seja, para a fase "as" tem-se:

$$
\begin{gathered}
\lambda_{a s}=\left[\begin{array}{lll}
L_{l s}+L_{m s} & -\frac{1}{2} L_{m s} & -\frac{1}{2} L_{m s}
\end{array}\right]\left[\begin{array}{l}
i_{a s} \\
i_{b s} \\
i_{c s}
\end{array}\right]+ \\
+L_{m s r}\left[\begin{array}{lll}
\cos \left(\theta_{r}\right) & \cos \left(\theta_{r}+\frac{2 \pi}{3}\right) & \left.\cos \left(\theta_{r}-\frac{2 \pi}{3}\right)\right]\left[\begin{array}{c}
i_{a r} \\
i_{b r} \\
i_{c r}
\end{array}\right]
\end{array}\right.
\end{gathered}
$$

Analogamente para as demais fases, a matriz de fluxos concatenados resulta em (KRAUSE, 2002): 


$$
\left[\begin{array}{l}
\lambda_{a s} \\
\lambda_{b s} \\
\lambda_{c s} \\
\lambda_{a r} \\
\lambda_{b r} \\
\lambda_{c r}
\end{array}\right]=\left[\begin{array}{cc}
{\left[L_{s}\right]} & {\left[L_{s r}\right]} \\
{\left[L_{r s}\right]} & {\left[L_{r}\right]}
\end{array}\right]\left[\begin{array}{l}
i_{a s} \\
i_{b s} \\
i_{c s} \\
i_{a r} \\
i_{b r} \\
i_{c r}
\end{array}\right]
$$

Na qual:

$$
\begin{gathered}
{\left[L_{s}\right]=\left[\begin{array}{ccc}
L_{l s}+L_{m s} & -\frac{1}{2} L_{m s} & -\frac{1}{2} L_{m s} \\
-\frac{1}{2} L_{m s} & L_{l s}+L_{m s} & -\frac{1}{2} L_{m s} \\
-\frac{1}{2} L_{m s} & -\frac{1}{2} L_{m s} & L_{l s}+L_{m s}
\end{array}\right]} \\
{\left[L_{r}\right]=\left[\begin{array}{ccc}
L_{l r}+L_{m r} & -\frac{1}{2} L_{m r} & -\frac{1}{2} L_{m r} \\
-\frac{1}{2} L_{m r} & L_{l r}+L_{m r} & -\frac{1}{2} L_{m r} \\
-\frac{1}{2} L_{m r} & -\frac{1}{2} L_{m r} & L_{l r}+L_{m r}
\end{array}\right]=L_{m s r}\left[\begin{array}{ccc}
\cos \left(\theta_{r}\right) & \cos \left(\theta_{r}+\frac{2 \pi}{3}\right) & \cos \left(\theta_{r}-\frac{2 \pi}{3}\right) \\
\cos \left(\theta_{r}-\frac{2 \pi}{3}\right) & \cos \left(\theta_{r}\right) & \cos \left(\theta_{r}+\frac{2 \pi}{3}\right) \\
\cos \left(\theta_{r}+\frac{2 \pi}{3}\right) & \cos \left(\theta_{r}-\frac{2 \pi}{3}\right) & \cos \left(\theta_{r}\right)
\end{array}\right]} \\
{\left[L_{r s}\right]=L_{m r s}\left[\begin{array}{ccc}
\cos \left(\theta_{r}\right) & \cos \left(\theta_{r}-\frac{2 \pi}{3}\right) & \cos \left(\theta_{r}+\frac{2 \pi}{3}\right) \\
\cos \left(\theta_{r}+\frac{2 \pi}{3}\right) & \cos \left(\theta_{r}\right) & \cos \left(\theta_{r}-\frac{2 \pi}{3}\right) \\
\cos \left(\theta_{r}-\frac{2 \pi}{3}\right) & \cos \left(\theta_{r}+\frac{2 \pi}{3}\right) & \cos \left(\theta_{r}\right)
\end{array}\right]}
\end{gathered}
$$

Por fim, como o caminho magnético visto pelos fluxos criados tanto por enrolamentos do estator quanto rotor é o mesmo, segue a seguinte equivalência para as mútuas estator-rotor e rotor-estator (Anexo B):

$$
L_{m r s}=\frac{N_{s}}{N_{r}} L_{m r} \quad(17) \quad L_{m s r}=\frac{N_{r}}{N_{s}} L_{m s}
$$

Para uma fase do estator, tem-se a seguinte equação relacionando tensão, fluxo e corrente: 


$$
u_{a s}=r_{a s} i_{a s}+\frac{d}{d t} \lambda_{a s}
$$

Entretanto, as resistências devem ser iguais entre os enrolamentos do estator e entre os enrolamentos do rotor segundo as premissas adotadas, ou seja:

$$
\begin{aligned}
& r_{a s}=r_{b s}=r_{c s}=r_{s} \\
& r_{a r}=r_{b r}=r_{c r}=r_{r}
\end{aligned}
$$

Para desenvolver o modelo matemático, a relação entre número de espiras deve ser incluída nos parâmetros de modo a facilitar os cálculos. As grandezas do rotor referenciadas para o lado do estator de uma fase são relacionadas segundo as expressões (22) a (27).

$$
\begin{array}{rlrl}
i_{a r}^{\prime} & =\frac{N_{r}}{N_{s}} i_{a r} & \text { (22) } & L_{r}^{\prime}=\left(\frac{N_{s}}{N_{r}}\right)^{2} L_{r} \\
u_{a r}^{\prime}=\frac{N_{r}}{N_{s}} u_{a r} & (24) & L_{m r}=\left(\frac{N_{r}}{N_{s}}\right)^{2} L_{m s} \\
\lambda_{a r}^{\prime}=\frac{N_{r}}{N_{s}} \lambda_{a r} & (26) & r_{r}^{\prime}=\left(\frac{N_{s}}{N_{r}}\right)^{2} r_{r}
\end{array}
$$

Voltando à matriz de fluxos concatenados:

$$
\begin{aligned}
& L_{m r s}=\frac{N_{s}}{N_{r}} L_{m r} \Rightarrow L_{m r s}=\frac{N_{r}}{N_{s}} L_{m s} \\
& {\left[\begin{array}{c}
\lambda_{a s} \\
\lambda_{b s} \\
\lambda_{c s} \\
\frac{N_{s}}{N_{r}}\left[\begin{array}{cc}
\lambda_{a r}^{\prime} \\
\lambda_{b r}^{\prime} \\
\lambda_{c r}^{\prime}
\end{array}\right]
\end{array}\right]=\left[\begin{array}{cc}
{\left[L_{s}\right]} & \frac{N_{r}}{N_{s}}\left[L_{s r}\right] \\
\frac{N_{s}}{N_{r}}\left[L_{r s}\right] & \left(\frac{N_{r}}{N_{s}}\right)^{2}\left[L_{r}\right]
\end{array}\right]\left[\begin{array}{c}
i_{a s} \\
i_{b s} \\
i_{c s} \\
N_{s}\left[\begin{array}{c}
i_{a r}^{\prime} \\
N_{r} \\
i_{b r}^{\prime} \\
i_{c r}^{\prime}
\end{array}\right]
\end{array}\right]} \\
& {\left[\begin{array}{l}
\lambda_{a s} \\
\lambda_{b s} \\
\lambda_{c s} \\
\lambda_{a r}^{\prime} \\
\lambda_{b r}^{\prime} \\
\lambda_{c r}^{\prime}
\end{array}\right]=\left[\begin{array}{cc}
{\left[L_{s}\right]} & {\left[L_{s r}^{\prime}\right.} \\
{\left[L_{r s}^{\prime}\right]} & {\left[L_{r}^{\prime}\right]}
\end{array}\right]\left[\begin{array}{c}
i_{a s} \\
i_{b s} \\
i_{c s} \\
i_{a r}^{\prime} \\
i_{b r}^{\prime} \\
i_{c r}^{\prime}
\end{array}\right]}
\end{aligned}
$$

Sendo: 


$$
\begin{gathered}
{\left[L_{r}^{\prime}\right]=\left[\begin{array}{ccc}
L_{l r}^{\prime}+L_{m s} & -\frac{1}{2} L_{m s} & -\frac{1}{2} L_{m s} \\
-\frac{1}{2} L_{m s} & L_{l r}^{\prime}+L_{m s} & -\frac{1}{2} L_{m s} \\
-\frac{1}{2} L_{m s} & -\frac{1}{2} L_{m s} & L_{l r}^{\prime}+L_{m s}
\end{array}\right]} \\
{\left[L_{s r}^{\prime}\right]=L_{m s}\left[\begin{array}{ccc}
\cos \left(\theta_{r}\right) & \cos \left(\theta_{r}+\frac{2 \pi}{3}\right) & \cos \left(\theta_{r}-\frac{2 \pi}{3}\right) \\
\cos \left(\theta_{r}-\frac{2 \pi}{3}\right) & \cos \left(\theta_{r}\right) & \cos \left(\theta_{r}+\frac{2 \pi}{3}\right) \\
\cos \left(\theta_{r}+\frac{2 \pi}{3}\right) & \cos \left(\theta_{r}-\frac{2 \pi}{3}\right) & \cos \left(\theta_{r}\right)
\end{array}\right]=L_{m s}\left[\begin{array}{rrr}
\cos \left(\theta_{r}\right) & \cos \left(\theta_{r}-\frac{2 \pi}{3}\right) & \cos \left(\theta_{r}+\frac{2 \pi}{3}\right) \\
\cos \left(\theta_{r}+\frac{2 \pi}{3}\right) & \cos \left(\theta_{r}\right) & \cos \left(\theta_{r}-\frac{2 \pi}{3}\right) \\
\cos \left(\theta_{r}-\frac{2 \pi}{3}\right) & \cos \left(\theta_{r}+\frac{2 \pi}{3}\right) & \cos \left(\theta_{r}\right)
\end{array}\right]}
\end{gathered}
$$

Observa-se que as matrizes $\left[L_{s r}^{\prime}\right]$ é a transposta de $\left[L_{r s}^{\prime}\right]$ pois defasagem do estator para o rotor é $\theta_{r}$ e do rotor para o estator é $-\theta_{r}$. A matriz relacionando correntes e tensões no estator e rotor para a máquina resulta em:

$$
\left[\begin{array}{l}
u_{a s} \\
u_{b s} \\
u_{c s} \\
u_{a r}^{\prime} \\
u_{b r}^{\prime} \\
u_{c r}^{\prime}
\end{array}\right]=\left[\begin{array}{cc}
{\left[r_{s}\right]} & 0 \\
0 & {\left[r_{r}^{\prime}\right]}
\end{array}\right]\left[\begin{array}{l}
i_{a s} \\
i_{b s} \\
i_{c s} \\
i_{a r}^{\prime} \\
i_{b r}^{\prime} \\
i_{c r}^{\prime}
\end{array}\right]+p\left[\begin{array}{ll}
{\left[L_{s}\right]} & {\left[L_{s r}^{\prime}\right]} \\
{\left[L_{r s}^{\prime}\right]} & {\left[L_{r}^{\prime}\right]}
\end{array}\right]\left[\begin{array}{l}
i_{a s} \\
i_{b s} \\
i_{c s} \\
i_{a r}^{\prime} \\
i_{b r}^{\prime} \\
i_{c r}^{\prime}
\end{array}\right]
$$

Com $p$ sendo o operador de Heaviside e:

$$
\left[r_{r}^{\prime}\right]=\left[\begin{array}{ccc}
r_{r}^{\prime} & 0 & 0 \\
0 & r_{r}^{\prime} & 0 \\
0 & 0 & r_{r}^{\prime}
\end{array}\right] \quad(35) \quad\left[r_{s}\right]=\left[\begin{array}{ccc}
r_{s} & 0 & 0 \\
0 & r_{s} & 0 \\
0 & 0 & r_{s}
\end{array}\right]
$$




\subsection{Sistemas de coordenadas ortogonais}

Visando simplificar as equações de máquinas síncronas, Park elaborou, na década de 20, uma transformação ortogonal para eliminar a dependência da posição angular nas indutâncias mútuas da máquina síncrona (PARK, 1929). Conhecida como transformada de Park, esta mudança de coordenadas revolucionou o estudo de máquinas síncronas. Posteriormente, as transformações foram aplicadas por Clarke e Kron para as máquinas de indução, facilitando os cálculos e estudos de transitórios eletromagnéticos nesta máquina.

A matriz de conversão entre as coordenadas $a b c$ e as coordenadas ortogonais $d q 0$ utilizada neste trabalho foi descrita por Krause (KRAUSE, 2002). Esta transformação é a generalização de todas as transformações de coordenadas na teoria de máquinas elétricas para um sistema de coordenadas que gira com uma velocidade arbitrária. Assim, pode-se utilizar a mesma transformação para um sistema de coordenadas na velocidade síncrona, fixado ao estator ou ao rotor, bastando escolher convenientemente a velocidade angular $\omega$.

A conversão do sistema trifásico $a b c$ em um sistema de coordenadas com eixos ortogonais será feita através da matriz $K$ (KRAUSE, 2002). É importante notar que a transformada é realizada para a máquina equivalente de um par de polos, portanto quando for necessário obter as variáveis mecânicas para a máquina real, deve-se dividir pelo número de pares de polos da máquina em questão.

$$
\begin{gathered}
{[K]=\frac{2}{3}\left[\begin{array}{ccc}
\cos (\theta) & \cos \left(\theta-\frac{2 \pi}{3}\right) & \cos \left(\theta+\frac{2 \pi}{3}\right) \\
\operatorname{sen}(\theta) & \operatorname{sen}\left(\theta-\frac{2 \pi}{3}\right) & \operatorname{sen}\left(\theta+\frac{2 \pi}{3}\right) \\
\frac{1}{2} & \frac{1}{2} & \frac{1}{2}
\end{array}\right]} \\
{[K]^{-1}=\left[\begin{array}{ccc}
\cos (\theta) & \operatorname{sen}(\theta) & 1 \\
\cos \left(\theta-\frac{2 \pi}{3}\right) & \operatorname{sen}\left(\theta-\frac{2 \pi}{3}\right) & 1 \\
\cos \left(\theta+\frac{2 \pi}{3}\right) & \operatorname{sen}\left(\theta-\frac{2 \pi}{3}\right) & 1
\end{array}\right]}
\end{gathered}
$$


Sendo assim, a transformação para um grandeza $f$ qualquer (corrente, tensão ou fluxo) das coordenadas $a b c$ para o $d q 0$ fica então:

$$
\begin{aligned}
{\left[F_{q d 0}\right]=\left[\begin{array}{l}
f_{q} \\
f_{d} \\
f_{0}
\end{array}\right] } & (39) & {\left[F_{q d 0}\right]=[K]\left[F_{a b c}\right] } \\
{\left[F_{a b c}\right]=\left[\begin{array}{l}
f_{a} \\
f_{b} \\
f_{c}
\end{array}\right] } & (41) & {\left[F_{a b c}\right]=[K]^{-1}\left[F_{q d 0}\right] }
\end{aligned}
$$

A figura 16 mostra os eixos $a b c$ e $d q$ no mesmo plano para melhor compreensão.

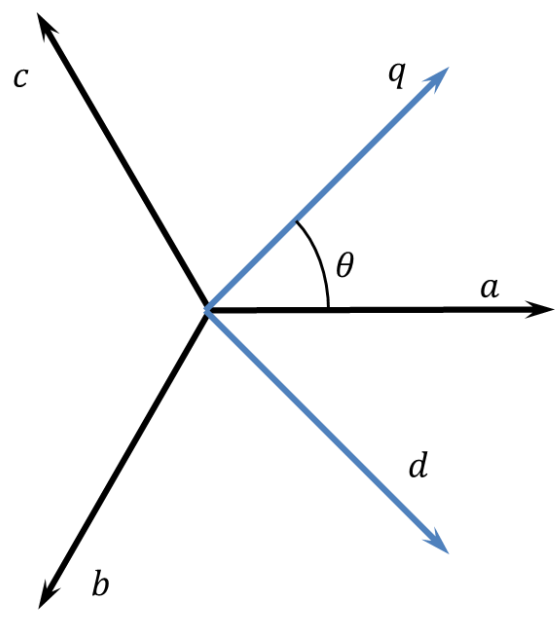

Figura 16 - Coordenadas dq e abc.

Colocando o sistema de coordenadas $d q 0$ no plano complexo, pode-se representar uma grandeza $\hat{F}$ qualquer da seguinte maneira:

$$
\widehat{F}=f_{q}-j f_{d}
$$

Esta passagem é verdadeira para quaisquer valores, porém facilita especialmente o trabalho com o regime permanente.

Indo além, é possível utilizar uma matriz, $\left[\mathrm{K}_{\mathrm{rs}}\right]$, para fazer transformações entre dois sistemas quaisquer de coordenadas $d q 0$ : 


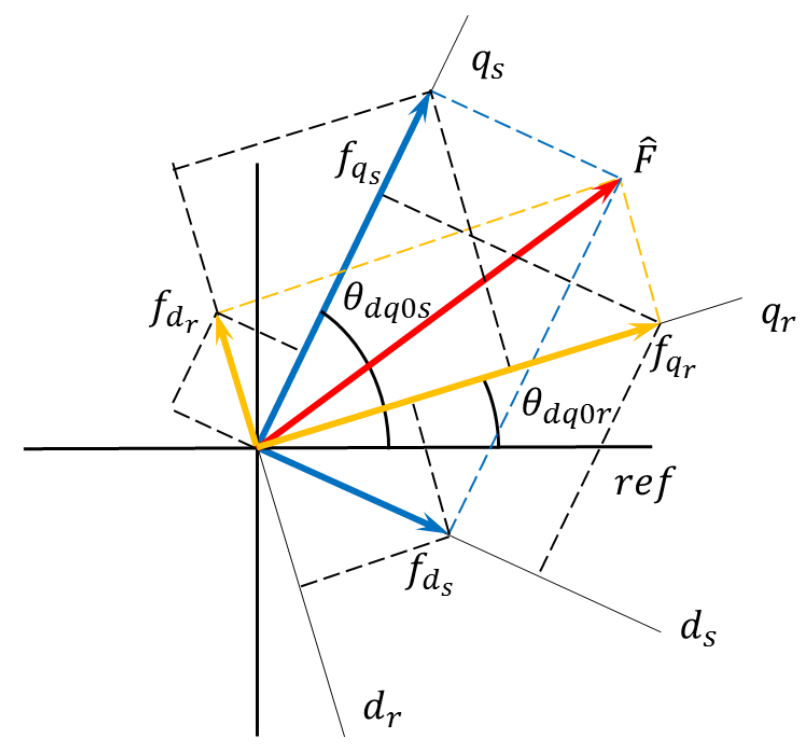

Figura 17 - Coordenadas do sistema $r$ e do sistema $s$

Decompondo o sistema $\mathrm{dq} 0_{\mathrm{r}}$ nas coordenadas do sistema $\mathrm{dq} 0_{\mathrm{s}}$ tem-se:

$$
\begin{gathered}
f_{q_{s}}=f_{q_{r}} \cos \left(\theta_{d q 0 r}-\theta_{d q 0 s}\right)-f_{d_{r}}\left(\theta_{d q 0 r}-\theta_{d q 0 s}\right) \\
f_{d_{s}}=f_{d_{r}} \cos \left(\theta_{d q 0 r}-\theta_{d q 0 s}\right)+f_{q_{r}} \operatorname{sen}\left(\theta_{d q 0 r}-\theta_{d q 0 s}\right)
\end{gathered}
$$

Portanto, a matriz de transformação do sistema de coordenadas $r$ para o $s$ resulta em:

$$
\begin{gathered}
{\left[K_{r s}\right]=\left[\begin{array}{ccc}
\cos \left(\theta_{d q 0 r}-\theta_{d q 0 s}\right) & -\operatorname{sen}\left(\theta_{d q 0 r}-\theta_{d q 0 s}\right) & 0 \\
\operatorname{sen}\left(\theta_{d q 0 r}-\theta_{d q 0 s}\right) & \cos \left(\theta_{d q 0 r}-\theta_{d q 0 s}\right) & 0 \\
0 & 0 & 1
\end{array}\right]} \\
{\left[\begin{array}{l}
f_{q_{s}} \\
f_{d_{s}} \\
f_{0 s}
\end{array}\right]=\left[K_{r s}\right]\left[\begin{array}{l}
f_{q_{r}} \\
f_{d_{r}} \\
f_{0 r}
\end{array}\right]} \\
{\left[\begin{array}{l}
f_{q_{r}} \\
f_{d_{r}} \\
f_{0 r}
\end{array}\right]=\left[K_{r s}\right]^{T}\left[\begin{array}{l}
f_{q_{s}} \\
f_{d_{s}} \\
f_{0 s}
\end{array}\right]}
\end{gathered}
$$

Esta transformação é utilizada para converter as grandezas das coordenadas dq0 do rotor para as do estator da máquina de indução duplamente alimentada. 


\subsection{Máquina de indução nas coordenadas dq0}

O modelo no sistema de coordenadas abc é transformado para um único sistema de coordenadas $d q 0$, para simplificar as equações da máquina tornando as iterações numéricas menos trabalhosas e facilitando o entendimento físico do problema.

Sendo assim é necessário utilizar duas transformações, uma para o circuito do rotor e outra para o do estator. Isto pode ser percebido pelos termos $\omega$ e $\left(\omega-\omega_{r}\right)$ nas equações (49) e (50). Tanto as variáveis do estator quanto as do rotor estão no mesmo sistema de coordenadas cuja velocidade angular é a arbitrária $\omega$.

Convertendo a equação (34) para $d q 0$ na forma matricial com $p$ como o operador de Heaviside (KRAUSE, 2002):

$$
\begin{gathered}
{\left[\begin{array}{l}
u_{q s} \\
u_{d s} \\
u_{0 s}
\end{array}\right]=\left[r_{s}\right]\left[\begin{array}{l}
i_{q s} \\
i_{d s} \\
i_{0 s}
\end{array}\right]+p\left[\begin{array}{l}
\lambda_{q s} \\
\lambda_{d s} \\
\lambda_{0 s}
\end{array}\right]+\omega\left[\begin{array}{c}
\lambda_{d s} \\
-\lambda_{q s} \\
\lambda_{0 s}
\end{array}\right]} \\
{\left[\begin{array}{l}
u_{q r}^{\prime} \\
u_{d r}^{\prime} \\
u_{0 r}^{\prime}
\end{array}\right]=\left[r_{r}^{\prime}\right]\left[\begin{array}{l}
i_{q r}^{\prime} \\
i_{d r}^{\prime} \\
i_{0 r}^{\prime}
\end{array}\right]+p\left[\begin{array}{l}
\lambda_{q r}^{\prime} \\
\lambda_{d r}^{\prime} \\
\lambda_{0 r}^{\prime}
\end{array}\right]+\left(\omega-\omega_{r}\right)\left[\begin{array}{c}
\lambda_{d r}^{\prime} \\
-\lambda_{q r}^{\prime} \\
\lambda_{0 r}^{\prime}
\end{array}\right]} \\
{\left[\begin{array}{l}
\lambda_{q s} \\
\lambda_{d s} \\
\lambda_{0 s}
\end{array}\right]=\left[\begin{array}{ccc}
L_{s s} & 0 & 0 \\
0 & L_{s s} & 0 \\
0 & 0 & L_{l s}
\end{array}\right]\left[\begin{array}{l}
i_{q s} \\
i_{d s} \\
i_{0 s}
\end{array}\right]+\left[\begin{array}{ccc}
L_{M} & 0 & 0 \\
0 & L_{M} & 0 \\
0 & 0 & 0
\end{array}\right]\left[\begin{array}{c}
i_{q r}^{\prime} \\
i_{d r}^{\prime} \\
i_{0 r}^{\prime}
\end{array}\right]} \\
{\left[\begin{array}{l}
\lambda_{q r}^{\prime} \\
\lambda_{d r}^{\prime} \\
\lambda_{0 r}^{\prime}
\end{array}\right]=\left[\begin{array}{ccc}
L_{r r}^{\prime} & 0 & 0 \\
0 & L_{r r}^{\prime} & 0 \\
0 & 0 & L_{l r}^{\prime}
\end{array}\right]\left[\begin{array}{l}
i_{q r}^{\prime} \\
i_{d r}^{\prime} \\
i_{0 r}^{\prime}
\end{array}\right]+\left[\begin{array}{ccc}
L_{M} & 0 & 0 \\
0 & L_{M} & 0 \\
0 & 0 & 0
\end{array}\right]\left[\begin{array}{l}
i_{q s} \\
i_{d s} \\
i_{0 s}
\end{array}\right]} \\
L_{s s}=L_{l s}+L_{M} \\
L_{r r}^{\prime}=L_{l r}^{\prime}+L_{M} \\
L_{M}=\frac{3}{2} L_{m s}
\end{gathered}
$$

Para uma análise preliminar, considerando o sistema de coordenadas com velocidade angular síncrona e regime permanente, os termos derivativos são nulos. $O$ termo dependente da velocidade angular do rotor mostra que, quanto maior a diferença en- 
tre a velocidade do rotor e a velocidade síncrona, maior a força contra eletromotriz resultante do movimento relativo entre o circuito do rotor e o campo girante resultante. 


\subsection{Potência e torque elétrico}

A potência elétrica instantânea num sistema trifásico é definida como:

$$
P_{a b c}=u_{a} i_{a}+u_{b} i_{b}+u_{c} i_{c}=\left[\begin{array}{lll}
u_{a} & u_{b} & u_{c}
\end{array}\right]\left[\begin{array}{l}
i_{a} \\
i_{b} \\
i_{c}
\end{array}\right]
$$

Entretanto, pode-se aplicar a transformação:

$$
P_{a b c}=\left[\begin{array}{lll}
u_{a} & u_{b} & u_{c}
\end{array}\right]\left[\begin{array}{l}
i_{a} \\
i_{b} \\
i_{c}
\end{array}\right]=\left[\begin{array}{l}
u_{a} \\
u_{b} \\
u_{c}
\end{array}\right]^{T}\left[\begin{array}{l}
i_{a} \\
i_{b} \\
i_{c}
\end{array}\right]=\left([K]^{-1}\left[\begin{array}{l}
u_{q} \\
u_{b} \\
u_{0}
\end{array}\right]\right)^{T}[K]^{-1}\left[\begin{array}{l}
i_{q} \\
i_{d} \\
i_{0}
\end{array}\right]
$$

Portanto a potência instantânea fica:

$$
P_{a b c}=P_{q d 0}=u_{a} i_{a}+u_{b} i_{b}+u_{c} i_{c}=\frac{3}{2}\left(u_{q} i_{q}+u_{d} i_{d}+2 u_{0} i_{0}\right)
$$

É importante notar que nas coordenadas $d q 0$ a potência acima pode ser vista como a potência ativa quando em regime permanente e simétrico balanceado. A potência reativa pode ser definida como:

$$
Q_{q d 0}=\frac{3}{2}\left(u_{q} i_{d}-u_{d} i_{q}\right)
$$

Ao invés de obter o torque pelo método da coenergia com as equações da máquina nas coordenadas $d q 0$, é mais simples obter a equação do torque em regime permanente partindo da equação da potência ativa.

Para o sistema de coordenadas com velocidade angular igual à síncrona e assumindo o sistema equilibrado, pode-se escrever:

$$
\begin{gathered}
{\left[\begin{array}{c}
u_{q s} i_{q s} \\
u_{d s} i_{d s} \\
0
\end{array}\right]=\left[r_{s}\right]\left[\begin{array}{c}
i_{q s} i_{q s} \\
i_{d s} i_{d s} \\
0
\end{array}\right]+\omega_{s}\left[\begin{array}{c}
\lambda_{d s} i_{q s} \\
-\lambda_{q s} i_{d s} \\
0
\end{array}\right]} \\
{\left[\begin{array}{c}
u_{q s} i_{q s} \\
u_{d s} i_{d s} \\
0
\end{array}\right]=\left[r_{s}\right]\left[\begin{array}{c}
i_{q s} i_{q s} \\
i_{d s} i_{d s} \\
0
\end{array}\right]+\omega_{s}\left[\begin{array}{c}
\left(L_{s s} i_{d s}+L_{M} i_{d r}^{\prime}\right) i_{q s} \\
-\left(L_{s s} i_{q s}+L_{M} i_{q r}^{\prime}\right) i_{d s} \\
0
\end{array}\right]}
\end{gathered}
$$

Pois em regime permanente, os fluxos são constantes no sistema de coordenadas em questão, a taxa de variação é nula; ou seja, a componente dependente da varia- 
ção do fluxo nas equações (49) e (50) são nulas. Pode-se escrever a potência baseado em (58) e (59):

$$
\begin{gathered}
P_{s}=\frac{3}{2}\left(u_{q s} i_{q s}+u_{d s} i_{d s}\right)= \\
=\frac{3}{2} r_{s}\left(i_{q s}^{2}+i_{d s}^{2}\right)+\frac{3}{2} \omega_{s}\left(\left(L_{s s} i_{d s}+L_{M} i_{d r}^{\prime}\right) i_{q s}-\left(L_{s s} i_{q s}+L_{M} i_{q r}^{\prime}\right) i_{d s}\right) \\
P_{s}=\frac{3}{2} r_{s}\left(i_{q s}^{2}+i_{d s}^{2}\right)+\frac{3}{2} \omega_{s} L_{M}\left(i_{d r}^{\prime} i_{q s}-i_{q r}^{\prime} i_{d s}\right)
\end{gathered}
$$

Considerando a equação do torque:

$$
P=T \Omega \quad(64) \quad \Omega=\frac{\omega}{p_{p}}
$$

E sabendo que os termos dependentes das resistências são perdas, resulta na expressão do torque elétrico em (66).

$$
T_{s}=\frac{3}{2} p_{p} L_{M}\left(i_{d r}^{\prime} i_{q s}-i_{q r}^{\prime} i_{d s}\right)
$$

No qual $p_{p}$ é o número de pares de polos do gerador

De maneira análoga para o rotor:

$$
\begin{gathered}
{\left[\begin{array}{c}
u_{q r}^{\prime} i_{q r}^{\prime} \\
u_{d r}^{\prime} i_{d r}^{\prime} \\
0
\end{array}\right]=\left[r_{r}^{\prime}\right]\left[\begin{array}{c}
i_{q r}^{\prime} i_{q r}^{\prime} \\
i_{d r}^{\prime} i_{d r}^{\prime} \\
0
\end{array}\right]+\left(\omega_{s}-\omega_{r}\right)\left[\begin{array}{c}
\lambda_{d r}^{\prime} i_{q r}^{\prime} \\
-\lambda_{q r}^{\prime} i_{d r}^{\prime} \\
0
\end{array}\right]} \\
{\left[\begin{array}{c}
u_{q r}^{\prime} i_{q r}^{\prime} \\
u_{d r}^{\prime} i_{d r}^{\prime} \\
0
\end{array}\right]=\left[\begin{array}{c}
\left.r_{r}^{\prime}\right] \\
i_{q r}^{\prime} i_{q r}^{\prime} \\
i_{d r}^{\prime} i_{d r}^{\prime} \\
0
\end{array}\right]+\left(\omega_{s}-\omega_{r}\right)\left[\begin{array}{c}
\left(L_{r r}^{\prime} i_{d r}^{\prime}+L_{M} i_{d s}\right) i_{q r}^{\prime} \\
-\left(L_{r r}^{\prime} i_{q r}^{\prime}+L_{M} i_{q s}\right) i_{d r}^{\prime} \\
0
\end{array}\right]} \\
+\frac{3}{2}\left(\omega_{s}-\omega_{r}\right)\left(\left(L_{r r}^{\prime} i_{d r}^{\prime}+L_{M} i_{d s}\right) i_{q r}^{\prime}-\left(L_{r r}^{\prime} i_{q r}^{\prime}+L_{M} i_{q s}\right) i_{d r}^{\prime}\right) \\
P_{r}^{\prime}=\frac{3}{2} r_{r}^{\prime}\left(i_{q r}^{\prime 2}+i_{d r}^{\prime 2}\right)+\frac{3}{2}\left(\omega_{s}-\omega_{r}\right) L_{M}\left(i_{d s}^{\prime} i_{q r}^{\prime}-i_{q s} i_{d r}^{\prime}\right) \\
T_{r}^{\prime}=\frac{3}{2} p_{p} L_{M}\left(i_{d s} i_{q r}^{\prime}-i_{q s} i_{d r}^{\prime}\right)
\end{gathered}
$$

O escorregamento é definido por 


$$
s=\frac{\omega_{s}-\omega_{r}}{\omega_{s}}=\frac{\Omega_{s}-\Omega_{r}}{\Omega_{s}}
$$

A potência reativa é então:

$$
\begin{gathered}
{\left[\begin{array}{c}
u_{q s} i_{d s} \\
u_{d s} i_{q s} \\
0
\end{array}\right]=\left[r_{s}\right]\left[\begin{array}{c}
i_{q s} i_{d s} \\
i_{d s} i_{q s} \\
0
\end{array}\right]+\omega_{s}\left[\begin{array}{c}
\lambda_{d s} i_{d s} \\
-\lambda_{q s} i_{q s} \\
0
\end{array}\right]} \\
Q_{s}=\frac{3}{2}\left(u_{q s} i_{d s}-u_{d s} i_{q s}\right)=\frac{3}{2} \omega_{s}\left(\lambda_{d s} i_{d s}+\lambda_{q s} i_{q s}\right) \\
Q_{s}=\frac{3}{2} \omega_{s}\left(\left(L_{M} i_{d s} i_{d r}^{\prime}+L_{M} i_{q s} i_{q r}^{\prime}\right)+L_{s s}\left(i_{q s}^{2}+i_{d s}^{2}\right)\right) \\
Q_{r}^{\prime}=\frac{3}{2}\left(\begin{array}{c}
u_{q r}^{\prime} i_{d r}^{\prime} \\
\left.u_{d r}^{\prime} i_{q r}^{\prime} i_{d r}^{\prime}-u_{d r}^{\prime} i_{q r}^{\prime}\right)=\frac{3}{2}\left(\omega_{s}-\omega_{r}\right)\left(\lambda_{d r}^{\prime} i_{d r}^{\prime}+\lambda_{q r}^{\prime} i_{q r}^{\prime}\right) \\
i_{q r}^{\prime} i_{d r}^{\prime} \\
i_{d r}^{\prime} i_{q r}^{\prime} \\
0
\end{array}\right]+\left(\omega_{s}-\omega_{r}\right)\left[\begin{array}{c}
\lambda_{d r}^{\prime} i_{d r}^{\prime} \\
-\lambda_{q r}^{\prime} i_{q r}^{\prime} \\
0
\end{array}\right] \\
Q_{r}^{\prime}=\frac{3}{2}\left(\omega_{s}-\omega_{r}\right)\left(L_{M}\left(i_{d s} i_{d r}^{\prime}+i_{q s} i_{q r}^{\prime}\right)+L_{r r}^{\prime}\left(i_{q s}^{2}+i_{d s}^{2}\right)\right)
\end{gathered}
$$

Pode-se então escrever o balanço energético do gerador, desprezando as perdas. Potência positiva indica ação como motor.

$$
\begin{gathered}
P_{s}=P_{m e c} \\
P_{r}^{\prime}=-s P_{s}
\end{gathered}
$$

Vale lembrar que as potências são invariantes independentemente do lado ao qual estão referidos, rotor ou estator.

A potência total absorvida no ponto de interconexão com a rede será a soma da potência elétrica do rotor e do estator devido ao esquema de conexão normalmente utilizado - derivação do estator para alimentação dos conversores. A figura 18 mostra o fluxo de potência no DFIG em função do escorregamento.

Operação supersíncrona:

$$
\begin{aligned}
& \omega_{r}>\omega_{s} \Rightarrow s<0 \Rightarrow P_{g}=P_{s}+P_{r} \\
& \omega_{r}-\omega_{e}=\omega_{s} \\
& \omega_{r}<\omega_{s} \Rightarrow s>0 \Rightarrow P_{g}=P_{s}-P_{r} \\
& \omega_{r}+\omega_{e}=\omega_{s}
\end{aligned}
$$$$
\text { Operação subsíncrona: }
$$ 
O fluxo de potência no modo gerador é visualizado na figura 18.

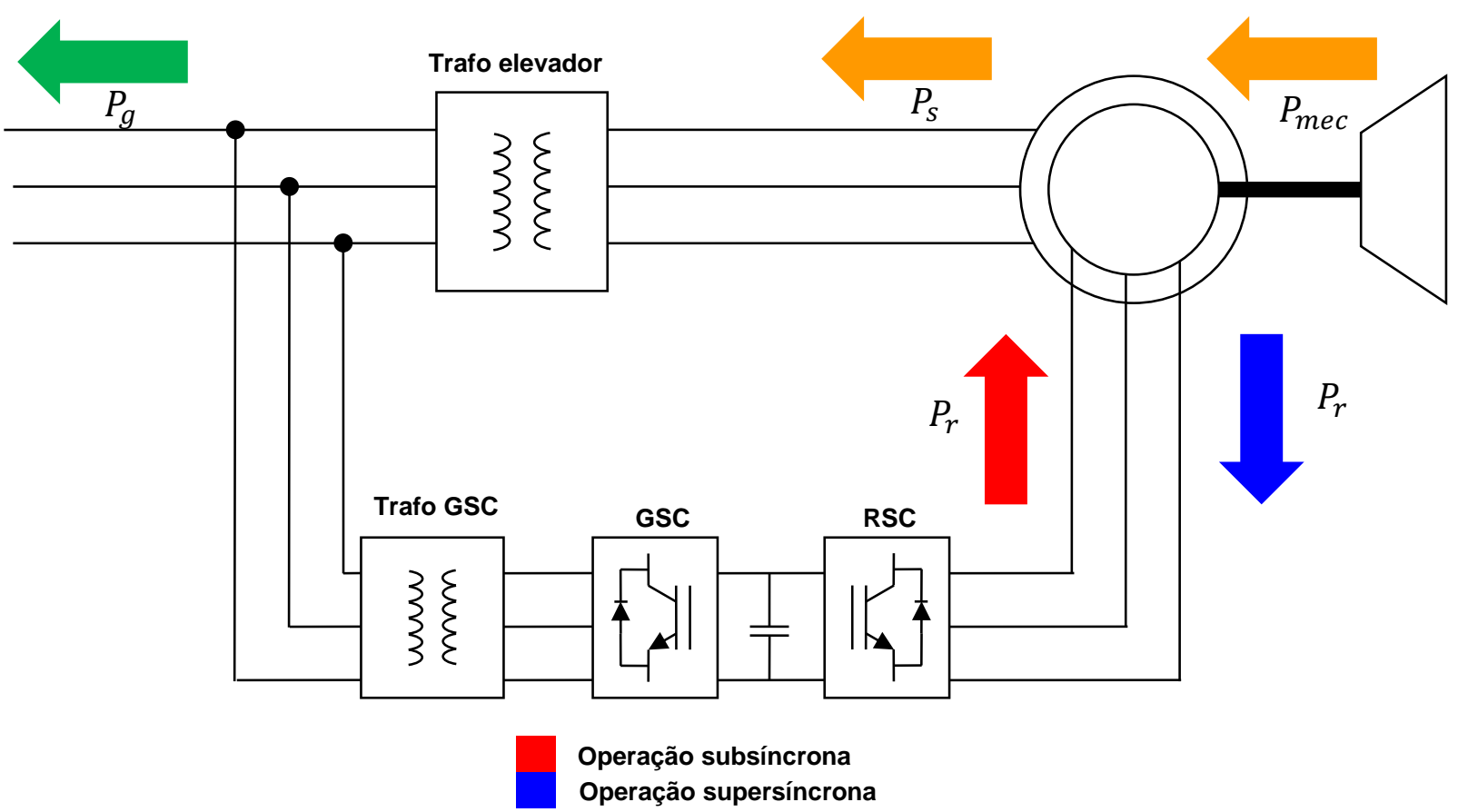

Figura 18 - Fluxo de potência no gerador de indução duplamente alimentado

Pela equação (84) percebe-se que quanto maior o escorregamento $s$, maior deve ser a potência que flui pelos rotores como explicado na figura 18.

A equação do torque fica:

$$
\begin{gathered}
T=\frac{P}{\Omega} \Rightarrow T_{s}=\frac{3}{2} p_{p} L_{M}\left(i_{d r}^{\prime} i_{q s}-i_{q r}^{\prime} i_{d s}\right) \\
T_{e}=T_{s}=-T_{r}^{\prime}
\end{gathered}
$$

O ângulo de carga pode ser encontrado da equação do torque. Para isso, primeiramente define-se um fasor $\widehat{F}_{a}$ da seguinte maneira:

$$
\begin{aligned}
\sqrt{2} \hat{F}_{a} & =f_{q}-j f_{d} \\
F_{a} \angle \varphi=\sqrt{2} F_{a} \cos (\omega t+\varphi) & =\underbrace{\sqrt{2} F_{a} \cos (\varphi)}_{f_{q}}-j \underbrace{\sqrt{2} F_{a} \operatorname{sen}(\varphi)}_{f_{d}}
\end{aligned}
$$

Ou seja, as correntes podem ter suas componentes $q_{r}$ e $q_{s}$ com alinhadas com as fases "ar" e "as": 


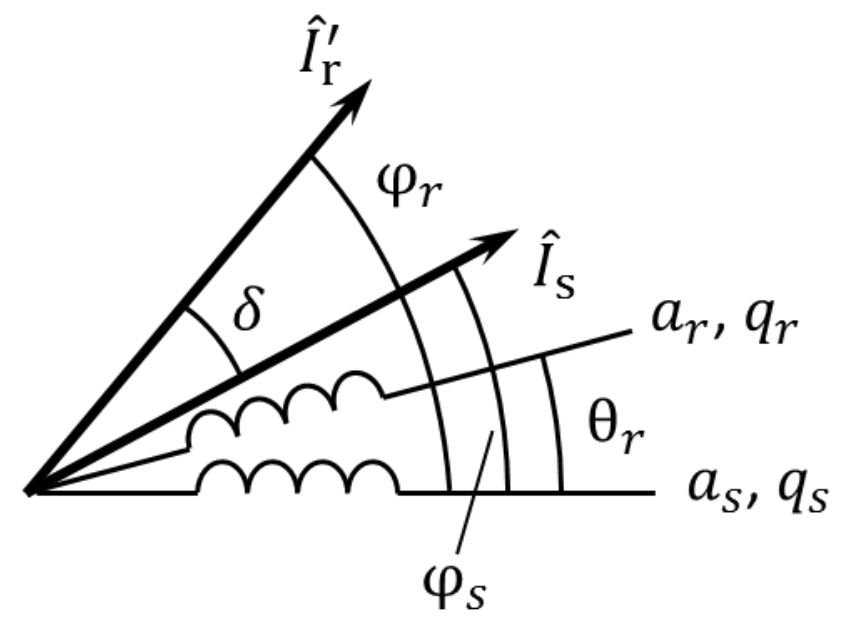

Figura 19 - Ângulo de carga e correntes no DFIG

Portanto, utilizando a transformação entre sistemas de coordenadas:

$$
\begin{gathered}
\operatorname{sen} \delta=\operatorname{sen}\left(\varphi_{r}-\varphi_{s}\right)=\frac{\left(i_{d r}^{\prime} i_{q s}-i_{q r}^{\prime} i_{d s}\right)}{\left|\hat{I}_{s}\right|\left|\hat{I}_{r}^{\prime}\right|} \\
T_{e l}=\frac{3}{2} p_{p} L_{M}\left|\hat{I}_{s}\right|\left|\hat{I}_{r}^{\prime}\right| \operatorname{sen} \delta
\end{gathered}
$$

E voltando para as coordenadas $a b c$, considerando valores eficazes segundo (83) tem-se:

$$
\begin{gathered}
T_{e l}=3 P_{p} L_{M}\left|\hat{I}_{a s}\right|\left|\hat{I}_{a r}^{\prime}\right| \operatorname{sen} \delta \\
\delta=\varphi_{r}-\varphi_{s}
\end{gathered}
$$

O ângulo delta também pode ser substituído nas equações da potência:

$$
\begin{gathered}
P_{S}=\frac{3}{2} r_{s}\left|\hat{I}_{s}\right|^{2}+\frac{3}{2} \omega_{s} L_{M}\left|\hat{I}_{s}\right|\left|\hat{I}_{r}^{\prime}\right| \operatorname{sen} \delta \\
Q_{s}=\frac{3}{2} \omega_{s} L_{s S}\left|\hat{I}_{s}\right|^{2}+\frac{3}{2} \omega_{s} L_{M}\left|\hat{I}_{s}\right|\left|\hat{I}_{r}^{\prime}\right| \cos \delta
\end{gathered}
$$

Outra maneira de visualizar o ângulo de carga é a partir dos fluxos conforme ilustrado na figura 20: 


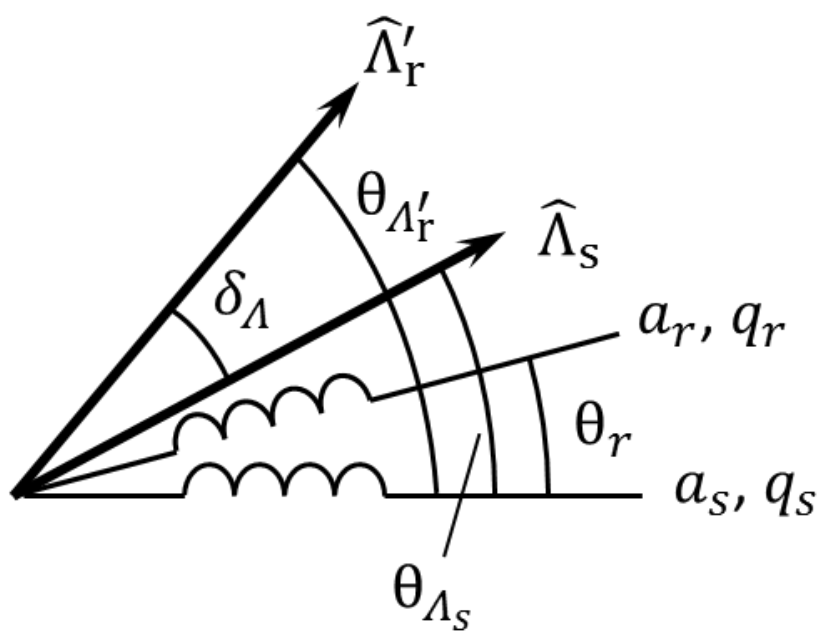

Figura 20 - Ângulo de carga a partir dos fluxos

O ângulo entre os fluxos pode ser encontrado a partir:

$$
\operatorname{sen} \delta_{\Lambda}=\operatorname{sen}\left(\theta_{\Lambda_{r}^{\prime}}-\theta_{\Lambda_{s}}\right)=\frac{\left(\lambda_{d r}^{\prime} \lambda_{q s}-\lambda_{q r}^{\prime} \lambda_{d s}\right)}{\left|\hat{\Lambda}_{s}\right|\left|\hat{\Lambda}_{r}^{\prime}\right|}
$$

Porém, o produto dos fluxos do rotor e estator podem ser escrito como:

$$
\lambda_{d r}^{\prime} \lambda_{q s}-\lambda_{q r}^{\prime} \lambda_{d s}=\left(L_{r r}^{\prime} L_{s s}-L_{M}^{2}\right)\left(i_{d r}^{\prime} i_{q s}-i_{q r}^{\prime} i_{d s}\right)
$$

Do que resulta:

$$
\frac{\left|\hat{\Lambda}_{s}\right|\left|\hat{\Lambda}_{r}^{\prime}\right|}{\left(L_{r r}^{\prime} L_{s s}-L_{M}^{2}\right)} \operatorname{sen} \delta_{\Lambda}=\left|\hat{I}_{s}\right|\left|\hat{I}_{r}^{\prime}\right| \operatorname{sen} \delta
$$

\subsection{Regime permanente}

Para melhor compreensão do funcionamento da máquina de indução duplamente alimentada, é necessário estudar seu comportamento em regime permanente.

Considerando a máquina conectada a um barramento infinito com tensão estável e balanceada, considerando reatâncias ao invés de indutâncias, as seguintes simplificações nas equações (49) a (53) são feitas considerando (43): 


$$
\begin{gathered}
\widehat{U}_{s}=\left(r_{s}+j X_{s s}\right) \hat{I}_{s}+j X_{M} \hat{I}_{r}^{\prime} \\
\widehat{U}_{r}^{\prime}=\left(r_{r}^{\prime}+j X_{r r}^{\prime} s\right) \hat{I}_{r}^{\prime}+j X_{M} \hat{I}_{s} s
\end{gathered}
$$

As correntes em regime permanente podem ser obtidas rearranjando os termos das equações (94) e (95):

$$
\begin{aligned}
& \hat{I}_{s}=\frac{\left(r_{r}^{\prime}+j X_{r r}^{\prime} s\right) \widehat{U}_{s}-j X_{M} \widehat{U}_{r}^{\prime}}{\left(\left(r_{s}+j X_{s S}\right)\left(r_{r}^{\prime}+j X_{r r}^{\prime} s\right)+X_{M}^{2} s\right)} \\
& \hat{I}_{r}^{\prime}=\frac{\left(r_{s}+j X_{s s}\right) \widehat{U}_{r}^{\prime}-j X_{M} \widehat{U}_{s} s}{\left(\left(r_{s}+j X_{s S}\right)\left(r_{r}^{\prime}+j X_{r r}^{\prime} s\right)+X_{M}^{2} s\right)}
\end{aligned}
$$

Para simplificar o cálculo das correntes em regime permanente resultantes da dupla alimentação, definem-se os seguintes parâmetros:

$$
\begin{gathered}
\widehat{D}_{c}=\left(r_{s}+j X_{s s}\right)\left(r_{r}^{\prime}+j X_{r r}^{\prime} s\right)+X_{M}^{2} s= \\
=r_{s} r_{r}^{\prime}-\left(X_{s S} X_{r r}^{\prime}-X_{M}^{2}\right) s+j\left(X_{s s} r_{r}^{\prime}+X_{r r}^{\prime} r_{s} s\right) \\
\left|\widehat{D}_{c}(s)\right|=\sqrt{\left(r_{s} X_{r r}^{\prime} s+X_{s s} r_{r}^{\prime}\right)^{2}+\left(s\left(-X_{s s} X_{r r}^{\prime}+X_{M}^{2}\right)-r_{s} r_{r}^{\prime}\right)^{2}} \\
\hat{Z}_{s s}=r_{s}+j X_{s s} \\
\hat{Z}_{r r}^{\prime}=r_{r}^{\prime}+j X_{r r}^{\prime} s \\
\hat{Z}_{M}=j X_{M}
\end{gathered}
$$

Sendo suas fases:

$$
\begin{gathered}
\varphi_{\widehat{D}_{c}}=\operatorname{atan}\left(-\frac{\left(r_{s} X_{r r}^{\prime} s+X_{s s} r_{r}^{\prime}\right)}{s\left(X_{s S} X_{r r}^{\prime}-X_{M}^{2}\right)-r_{s} r_{r}^{\prime}}\right) \\
\varphi_{\hat{Z}_{r r}^{\prime}}=\operatorname{atan}\left(\frac{X_{r r}^{\prime} s}{r_{r}^{\prime}}\right)
\end{gathered}
$$

$$
\varphi_{\widehat{Z}_{M}}=\frac{\pi}{2}
$$$$
\varphi_{\widehat{Z}_{s s}}=\operatorname{atan}\left(\frac{X_{s s}}{r_{s}}\right)
$$

Sendo assim, as correntes podem ser reescritas conforme (107) e (108) a seguir.

$$
\begin{gathered}
\hat{I}_{s}=\frac{\widehat{U}_{s} \hat{Z}_{r r}^{\prime}-\hat{Z}_{M} \widehat{U}_{r}^{\prime}}{\widehat{D}_{c}} \\
\hat{I}_{r}^{\prime}=\frac{\widehat{U}_{r}^{\prime} \hat{Z}_{s s}-\hat{Z}_{M} \widehat{U}_{s} s}{\widehat{D}_{c}}
\end{gathered}
$$

A figura 21 apresenta as equações da máquina em forma vetorial para melhor visualização dos vetores. 


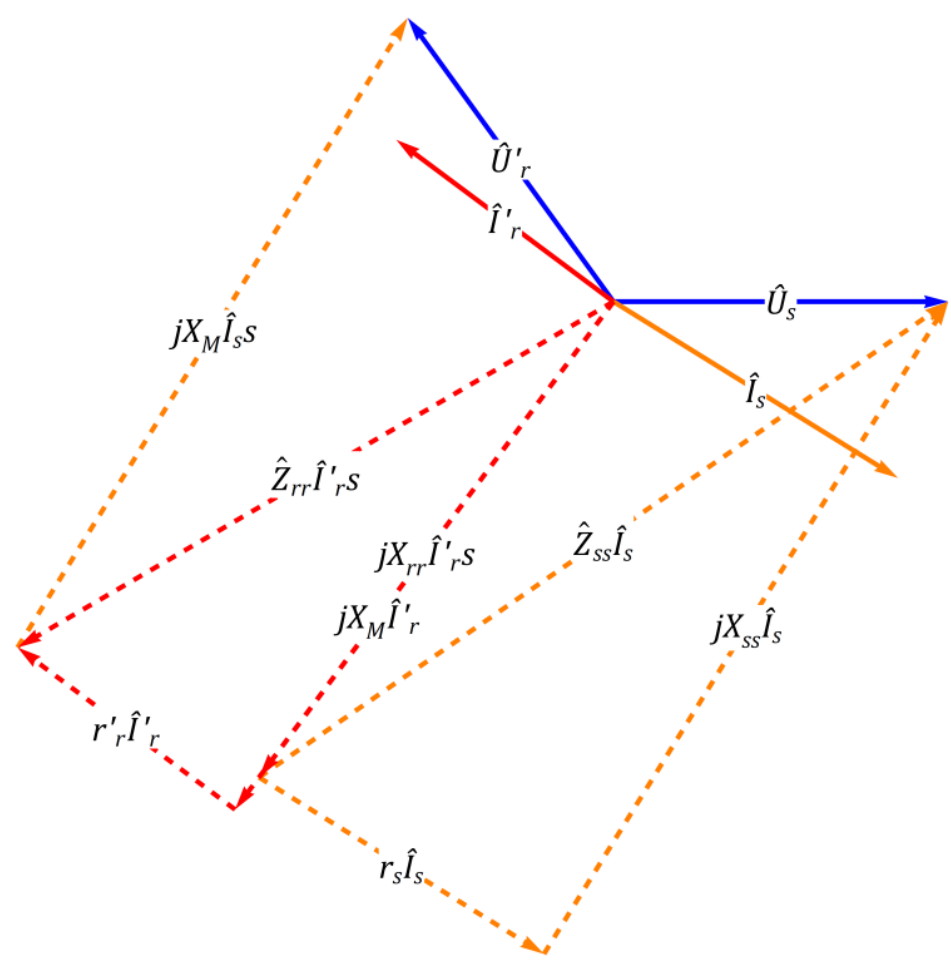

Figura 21 - Diagrama vetorial da máquina de indução duplamente alimentada

A tensão de excitação em regime permanente pode então ser obtida como:

$$
\begin{gathered}
u_{q r}^{\prime}=\operatorname{Re}\left[\frac{\widehat{U}_{s} \hat{Z}_{r r}^{\prime}-\hat{I}_{s} \widehat{D}_{c}}{\hat{Z}_{M}}\right] \\
u_{d r}^{\prime}=-\operatorname{Im}\left[\frac{\widehat{U}_{s} \hat{Z}_{r r}^{\prime}-\hat{I}_{s} \widehat{D}_{c}}{\hat{Z}_{M}}\right] \\
\theta_{e}+\theta_{r}=\operatorname{atan} \frac{-u_{d r}^{\prime}}{u_{q r}^{\prime}}
\end{gathered}
$$

Dessas equações percebe-se o ângulo $\theta_{e}$ da tensão de excitação $\widehat{U}_{r}^{\prime}$ que está em relação aos circuitos do rotor, controla a carga do gerador para um dado escorregamento. Portanto pode-se definir um ângulo de carga proporcional a tensão de excitação:

$$
\delta_{U}=\theta_{e}+\theta_{r}-\theta_{U s}
$$

Ao observar a figura 22 abaixo, percebe-se que é possível variar livremente (dentro de limites dos conversores e da unidade geradora) o ângulo de carga. Além disso, é possível obter o ângulo inicial do rotor sabendo a potência ativa inicial, as tensões estatórica e rotórica e seus ângulos iniciais. 


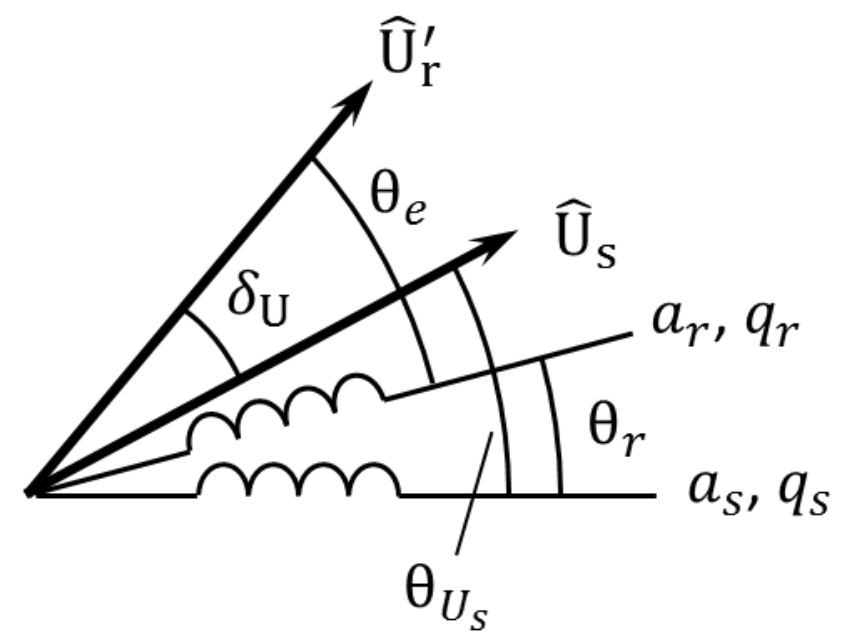

Figura 22 - Tensões estatórica e rotórica com ângulos iniciais e ângulo do rotor em relação à fase $a$ do rotor e estator

Para melhor entender a relação entre ângulos e os fasores da máquina, o seguinte diagrama é plotado considerando resistências nulas.

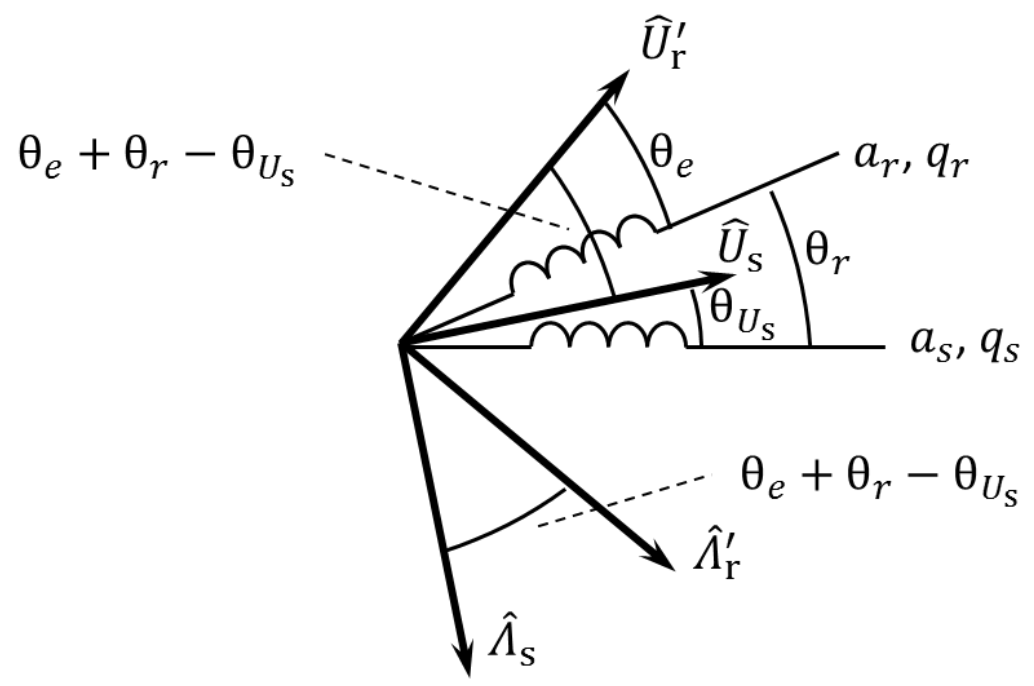

Figura 23 - Diagrama dos fluxos e tensões do DFIG desprezando resistências

É importante saber os limites de operação do gerador durante a operação interconectada ao sistema de potência. A curva de capabilidade do gerador mostra a região permitida para a operação da máquina.

A curva de capabilidade do gerador de indução pode ser desenvolvida de maneira semelhante à do gerador síncrono. Partindo-se da equação (94), considerando equações por unidade (pu) e a tensão do estator como referência $\left(\hat{u}_{s}=1\right)$, resistência do estator nula e multiplicam-se ambos os lados da equação por: 


$$
\frac{\left|\hat{u}_{s}\right|}{x_{s s}}
$$

Resultando em

$$
\frac{\left|\hat{u}_{s}\right|}{x_{s s}} j x_{M} \hat{\imath}_{r}^{\prime}=\frac{\left|\hat{u}_{s}\right|}{x_{s s}} \hat{u}_{s}-j\left|\hat{u}_{s}\right| \hat{\imath}_{s}
$$

Com esta equação pode-se plotar a curva de capabilidade da máquina que determina os limites de operação da máquina elétrica. A curva visualizada na figura 24 também inclui a região de operação da máquina como motor.

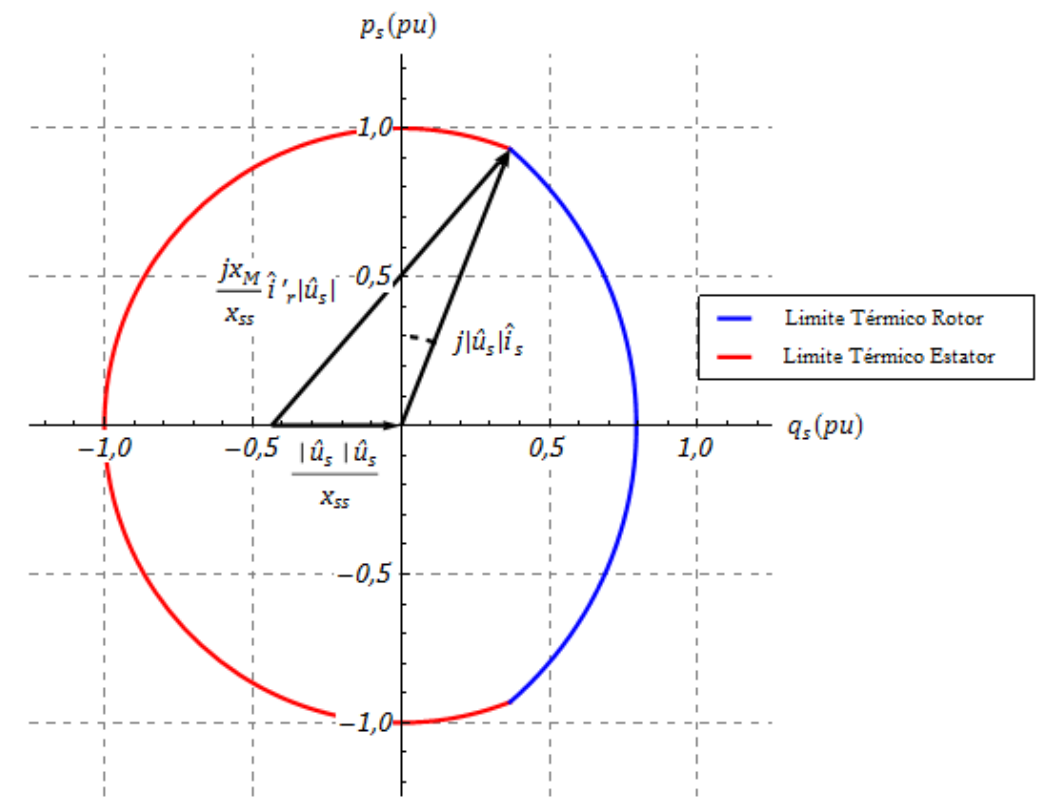

Figura 24 - Curva de capabilidade para o DFIG

Outra curva utilizada é a curva $\mathrm{V}$ do gerador. Ela mostra a corrente estatórica em função da corrente de excitação (corrente rotórica) para potência ativa constante ou para fator de potência constante.

Para plotar a curva $V$ do gerador, deduzem-se duas equações paramétricas a partir da equação (113) em pu e considerando a tensão do estator como referência.

$$
C\left(p_{s}, q_{s}\right)=\left\{\frac{x_{s s}}{x_{M}} \sqrt{\left(\frac{p_{s}}{u_{q s}}\right)^{2}+\left(\frac{q_{s}}{u_{q s}}-\frac{u_{q s}}{x_{s s}}\right)^{2}}, \frac{\sqrt{p_{s}^{2}+q_{s}^{2}}}{u_{q s}}\right\}
$$

Para plotar a característica com fator de potência constante, as seguintes igualdades devem ser substituídas na equação (114): 


$$
\begin{gathered}
p_{s}=s_{s} \cos \varphi_{s} \\
q_{s}=s_{s} \sqrt{1-\cos ^{2} \varphi_{s}}
\end{gathered}
$$

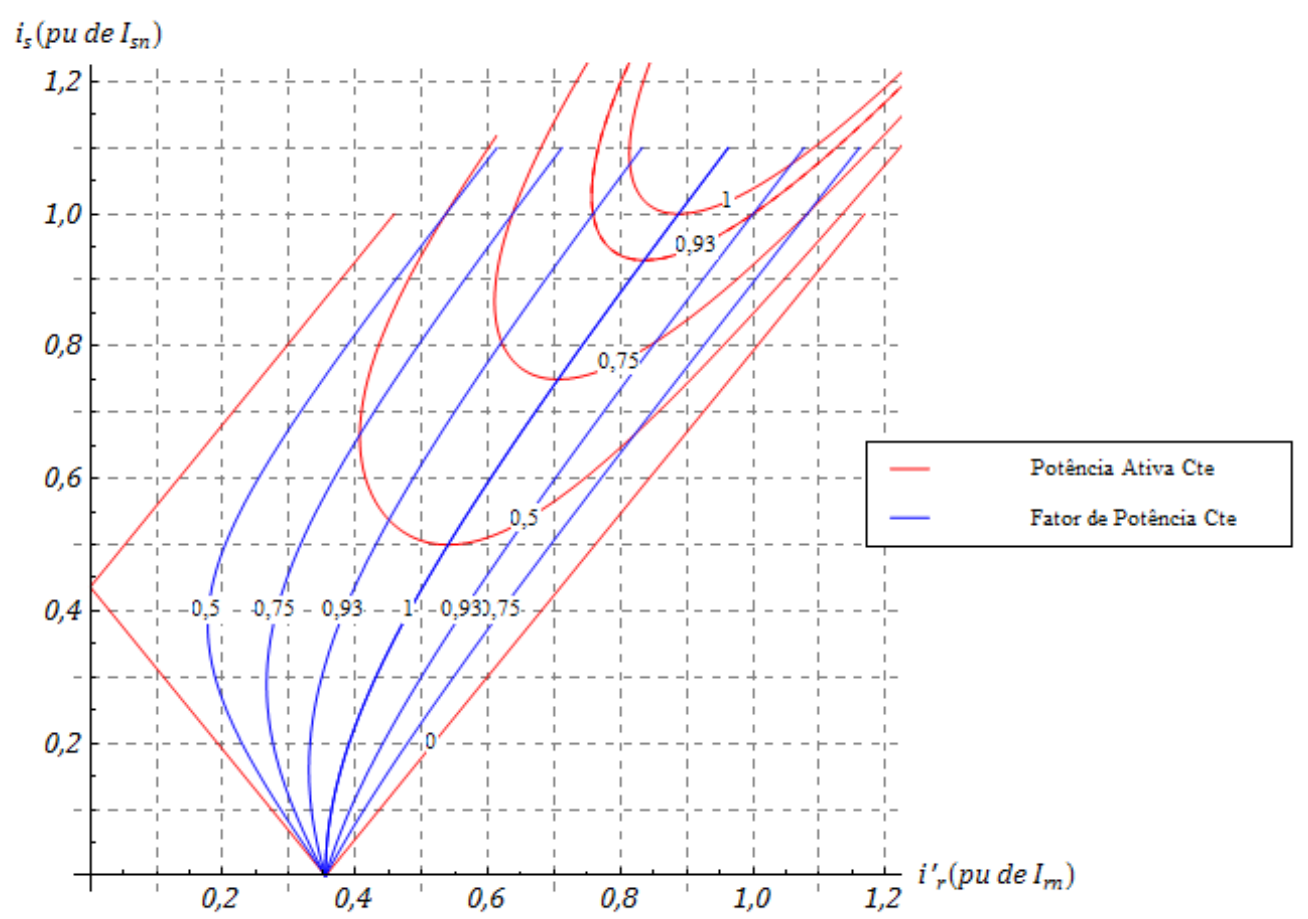

Figura 25 - Diagrama V do DFIG

Além destas duas curvas, é necessário apresentar também curvas que indiquem os limites dos conversores. A figura a seguir apresenta um exemplo de tal curva. 


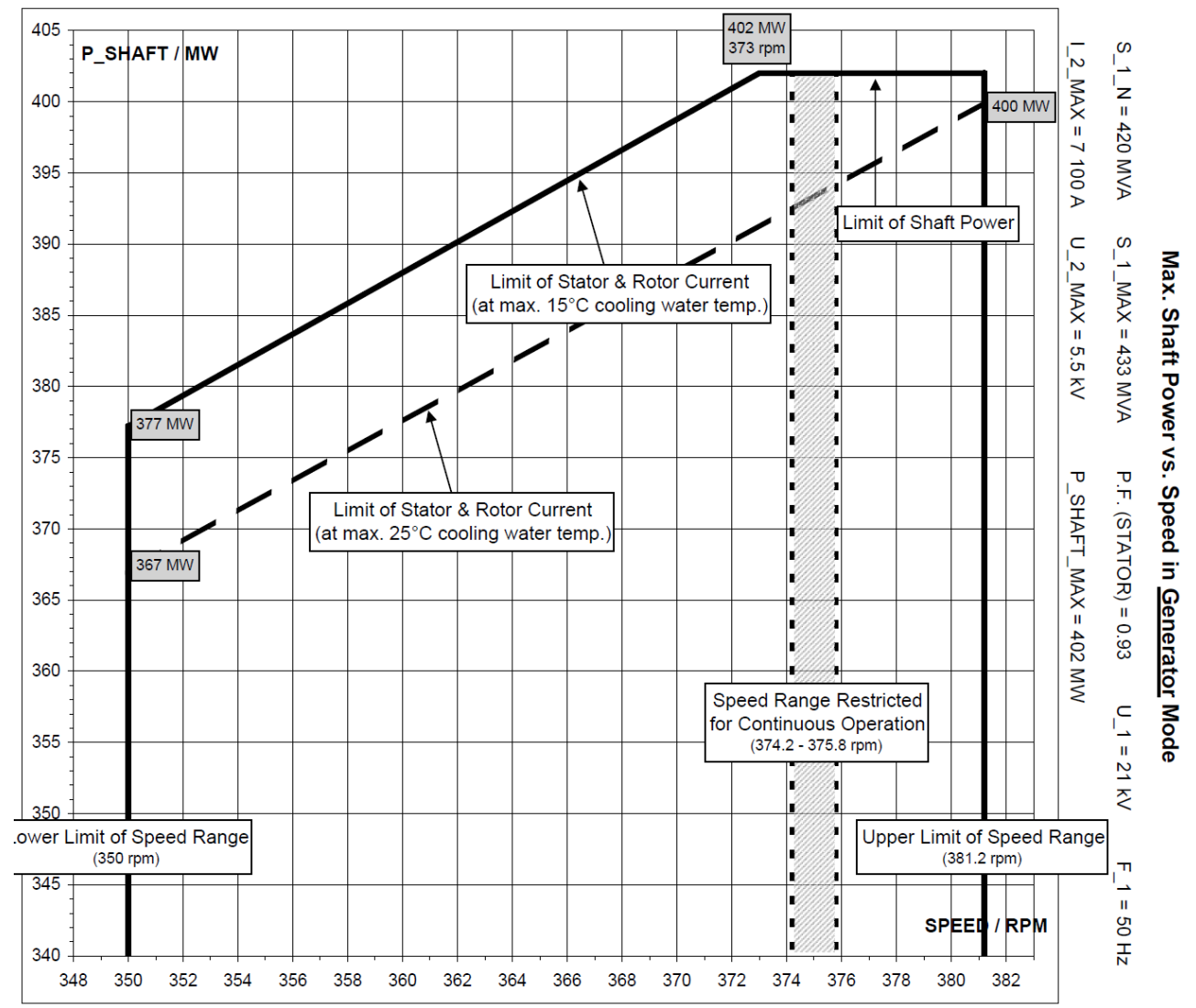

Figura 26 - Limites de potência do estator em função do escorregamento (Fonte: @ VOITH Hydro)

A figura 26 mostra a faixa (em cinza) proibida para operação contínua, sendo permitido o ponto de operação apenas passar por esta. Como a frequência da corrente de excitação nesta faixa é muito reduzida, a expansão e contração térmica dos materiais passam a acompanhar o valor instantâneo da corrente ao invés do valor eficaz, podendo resultar em fadiga prematura do equipamento. 


\subsection{Transientes}

É importante o conhecimento do comportamento do gerador em regime permanente para sua correta operação. Entretanto, os transientes elétricos merecem especial atenção pois podem causar danos aos equipamentos, representar risco a segurança das pessoas envolvidas na manutenção e operação e prejudicar a qualidade de energia ofertada ao sistema.

Pela lei de Faraday, o fluxo é a integral da tensão adicionado ao valor inicial:

$$
\phi=\int u d t+\phi_{0}
$$

Assim, quando a tensão é anulada, existe um fluxo residual. O fluxo eventualmente descarrega a energia magnética nas resistências existentes no circuito.

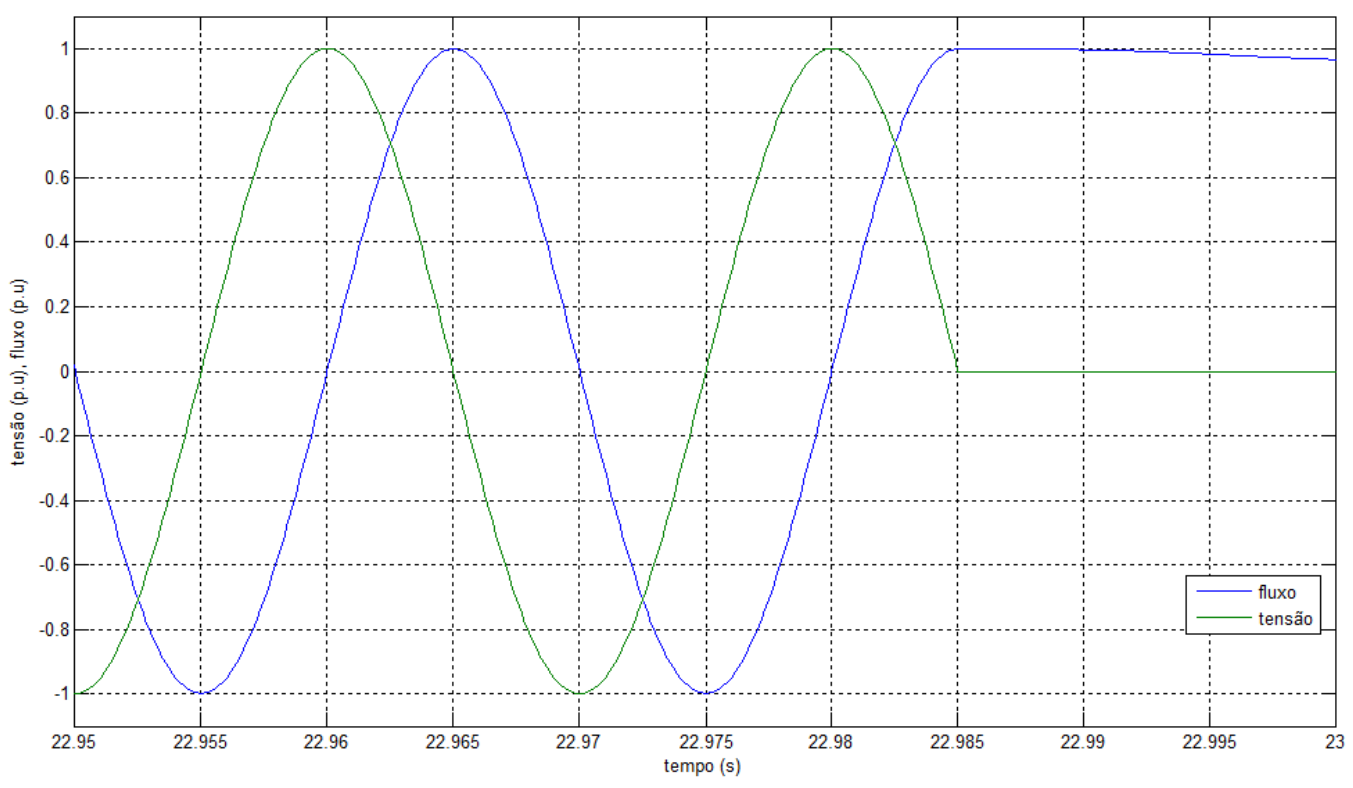

Figura 27 - Relação entre tensão e fluxo

Para o estator de um gerador trifásico, as tensões produzem um campo girante no na máquina quando em regime permanente. Quando ocorre um curto trifásico brusco, as tensões são zeradas subitamente, o fluxo residual é visto como um fluxo con- 
gelado no espaço. De fato, para qualquer variação repentina na tensão (um afundamento de tensão, por exemplo), o fluxo apresenta este comportamento.

A figura 28 mostra o fluxo nas coordenadas $d q$ fixadas no estator para um curtocircuito trifásico. A figura da esquerda é função do tempo e a da direita é a representação no plano complexo.
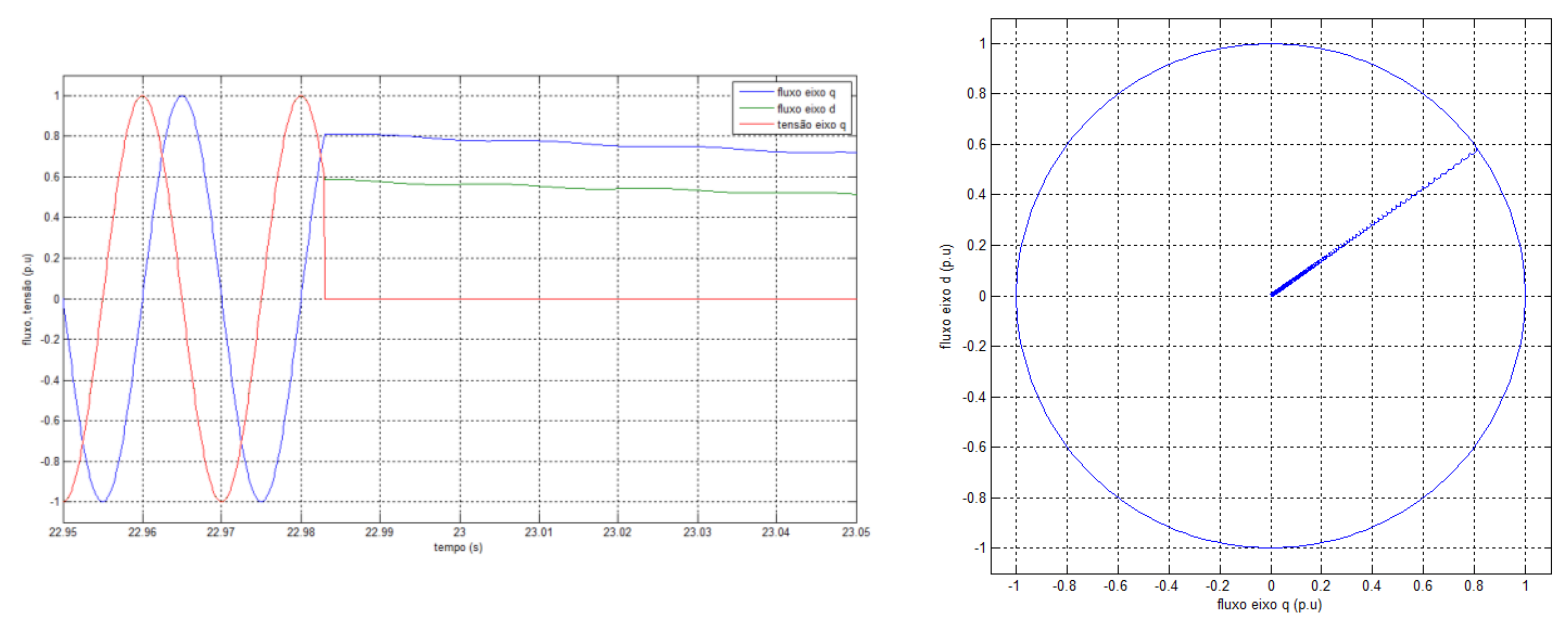

Figura 28 - Fluxo congelado nas coordenadas $d q$ estacionárias

\subsubsection{Curto-circuito trifásico}

Para calcular o curto-circuito trifásico primeiramente as equações (49) a (52) são rearranjadas para conter apenas fluxos por segundo e tensões (KRAUSE, 2002) segundo:

$$
\lambda=\frac{\psi}{\omega_{b}}=\frac{x}{\omega_{b}} i
$$

Além disso, foram considerados valores por unidade. A sequência zero pode ser desprezada pois o curto é simétrico. 


$$
\left[\begin{array}{l}
u_{q s} \\
u_{d s} \\
u_{q r}^{\prime} \\
u_{d r}^{\prime}
\end{array}\right]=\left[\begin{array}{cccc}
\frac{r_{s} x_{r r}^{\prime}}{D}+\frac{p}{\omega_{b}} & \frac{\omega}{\omega_{b}} & -\frac{r_{s} x_{M}}{D} & 0 \\
-\frac{\omega}{\omega_{b}} & \frac{r_{s} x_{r r}^{\prime}}{D}+\frac{p}{\omega_{b}} & 0 & -\frac{r_{s} x_{M}}{D} \\
-\frac{r_{r}^{\prime} x_{M}}{D} & 0 & \frac{r_{r}^{\prime} x_{s s}}{D}+\frac{p}{\omega_{b}} & \frac{\left(\omega-\omega_{r}\right)}{\omega_{b}} \\
0 & -\frac{r_{r}^{\prime} x_{M}}{D} & -\frac{\left(\omega-\omega_{r}\right)}{\omega_{b}} & \frac{r_{r}^{\prime} x_{s s}}{D}+\frac{p}{\omega_{b}}
\end{array}\right]\left[\begin{array}{l}
\psi_{q s} \\
\psi_{d s} \\
\psi_{q r}^{\prime} \\
\psi_{d r}^{\prime}
\end{array}\right]
$$

Fazendo-se a seguinte mudança de variáveis:

$$
\begin{gathered}
\frac{1}{\tau_{r}}=k_{r}=\frac{r_{r}^{\prime} x_{s s} \omega_{b}}{D} \\
\frac{1}{\tau_{s}}=k_{s}=\frac{r_{s} x_{r r}^{\prime} \omega_{b}}{D} \\
k_{r M}=\frac{r_{r}^{\prime} x_{M} \omega_{b}}{D} \\
k_{S M}=\frac{r_{s} x_{M} \omega_{b}}{D}
\end{gathered}
$$

$$
\begin{gathered}
x_{s}(p)=\left(\frac{1}{\tau_{s}}+p\right) \\
x_{r}(p)=\left(\frac{1}{\tau_{r}}+p\right) \\
\omega_{b}=\omega_{s} \\
D=x_{s s} x_{r r}^{\prime}-x_{M}^{2}
\end{gathered}
$$

Resulta em para o sistema de coordenadas $d q 0$ na velocidade síncrona:

$$
\left[\begin{array}{l}
u_{q s} \\
u_{d s} \\
u_{q r}^{\prime} \\
u_{d r}^{\prime}
\end{array}\right]=\left[\begin{array}{cccc}
\frac{x_{s}(p)}{\omega_{s}} & 1 & -\frac{k_{s M}}{\omega_{s}} & 0 \\
-1 & \frac{x_{s}(p)}{\omega_{s}} & 0 & -\frac{k_{s M}}{\omega_{s}} \\
-\frac{k_{r M}}{\omega_{s}} & 0 & \frac{x_{r}(p)}{\omega_{s}} & s \\
0 & -\frac{k_{r M}}{\omega_{s}} & -s & \frac{x_{r}(p)}{\omega_{s}}
\end{array}\right]\left[\begin{array}{l}
\psi_{q s} \\
\psi_{d s} \\
\psi_{q r}^{\prime} \\
\psi_{d r}^{\prime}
\end{array}\right]
$$

Com reatâncias, resistências, tensões e fluxos em pu e frequências em radianos por segundo.

Encontrar a resposta ao curto-circuito nos terminais do estator é equivalente a encontrar a resposta para um degrau na tensão do estator e subtrair das equações de regime permanente (CONCORDIA, 1951). Portanto, para a resposta do sistema em repouso a uma perturbação de tensão trifásica dos terminais do estator, será resolvido o seguinte sistema: 


$$
\left[\begin{array}{c}
\frac{u_{q s}}{p} \\
\frac{u_{d s}}{p} \\
0 \\
0
\end{array}\right]=\left[\begin{array}{cccc}
\frac{x_{s}(p)}{\omega_{s}} & 1 & -\frac{k_{s M}}{\omega_{s}} & 0 \\
-1 & \frac{x_{s}(p)}{\omega_{s}} & 0 & -\frac{k_{s M}}{\omega_{s}} \\
-\frac{k_{r M}}{\omega_{s}} & 0 & \frac{x_{r}(p)}{\omega_{s}} & s \\
0 & -\frac{k_{r M}}{\omega_{s}} & -s & \frac{x_{r}(p)}{\omega_{s}}
\end{array}\right]\left[\begin{array}{l}
\psi_{q s} \\
\psi_{d s} \\
\psi_{q r}^{\prime} \\
\psi_{d r}^{\prime}
\end{array}\right]
$$

O Anexo A apresenta a resolução detalhada do sistema de equações. O resultado no domínio do tempo aproximado para pequenos valores de resistência é:

$$
\begin{aligned}
& \psi_{q s}(t)=-u_{d s}+e^{-t k_{s}} \sqrt{u_{q s}^{2}+u_{d s}^{2}} \operatorname{sen}\left(\omega_{s} t-\theta_{U_{s}}\right) \\
& \psi_{d s}(t)=u_{q s}-e^{-t k_{s}} \sqrt{u_{q S}^{2}+u_{d s}^{2}} \cos \left(\omega_{s} t-\theta_{U_{s}}\right) \\
& \psi_{q r}^{\prime}(t)=-k_{r M} \frac{\sqrt{u_{q s}^{2}+u_{d s}^{2}}}{\sqrt{T_{r}^{2}+s^{2} \omega_{s}^{2}}} \cos \left(\theta_{U_{s}}+\theta_{k 1}\right)+ \\
& -e^{-t k_{s}} k_{r M} \frac{\sqrt{u_{q s}^{2}+u_{d s}^{2}}}{\sqrt{k_{r}^{2}+\left(\omega_{s}-s \omega_{s}\right)^{2}}} \cos \left(\omega_{s} t-\theta_{U_{s}}+\theta_{k 2}\right)+ \\
& +e^{-t k_{r}} k_{r M} \omega_{s} \frac{\sqrt{u_{q s}^{2}+u_{d s}^{2}}}{\sqrt{k_{r}^{2}+s^{2} \omega_{s}^{2}} \sqrt{k_{r}^{2}+\left(\omega_{s}-s \omega_{s}\right)^{2}}} \cos \left(s \omega_{s} t-\theta_{u s}-\theta_{k 1}+\theta_{k 2}\right) \\
& \psi_{d r}^{\prime}(t)=k_{r M} \frac{\sqrt{u_{q s}^{2}+u_{d s}^{2}}}{\sqrt{T_{r}^{2}+s^{2} \omega_{s}^{2}}} \operatorname{sen}\left(\theta_{U_{s}}+\theta_{k 1}\right)+ \\
& -e^{-t k_{s}} k_{r M} \frac{\sqrt{u_{q s}^{2}+u_{d s}^{2}}}{\sqrt{k_{r}^{2}+\left(\omega_{s}-s \omega_{s}\right)^{2}}} \operatorname{sen}\left(\omega_{s} t-\theta_{U_{s}}+\theta_{k 2}\right)+ \\
& +e^{-t k_{r}} k_{r M} \omega_{s} \frac{\sqrt{u_{q s}^{2}+u_{d s}^{2}}}{\sqrt{k_{r}^{2}+s^{2} \omega_{s}^{2}} \sqrt{k_{r}^{2}+\left(\omega_{s}-s \omega_{s}\right)^{2}}} \operatorname{sen}\left(s \omega_{s} t-\theta_{U_{s}}-\theta_{k 1}+\theta_{k 2}\right) \\
& \theta_{k 1}=\operatorname{atan} 2\left(k_{r}, s \omega_{s}\right) \\
& \theta_{k 2}=\operatorname{atan} 2\left(k_{r},\left(\omega_{s}-s \omega_{s}\right)\right)
\end{aligned}
$$


Esses resultados devem ser subtraídos das componentes de regime permanente antes do curto-circuito.

Além disso, o termo que multiplica $e^{-t k_{s}}$ nos fluxos do rotor é muito menor que o termo que multiplica $e^{-t k_{r}}$ para valores pequenos de escorregamento, sendo desprezado para facilitar os cálculos.

Sendo assim, os fluxos em pu devido ao curto trifásico brusco nas coordenadas $d q 0$ síncronas são:

$$
\begin{gathered}
\psi_{q s}(t)=-e^{-t T_{s}} \operatorname{sen}\left(\omega_{s} t\right) \\
\psi_{d s}(t)=e^{-t k_{s}} \cos \left(\omega_{s} t\right) \\
\psi_{q r}^{\prime}(t)=\frac{\sqrt{{u_{q r 0}^{\prime}{ }^{2}+u_{q r 0}^{\prime}}^{2}}}{\sqrt{k_{r}^{2}+s^{2} \omega_{s}^{2}}} \omega_{s} \operatorname{sen}\left(\theta_{r 0}+\theta_{e 0}+\theta_{k 1}\right)+ \\
-\frac{e^{-t k_{r}} \omega_{s}}{\sqrt{k_{r}^{2}+s^{2} \omega_{s}^{2}}} \frac{k_{r M}}{\sqrt{k_{r}^{2}+\left(\omega_{s}-s \omega_{s}\right)^{2}}} \cos \left(s \omega_{s} t-\theta_{k 1}+\theta_{k 2}\right) \\
\psi_{d r}^{\prime}(t)=\frac{\sqrt{u_{q r 0}^{\prime}+u_{q r 0}^{\prime}}}{\sqrt{k_{r}^{2}+s^{2} \omega_{s}^{2}}} \omega_{s} \cos \left(\theta_{r 0}+\theta_{e 0}+\theta_{k 1}\right)+ \\
-\frac{e^{-t k_{r}} \omega_{s}}{\sqrt{k_{r}^{2}+s^{2} \omega_{s}^{2}}} \frac{k_{r M}}{\sqrt{k_{r}^{2}+\left(\omega_{s}-s \omega_{s}\right)^{2}}} \operatorname{sen}\left(s \omega_{s} t-\theta_{k 1}+\theta_{k 2}\right)
\end{gathered}
$$

A soma $\theta_{r 0}+\theta_{e 0}$ é função da condição de carga da máquina antes do curto-circuito e pode ser obtida a partir da equação (111).

Esses resultados podem ser convertidos paras as correntes por meio das equações (51) e (52). Portanto, as correntes nas coordenadas $d q 0$ síncrona resultam:

$$
\begin{gathered}
i_{q s}=-\frac{x_{r r}^{\prime}}{D} e^{-t k_{s}} \operatorname{sen}\left(\omega_{s} t\right)+ \\
-\frac{x_{M}}{D} \frac{\sqrt{{u_{q r 0}^{\prime}}^{2}+u_{q r 0}^{\prime}}}{\sqrt{k_{r}^{2}+s^{2} \omega_{s}^{2}}} \omega_{s} \operatorname{sen}\left(\theta_{r 0}+\theta_{e 0}+\theta_{k 1}\right)+ \\
+\frac{x_{M}}{D} \frac{e^{-t k_{r} \omega_{s}}}{\sqrt{k_{r}^{2}+s^{2} \omega_{s}^{2}}} \frac{k_{r M}}{\sqrt{k_{r}^{2}+\left(\omega_{s}-s \omega_{s}\right)^{2}}} \cos \left(s \omega_{s} t-\theta_{k 1}+\theta_{k 2}\right) \\
i_{d s}=\frac{x_{r r}^{\prime}}{D} e^{-t k_{s}} \cos \left(\omega_{s} t\right)+
\end{gathered}
$$




$$
\begin{gathered}
-\frac{x_{M}}{D} \frac{\sqrt{u_{q r 0}^{\prime 2}+u_{q r 0}^{\prime}}}{\sqrt{k_{r}^{2}+s^{2} \omega_{s}^{2}}} \omega_{s} \cos \left(\theta_{r 0}+\theta_{e 0}+\theta_{k 1}\right)+ \\
+\frac{x_{M}}{D} \frac{e^{-t k_{r} \omega_{s}}}{\sqrt{k_{r}^{2}+s^{2} \omega_{s}^{2}}} \frac{k_{r M}}{\sqrt{k_{r}^{2}+\left(\omega_{s}-s \omega_{s}\right)^{2}}} \operatorname{sen}\left(s \omega_{s} t-\theta_{k 1}+\theta_{k 2}\right) \\
+\frac{x_{q r}^{\prime}=\frac{x_{M}}{D} e^{-t k_{s}} \operatorname{sen}\left(\omega_{s} t\right)+}{D} \frac{\sqrt{u_{q r 0}^{\prime}{ }^{2}+u_{q r 0}^{\prime}}}{\sqrt{k_{r}^{2}+s^{2} \omega_{s}^{2}}} \omega_{s} \operatorname{sen}\left(\theta_{r 0}+\theta_{e 0}+\theta_{k 1}\right)+ \\
\sqrt{k_{r}^{2}+s_{r}^{2} \omega_{s}^{2}} \frac{k_{r M}}{\sqrt{k_{r}^{2}+\left(\omega_{s}-s \omega_{s}\right)^{2}}} \cos \left(s \omega_{s} t-\theta_{k 1}+\theta_{k 2}\right) \\
-\frac{x_{s s}}{D} \frac{e^{-t k_{r}} \omega_{s}}{\sqrt{k_{r}^{2}+s^{2} \omega_{s}^{2}}} \frac{x_{M}}{\sqrt{T_{r}^{2}+\left(\omega_{s}-s \omega_{s}\right)^{2}}} e^{-t k_{s}} \cos \left(\omega_{s} t\right)+ \\
+\frac{x_{s s}}{D} \frac{\sqrt{u_{q r 0}^{\prime}{ }^{2}+u_{q r 0}^{\prime}}}{\sqrt{k_{r}^{2}+s^{2} \omega_{s}^{2}}} \omega_{s} \cos \left(\theta_{r 0}+\theta_{e 0}+\theta_{k 1}\right)+
\end{gathered}
$$

É importante notar que quando os resultados são dados nas coordenadas síncronas, deve ser feita a conversão entre sistemas de coordenadas para obter as correntes do estator e do rotor.

Transformando das coordenadas $d q 0$ síncrona alinhada com a tensão da fase "as" do estator para as coordenadas $a b c$ resulta:

$$
\begin{gathered}
i_{a s}=-\frac{x_{M}}{D} \frac{\sqrt{u_{q r 0}^{\prime}{ }^{2}+u_{q r 0}^{\prime}{ }^{2}}}{\sqrt{k_{r}^{2}+s^{2} \omega_{s}^{2}}} \omega_{s} \operatorname{sen}\left(\omega_{s} t+\theta_{r 0}+\theta_{e 0}+\theta_{k 1}\right)+ \\
+\frac{x_{r r}^{\prime}}{D} e^{-t k_{s}} \operatorname{sen}\left(\theta_{s}\right)+ \\
+\frac{x_{M}}{D} \frac{e^{-t k_{r}} \omega_{s}}{\sqrt{k_{r}^{2}+s^{2} \omega_{s}^{2}}} \frac{k_{r M}}{\sqrt{k_{r}^{2}+\left(\omega_{s}-s \omega_{s}\right)^{2}}} \cos \left(\omega_{r} t+\theta_{s}+\theta_{k 1}\right) \\
i_{a r}^{\prime}=\frac{x_{s s}}{D} \frac{\sqrt{u_{q r 0}^{\prime}{ }^{2}+u_{q r 0}^{\prime}}}{\sqrt{T_{r}^{2}+s^{2} \omega_{s}^{2}}} \omega_{s} \operatorname{sen}\left(\operatorname{si} \omega_{s} t+\theta_{e 0}+\theta_{k 1}\right)+
\end{gathered}
$$




$$
\begin{gathered}
+\frac{x_{M}}{D} e^{-t k_{s}} \operatorname{sen}\left(\omega_{r} t-\theta_{s}+\theta_{r 0}\right)+ \\
-\frac{x_{s s}}{D} \frac{e^{-t k_{r}} \omega_{s}}{\sqrt{k_{r}^{2}+s^{2} \omega_{s}^{2}}} \frac{k_{r M}}{\sqrt{k_{r}^{2}+\left(\omega_{s}-s \omega_{s}\right)^{2}}} \cos \left(\theta_{s}+\theta_{k 1}-\theta_{r 0}\right)
\end{gathered}
$$

Para obter as correntes das fases "bs", "cs", "br" e "cr" deve-se defasar as fases "as" e "ar" de $\pm \frac{2 \pi}{3}$ convenientemente.

As figuras a seguir representam as grandezas nas coordenadas do rotor e nas do estator para melhor compreensão da dependência do angulo inicial em função da referência selecionada.

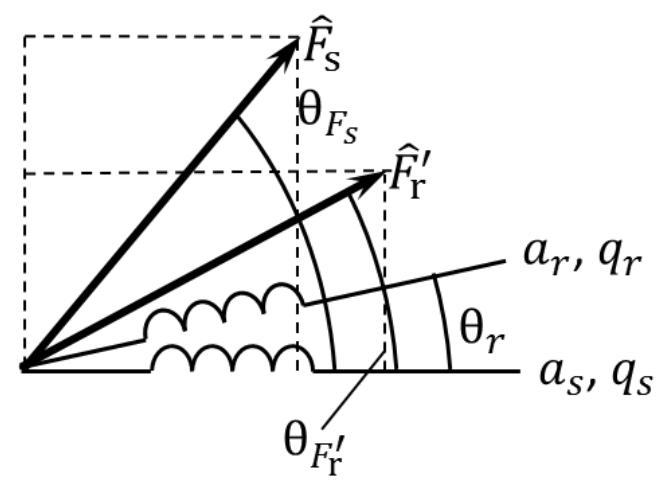

Figura 29 - Grandezas nas coordenadas dq0 do estator

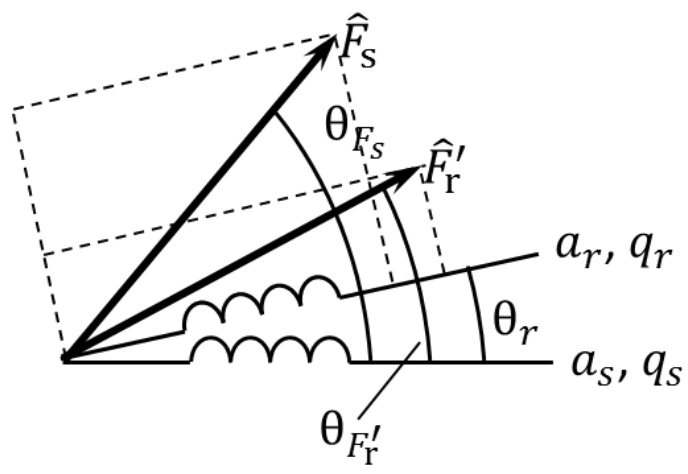

Figura 30 - Grandezas nas coordenadas dq0 do rotor

Além disso, para considerar as constantes de tempo em segundos é necessário dividir pela impedância de base conforme:

$$
\begin{aligned}
& k_{s}=\frac{r_{s} x_{r r}^{\prime} \omega_{b}}{D Z_{b}}=\frac{1}{\tau_{s}} \\
& k_{r}=\frac{r_{r}^{\prime} x_{s s} \omega_{b}}{D Z_{b}}=\frac{1}{\tau_{r}}
\end{aligned}
$$

É apresentado nas equações (148) e (149) o valor máximo possível do curto-circuito em pu para correntes do estator e rotor em função da condição de carga, do escorregamento e do instante do curto. São consideradas aproximações conservativas as equações (148) e (149).

$$
i_{s \max }=\frac{x_{M} \omega_{s}}{D \sqrt{k_{r}^{2}+s^{2} \omega_{s}^{2}}}\left(\sqrt{u_{q r 0}^{\prime}{ }^{2}+u_{q r 0}^{\prime}}+\frac{k_{r M}}{\sqrt{k_{r}^{2}+\left(\omega_{s}-s \omega_{s}\right)^{2}}}\right)+\frac{x_{r r}^{\prime}}{D} \operatorname{sen}\left(\theta_{s}\right)
$$




$$
\begin{gathered}
i_{r \max }^{\prime}=\frac{x_{s s} \omega_{s}}{D \sqrt{k_{r}^{2}+s^{2} \omega_{s}^{2}}}\left(\sqrt{u_{q r 0}^{\prime}{ }^{2}+u_{q r 0}^{\prime}{ }^{2}}-\frac{k_{r M} \cos \left(\theta_{s}+\theta_{T 1}-\theta_{r 0}\right)}{\sqrt{k_{r}^{2}+\left(\omega_{s}-s \omega_{s}\right)^{2}}}\right)+ \\
+\frac{x_{M}}{D} \operatorname{sen}\left(\theta_{s}\right)
\end{gathered}
$$

O valor eficaz em pu para o regime permanente pode ser escrito como

$$
\begin{gathered}
i_{s r p}=-\frac{x_{M}}{D} \frac{\sqrt{u_{q r 0}^{\prime 2}+u_{q r 0}^{\prime}{ }^{2}}}{\sqrt{k_{r}^{2}+s^{2} \omega_{s}^{2}}} \omega_{s} \\
i_{r r p}^{\prime}=\frac{x_{s s}}{D} \frac{\sqrt{u_{q r 0}^{\prime}{ }^{2}+u_{q r 0}^{\prime}}}{\sqrt{k_{r}^{2}+s^{2} \omega_{s}^{2}}} \omega_{s}
\end{gathered}
$$

A expressão do torque eletromagnético por unidade pode ser encontrada substituindo escrevendo a equação (93) por unidades e substituindo em (81):

$$
T_{e}=\frac{x_{M}}{D}\left(\psi_{d r}^{\prime} \psi_{q s}-\psi_{q r}^{\prime} \psi_{d s}\right)
$$

O torque eletromagnético devido ao curto-circuito trifásico brusco resulta então em:

$$
\begin{gathered}
T_{e}=-e^{-t k_{s}} \frac{x_{M}}{D} \frac{\sqrt{u_{q r 0}^{\prime}{ }^{2}+u_{q r 0}^{\prime}}}{\sqrt{k_{r}^{2}+s^{2} \omega_{s}^{2}}} \omega_{s} \operatorname{sen}\left(\omega_{s} t+\theta_{r 0}+\theta_{e 0}+\theta_{k 1}\right) \\
+\frac{x_{M}}{D} \frac{e^{-t\left(k_{r}+k_{s}\right)}}{\sqrt{k_{r}^{2}+s^{2} \omega_{s}^{2}}} \frac{\omega_{s} k_{r M}}{\sqrt{k_{r}^{2}+\left(\omega_{s}-s \omega_{s}\right)^{2}}} \cos \left(\omega_{r} t+\theta_{k 1}-\theta_{k 2}\right)
\end{gathered}
$$

Uma aproximação conservativa para obter-se o torque eletromagnético máximo em função do escorregamento é considerar a soma das parcelas oscilatórias. Portanto:

$$
T_{\text {emax }}=\frac{x_{M}}{D} \frac{\omega_{s}}{\sqrt{k_{r}^{2}+s^{2} \omega_{s}^{2}}} \sqrt{\left(\left(u_{q r 0}^{\prime}{ }^{2}+{u_{q r 0}^{\prime}}^{2}\right)+\left(\frac{k_{r M}}{\sqrt{k_{r}^{2}+(1-s)^{2} \omega_{s}^{2}}}\right)^{2}\right)}
$$




\section{SIMULAÇÕES E DISCUSSÃO}

Simulações para o curto-circuito trifásico foram executadas no software Matlab para comparação com os resultados analíticos. A figura 31 mostra o arranjo utilizado.
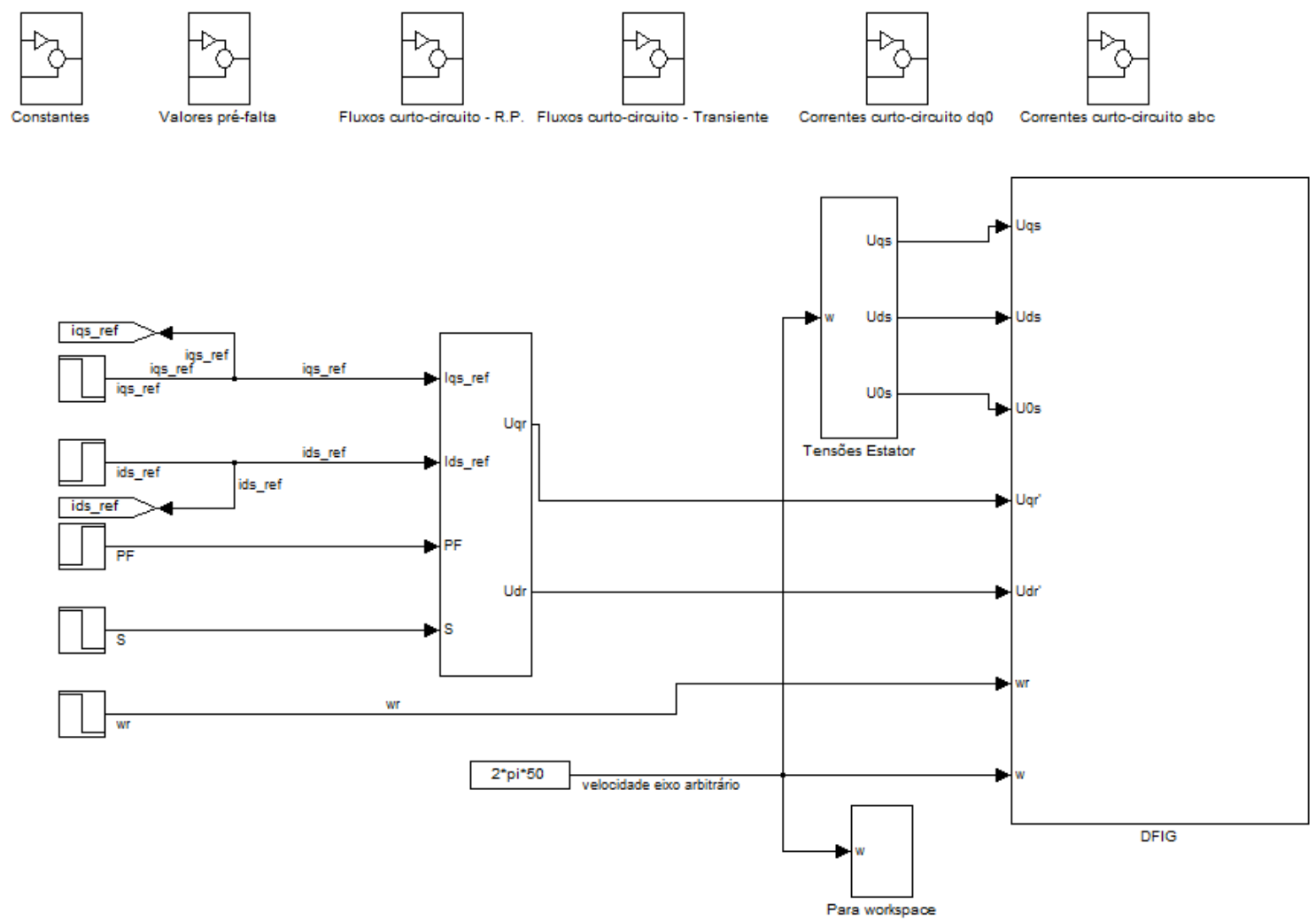

Figura 31 - Diagrama de blocos da simulação em Matlab

Para comparar os resultados da simulação com as equações obtidas, foram inseridos no Simulink um modelo baseado no proposto por Krause (Krause, 2002) e as equações desenvolvidas para a solução analítica.

O bloco "Valores pré-falta" determina os valores necessários para as equações como tensão de excitação e fluxos de regime permanente no instante imediatamente antes do curto-circuito. O bloco "Constantes" calcula os argumentos e valores que dependem do escorregamento além dos decaimentos exponenciais. 
Os demais blocos computam efetivamente as equações analíticas obtidas. A figura 32 mostra um exemplo para o fluxo do estator no eixo $q$ de como as equações foram inseridas no Simulink.

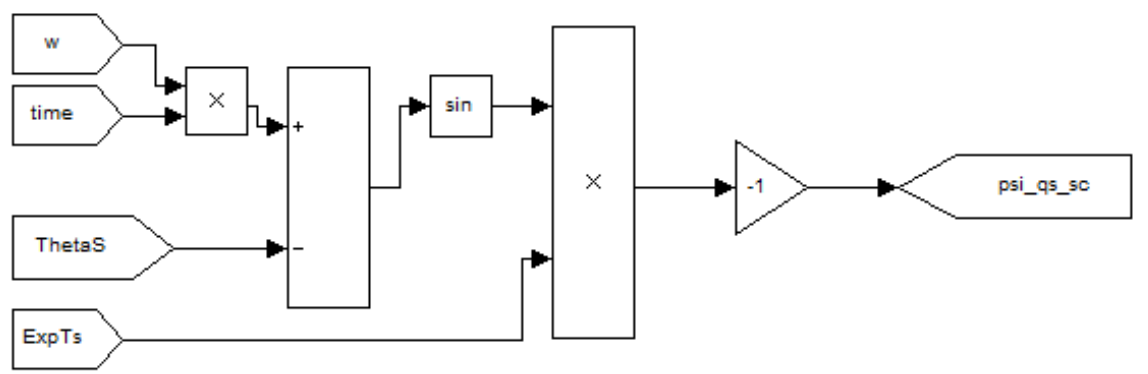

Figura 32 - Diagrama de blocos da equação que rege o fluxo do estator do eixo q

As figuras 33 e 34, 35 e 36 mostram a comparação entre os fluxos do estator e rotor para simulados e calculados para escorregamento $-0,05$, potência e fator de potência nominais e ângulo da tensão do estator no instante do curto-circuito igual a $90^{\circ}$ elétricos.

As coordenadas para os fluxos do rotor estão com o referencial fixado na fase "ar".

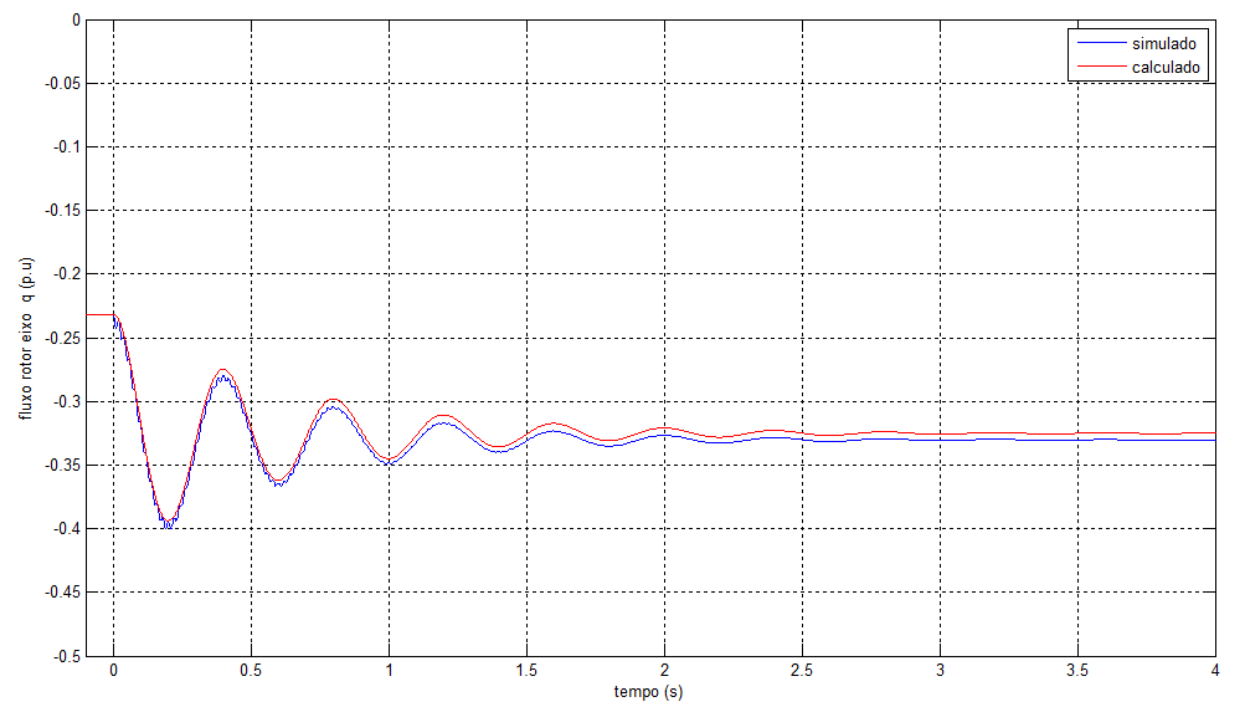

Figura 33 - Fluxo do rotor eixo q devido ao curto-circuito trifásico brusco. 


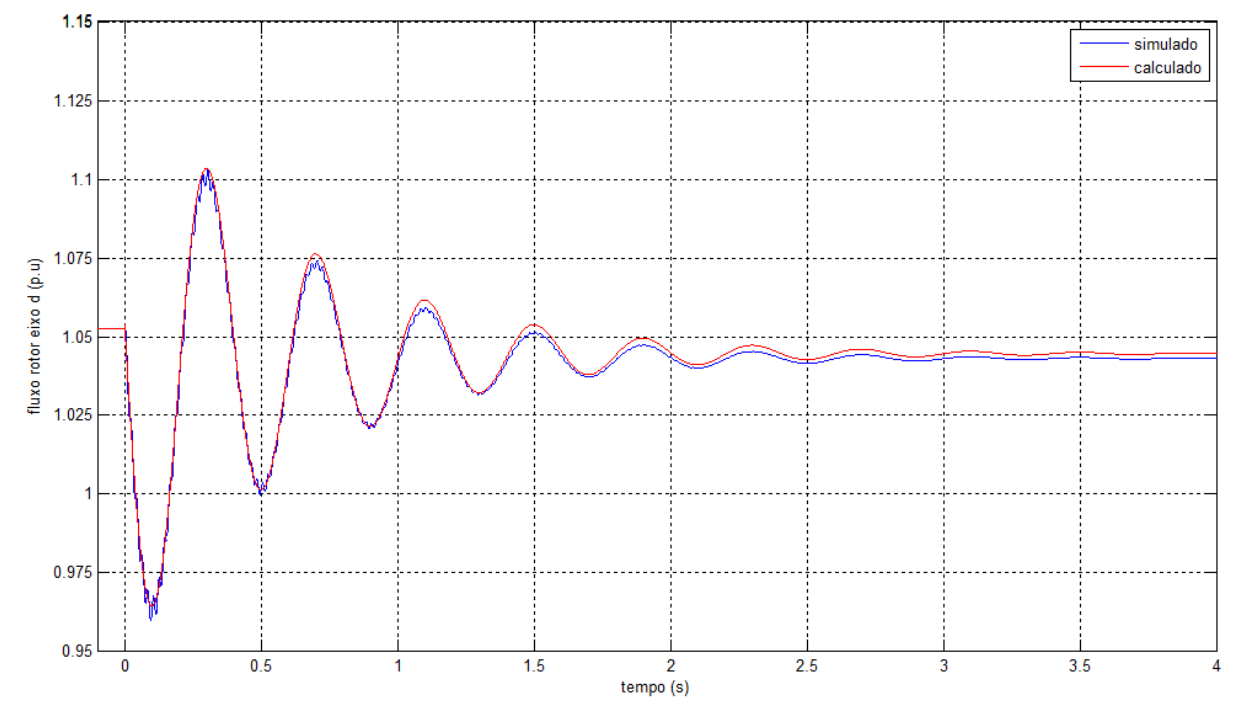

Figura 34 - Fluxo do rotor eixo d devido ao curto-circuito trifásico brusco.

Observa-se no fluxo do rotor simulado uma pequena componente adicional com frequência $\omega_{s}$ que não aparece no valor calculado devido à aproximação realizada durante a resolução da resposta do fluxo ao degrau na tensão do estator. Além disso, há um pequeno erro em regime permanente que se mostra desprezível, conforme os resultados para as correntes a seguir.

A componente oscilatória amortecida predominante no fluxo do rotor é devido ao fluxo congelado no espaço do estator. O fluxo congelado é visto com frequência $\omega_{r}$ pelos circuitos do rotor nas coordenadas $a b c$. Quando convertido para o sistema de coordenadas $d q 0$, a frequência da oscilação é a diferença entre a frequência síncrona e do rotor. A componente em regime permanente se deve à tensão excitação mantida inalterada para estas simulações.

O fluxo congelado do estator é visto no sistema de coordenadas $d q 0$ síncrono, como uma componente oscilatória cuja frequência $\omega_{s}$. 

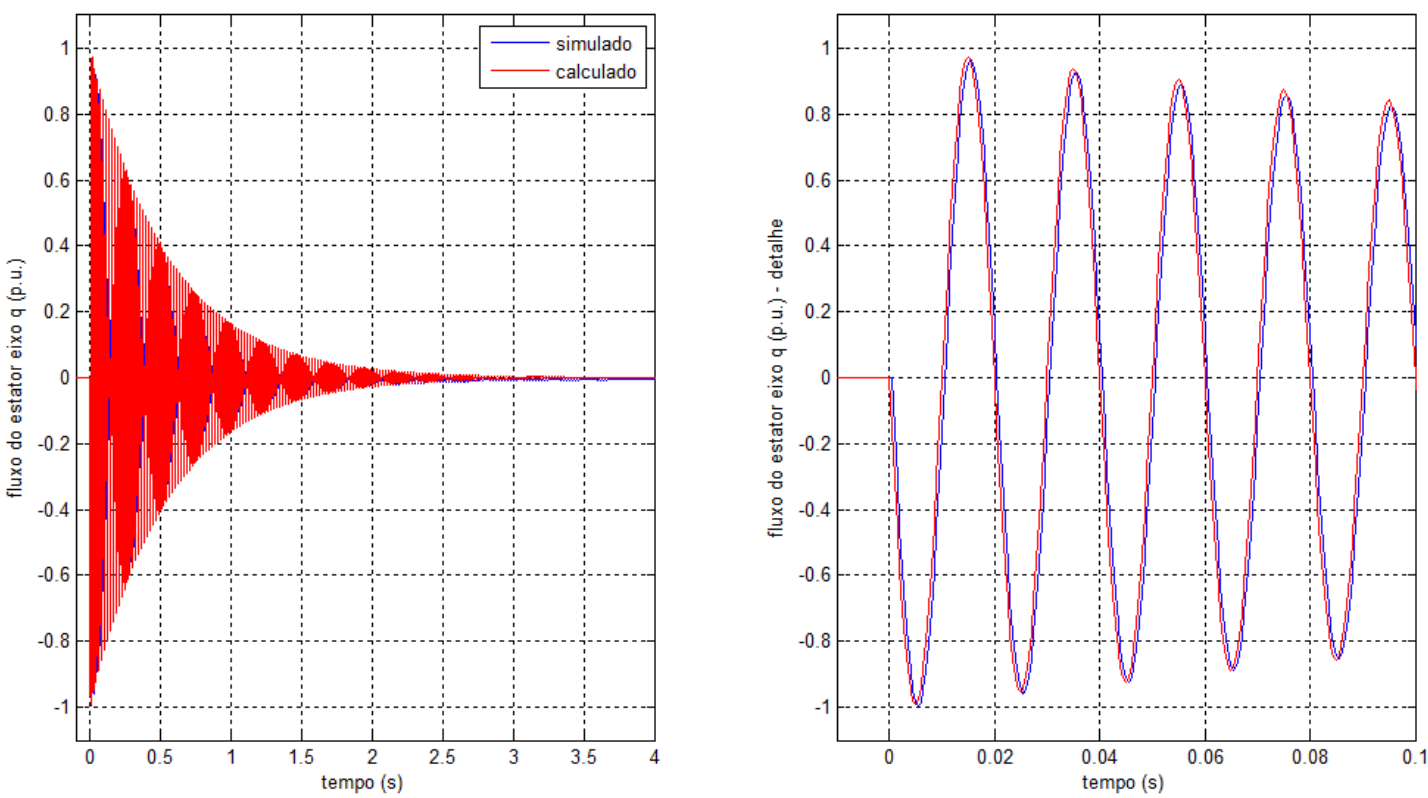

Figura 35 - Fluxo do estator eixo q devido ao curto-circuito trifásico brusco.
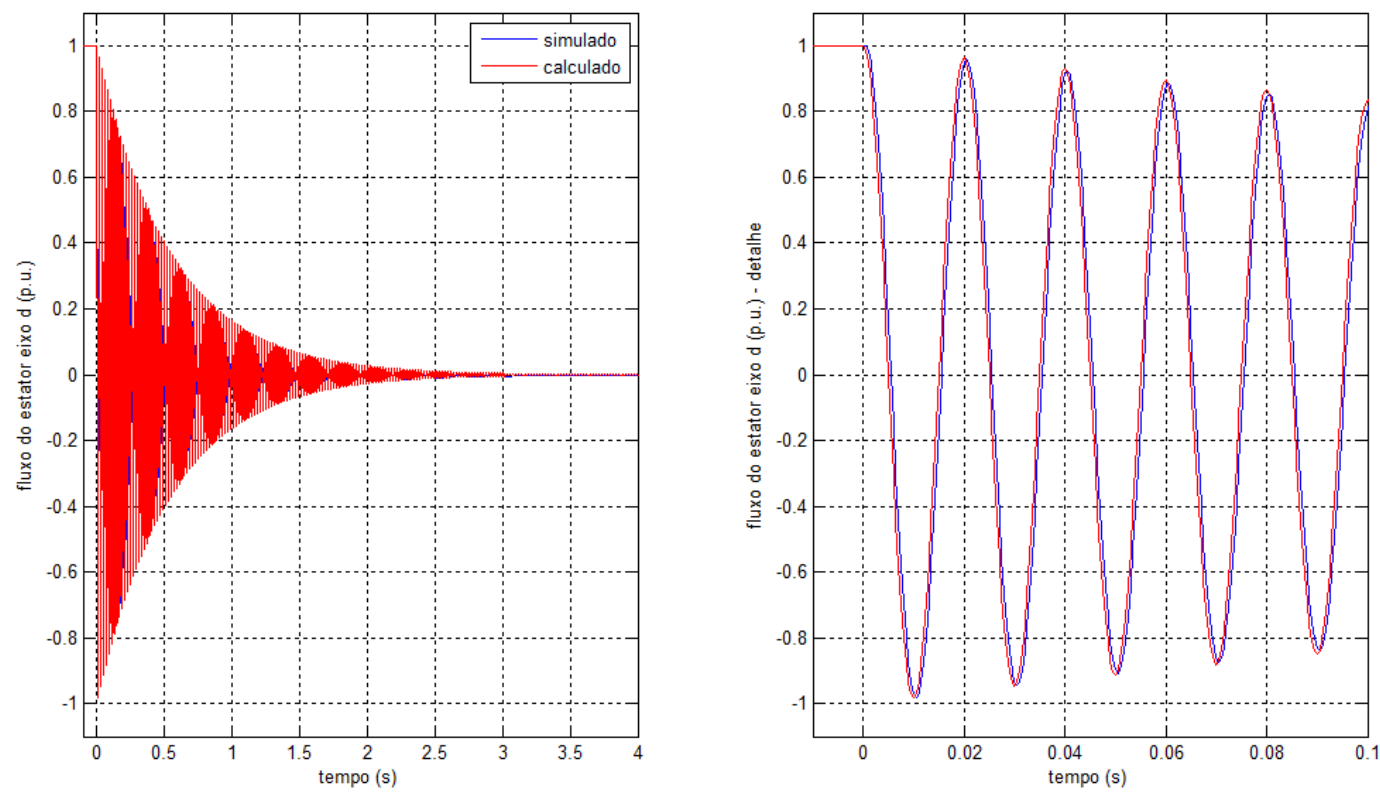

Figura 36 - Fluxo do estator eixo d devido ao curto-circuito trifásico brusco.

As figuras 37 e 38 apresentam as correntes devido ao curto-circuito trifásico brusco nas coordenadas $a b c$ para escorregamento $-0,05$, potência e fator de potência nominais e ângulo da tensão $\theta_{s}$ do estator no instante do curto igual a $90^{\circ}$ elétricos. 
Como as correntes estator são compostas por ambos os fluxos do estator e rotor assim como as correntes do rotor, ambas as componentes oscilatórias de ambos os fluxos são observadas nas correntes.
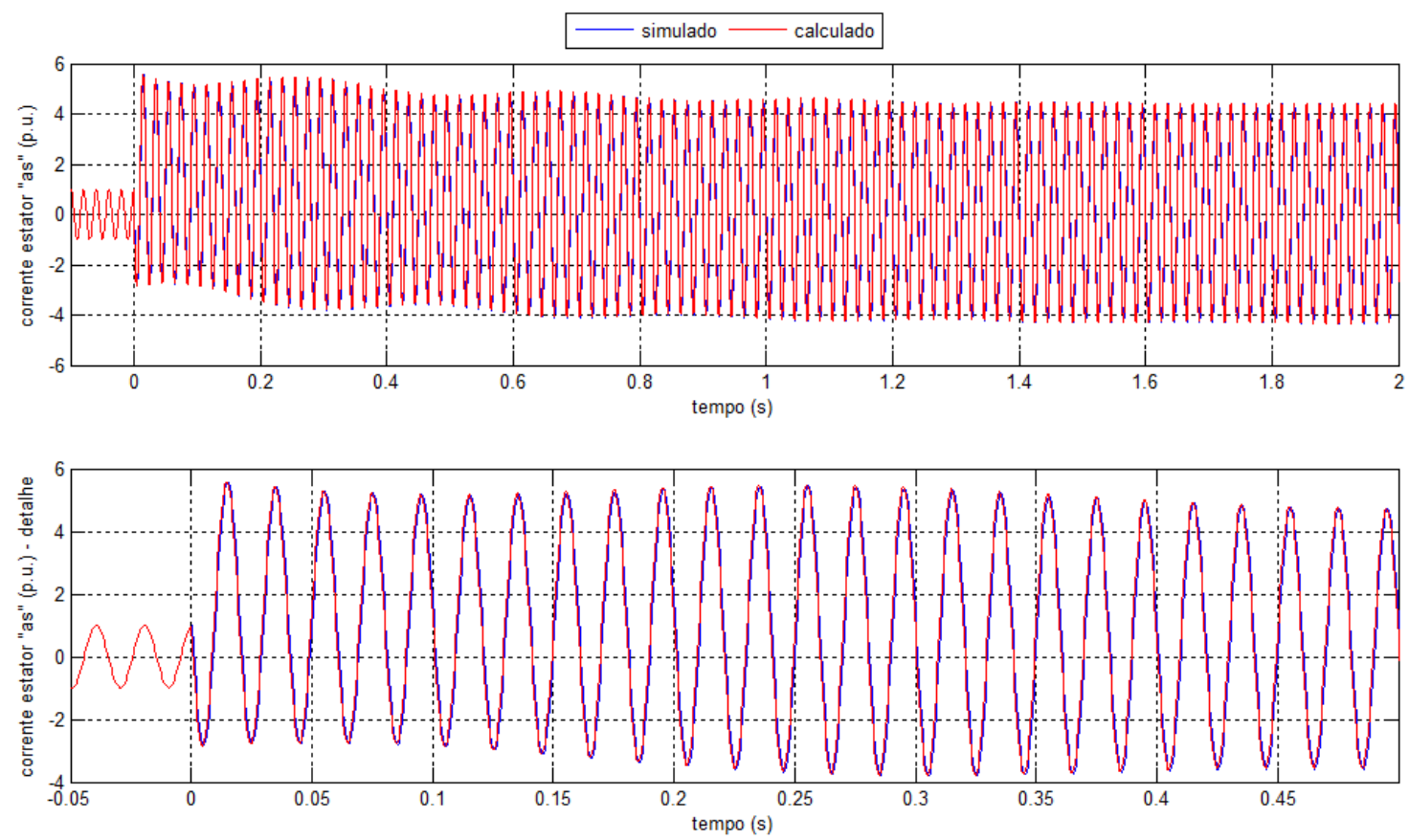

Figura 37 - Corrente do estator fase "as" devido ao curto-circuito trifásico brusco. Potência e Fator de potência nominais, escorregamento $-0,05 . \theta_{s}=90^{\circ}$
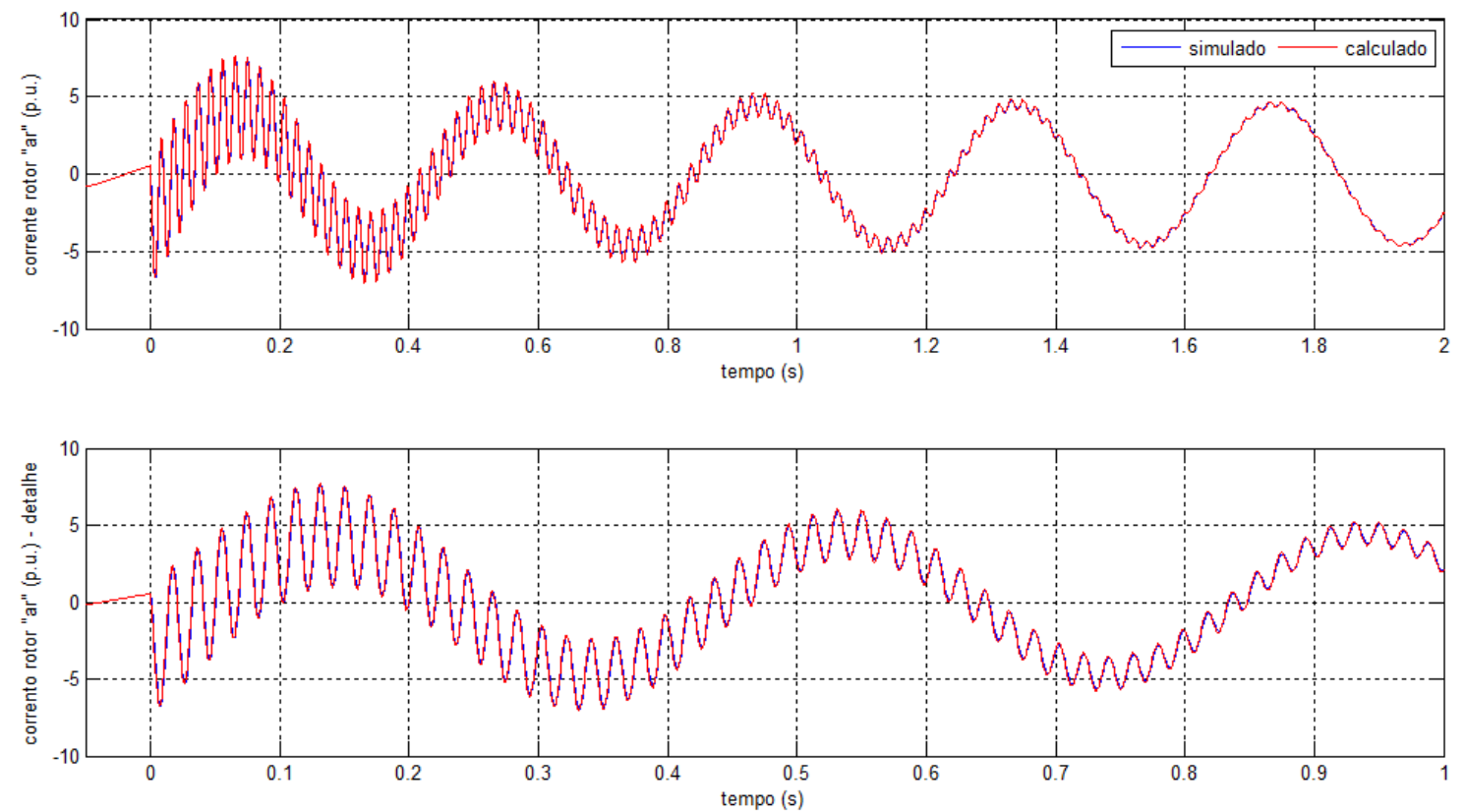

Figura 38 - Corrente do rotor fase "ar" devido ao curto-circuito trifásico brusco. Potência e Fator de potência nominais, escorregamento $-0,05 . \theta_{s}=90^{\circ}$ 
As correntes do rotor estão referenciadas ao circuito do rotor, girando com frequência $\omega_{r}$.

A corrente da fase "as" do estator apresenta uma componente constante com decaimento exponencial devido ao fluxo do estator; uma componente oscilatória com decaimento exponencial devido ao fluxo do rotor e com frequência angular igual à diferença entre a velocidade síncrona e a do eixo do rotor e a componente de regime permanente.

A corrente da fase "ar" do rotor também apresenta componente constante com decaimento exponencial; componente oscilatória com decaimento exponencial e componente de regime permanente. Entretanto, a componente oscilatória com decaimento exponencial possui frequência angular igual à velocidade do rotor.

As constantes de tempo do decaimento exponencial das componentes oscilatória e constante presentes nas correntes do estator são $\frac{1}{k_{r}} \mathrm{e} \frac{1}{k_{s}}$. As componentes oscilatória e contínua do rotor apresentam $\frac{1}{k_{s}}$ e $\frac{1}{k_{r}}$, respectivamente.

Nas figuras 39 e 40 são apresentados os resultados calculado e simulado para as correntes das fases "as" e "ar", considerando escorregamento nulo, potência e fator de potência nominais e ângulo da tensão do estator no instante do curto igual a $90^{\circ}$ elétricos. Percebe-se que as correntes resultantes neste caso alcançam os maiores valores.
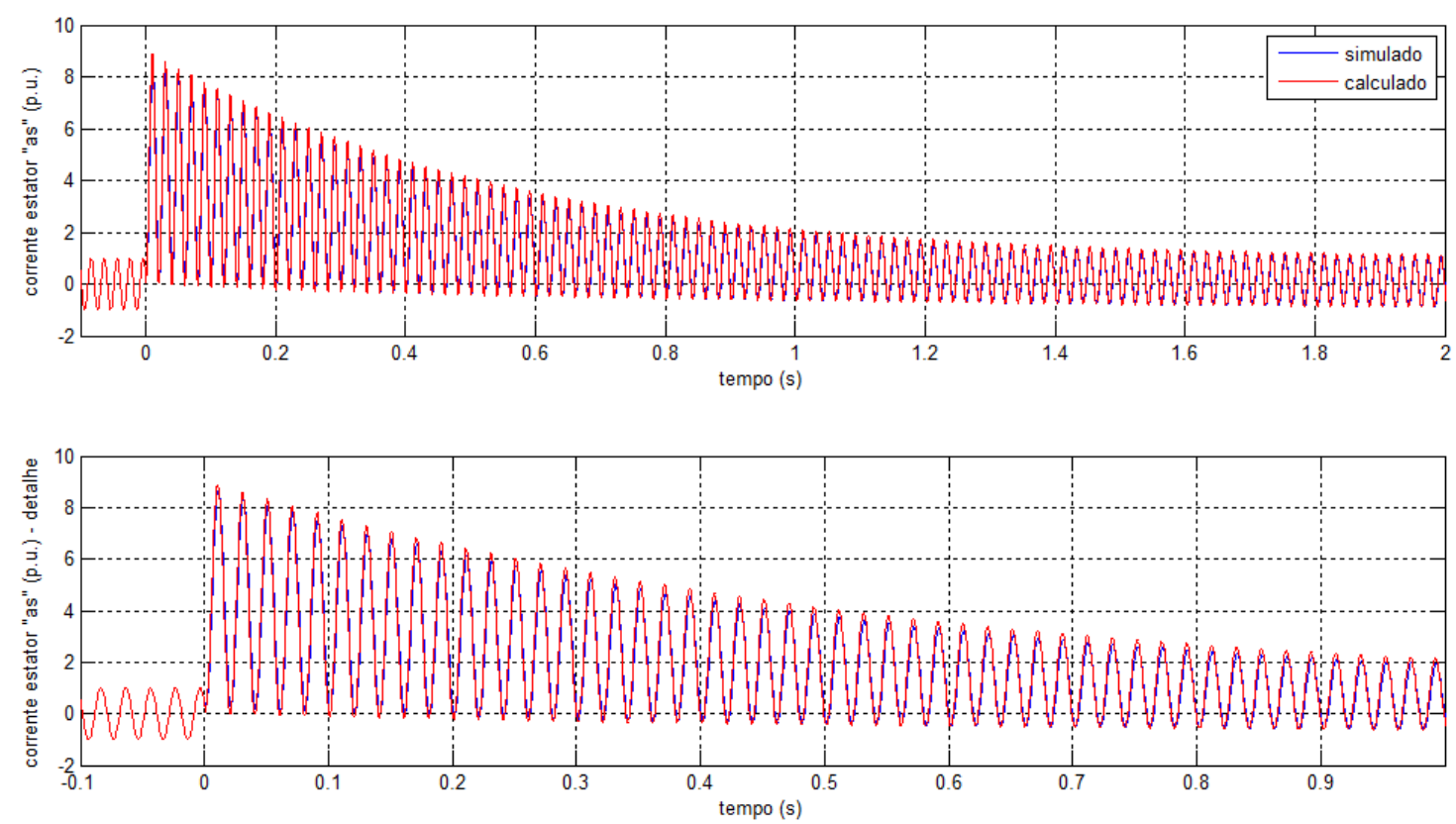
Figura 39 - Corrente do estator fase "as" devido ao curto-circuito trifásico brusco. Potência e Fator de potência nominais, escorregamento nulo. $\theta_{s}=90^{\circ}$
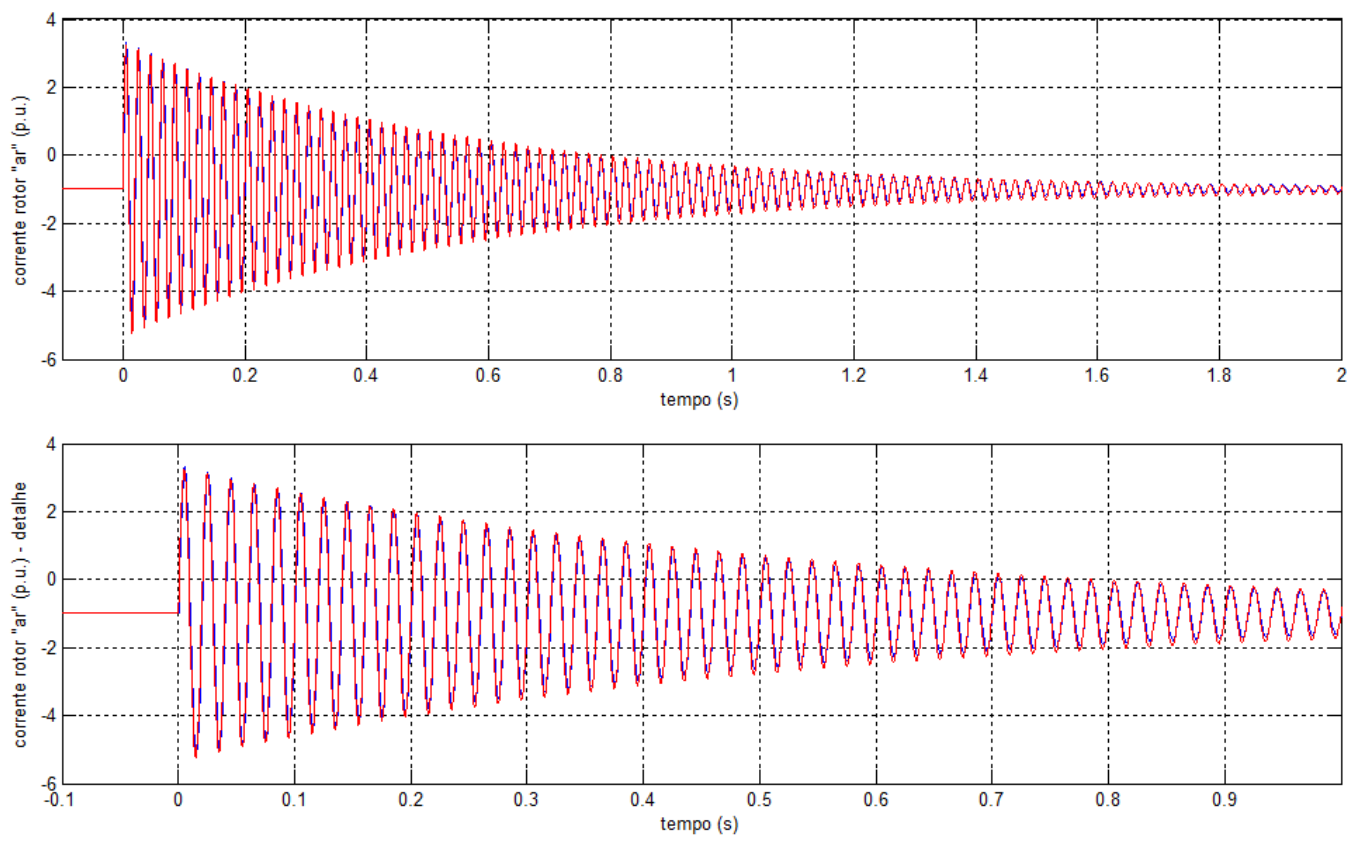

Figura 40 - Corrente do rotor fase "ar" devido ao curto-circuito trifásico brusco. Potência e Fator de potência nominais, escorregamento nulo. $\theta_{s}=90^{\circ}$

As figuras 41 e 42 mostram os resultados para as correntes nas coordenadas abc para escorregamento -0.5 , considerado elevado para a aplicação em questão. A solução analítica ainda mantém uma boa aproximação. 

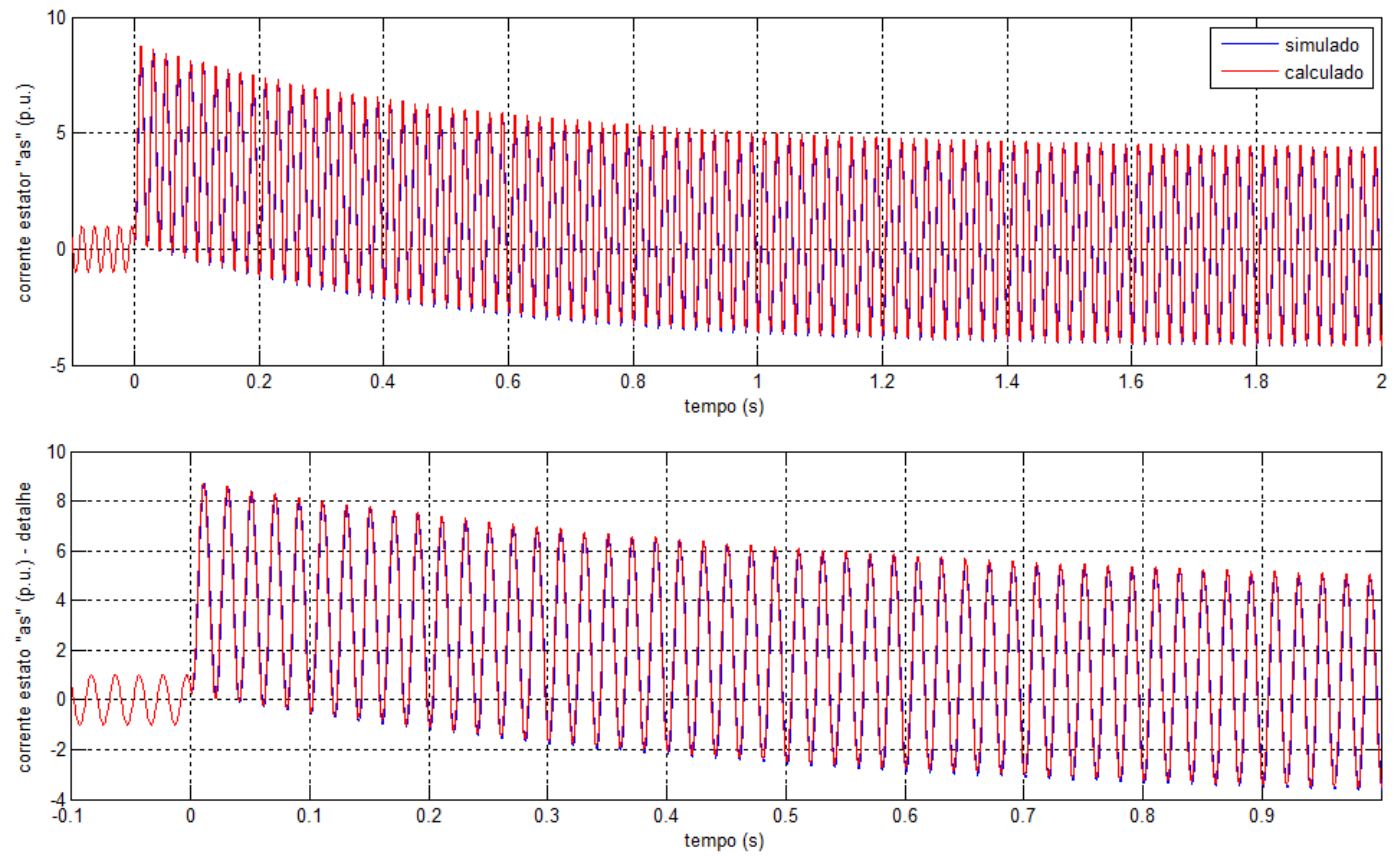

Figura 41 - Corrente do estator fase "as" devido ao curto-circuito trifásico brusco. Potência e Fator de potência nominais, escorregamento $-0.5 . \theta_{s}=90^{\circ}$
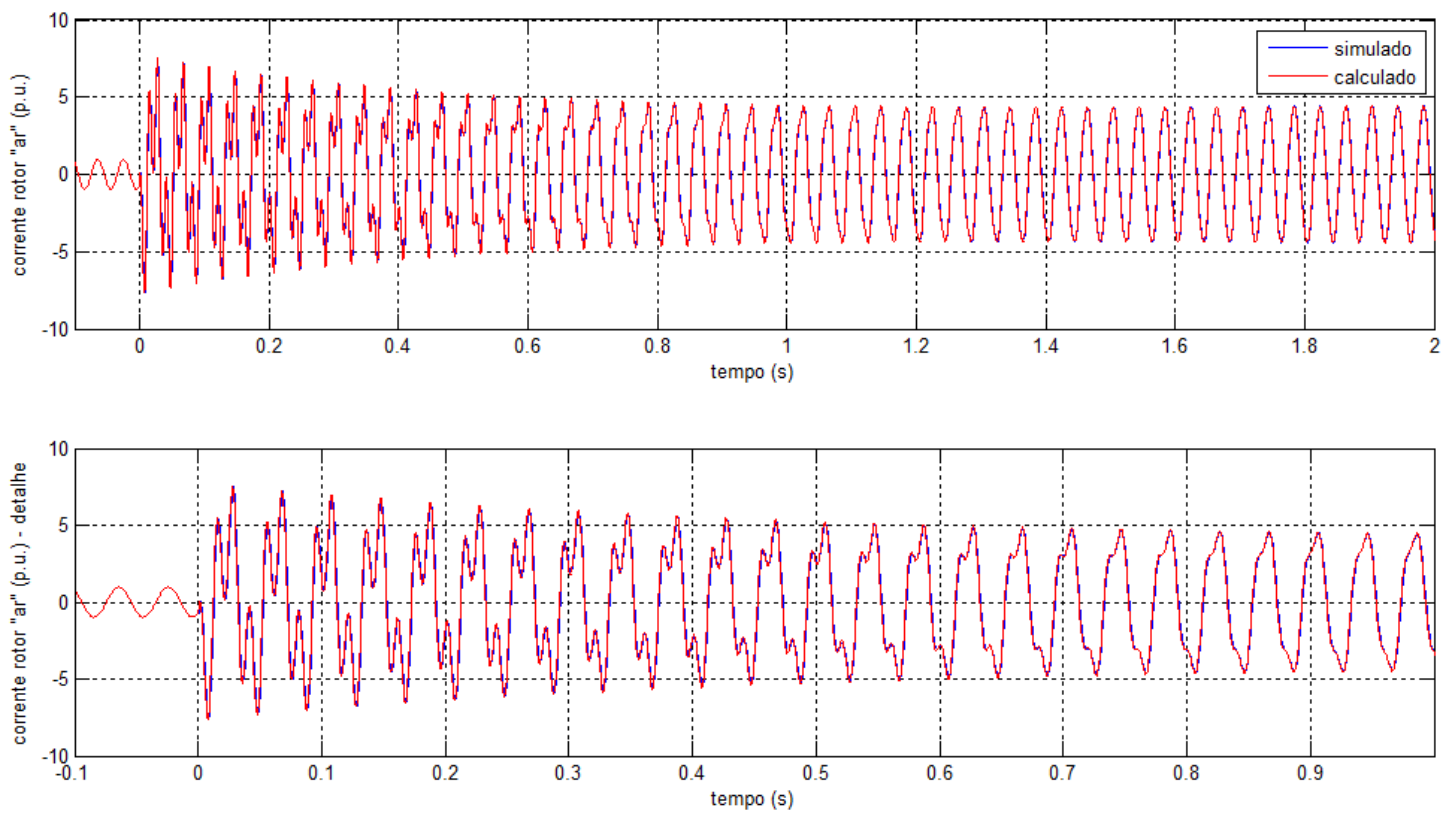

Figura 42 - Corrente do rotor fase "ar" devido ao curto-circuito trifásico brusco. Potência e Fator de potência nominais, escorregamento $-0.5 . \theta_{s}=90^{\circ}$

Devido ao valor de escorregamento elevado, a componente oscilatória com decaimento exponencial na corrente do estator praticamente inexiste e a do rotor cria $o$ efeito visualizado com duas frequências sobrepostas. 
O torque eletromagnético é apresentado na figura 43. Quando o fluxo do estator congela, o fluxo do rotor continua com velocidade angular síncrona. Conforme o ângulo entre os fluxos varia, o torque varia entre máximo e mínimo até que o fluxo do estator tenha se descarregado.
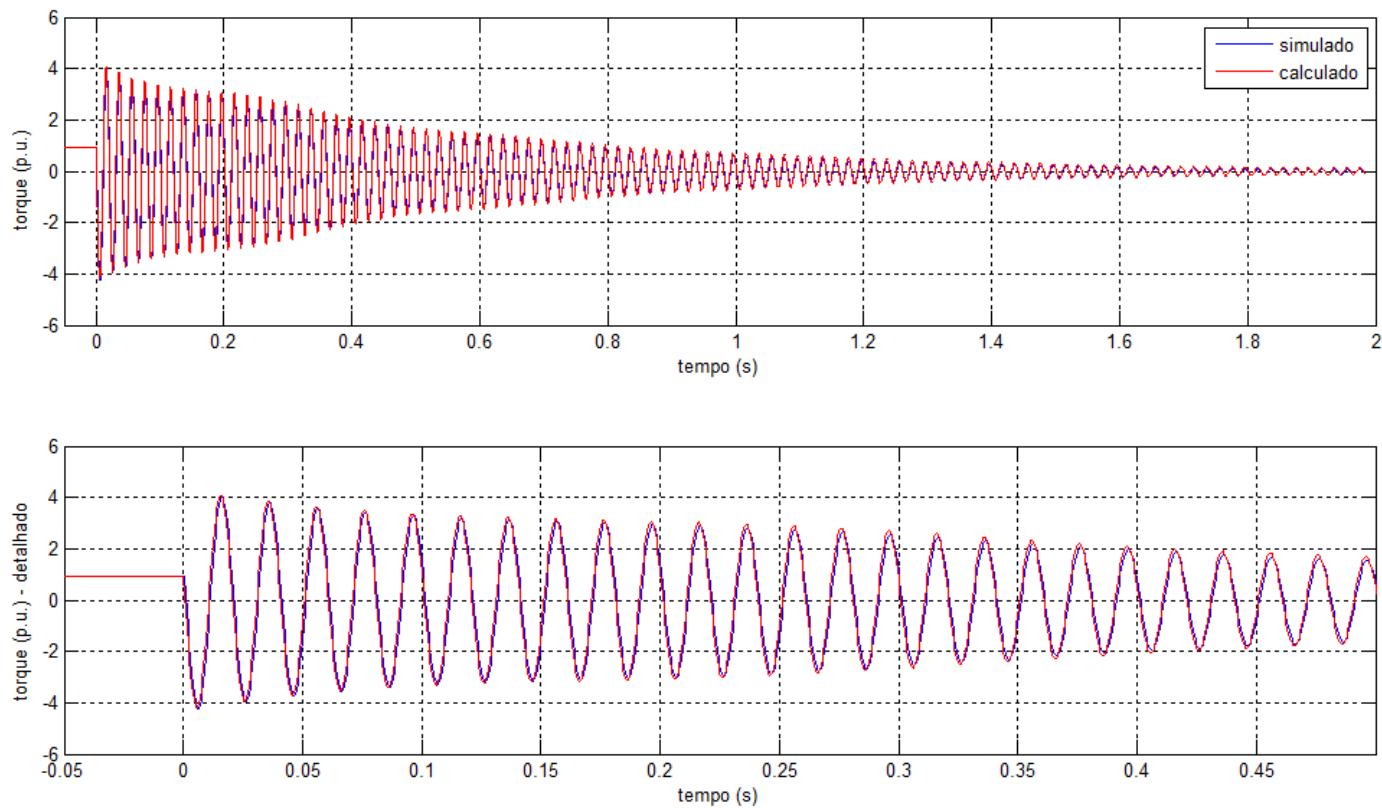

Figura 43 - Torque eletromagnético devido ao curto-circuito trifásico brusco para escorregamento -0.05 . Valores simulados. Potência e Fator de potência nominais $\theta_{s}=90^{\circ}$
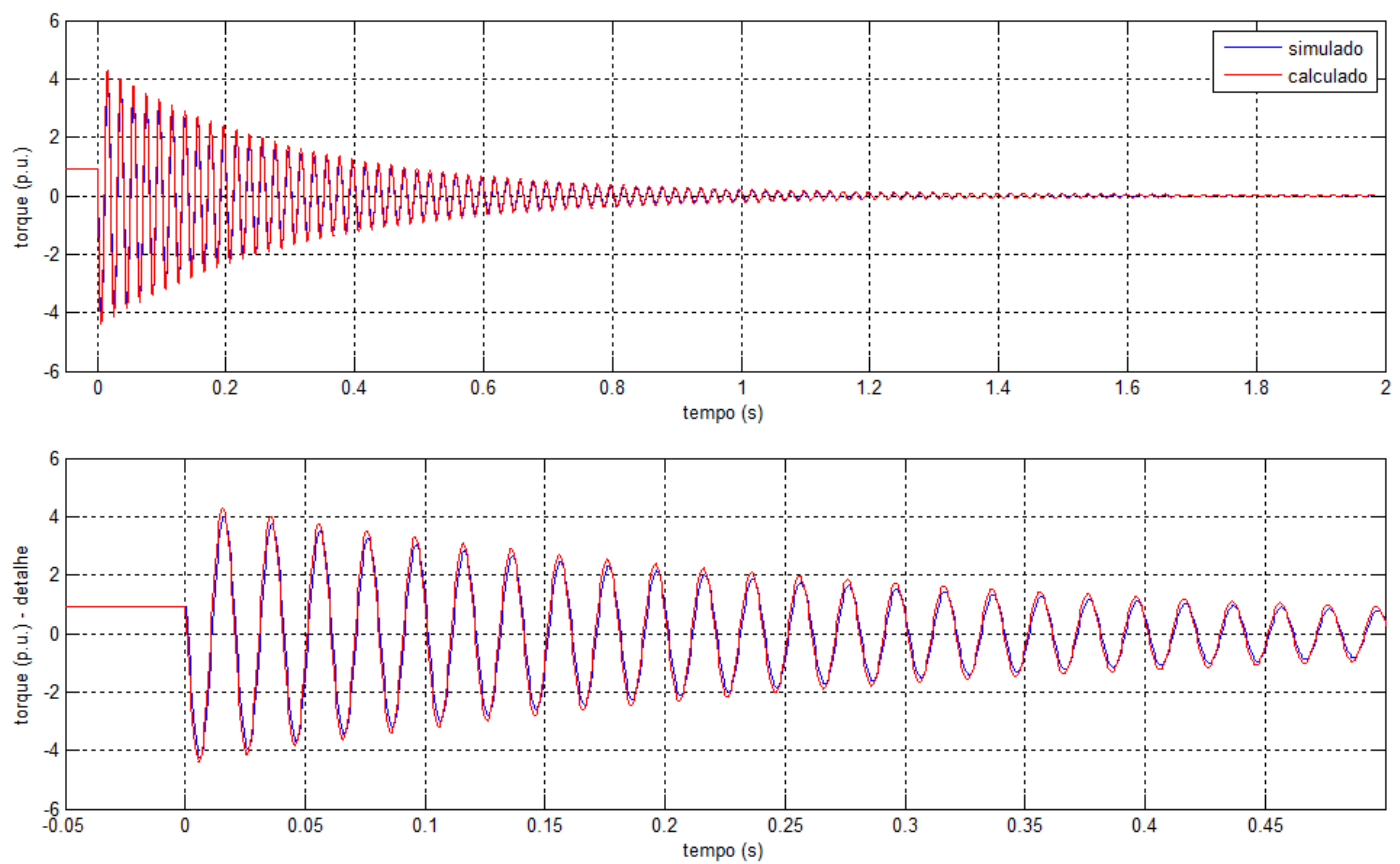

Figura 44 - Torque eletromagnético devido ao curto-circuito trifásico brusco para escorregamento nulo. Potência e Fator de potência nominais $\theta_{\mathrm{s}}=90^{\circ}$ 


\section{CONCLUSÃo}

Os geradores de indução duplamente alimentados - DFIGs - são utilizados em usinas hidrelétricas reversíveis modernas para geração com velocidade variável, aumentando a eficiência do conjunto turbina gerador, aumentando a faixa operativa e melhorando a estabilidade transitória do sistema de potência com grande representação de fontes de energia variáveis.

Neste trabalho foi apresentada a solução analítica do curto-circuito trifásico no DFIG. O curto trifásico é o mais incomum nos sistemas de potência, mas tem a função fundamental de permitir a melhor compreensão do que ocorre no gerador durante curtos-circuitos.

Mesmo com programas computacionais modernos, a solução analítica de curtocircuito traz noções físicas para o entendimento do problema que não podem ser observadas nas simulações, então a importância deste tópico.

As expressões analíticas desenvolvidas permitiram estudar o curto-circuito trifásico brusco sem ação de controle e também podem ser utilizadas para estudar afundamentos trifásicos de tensão na rede e a sincronização da unidade.

Simulações com o modelo de gerador com tensão de excitação e velocidade fixas foram apresentadas e comparadas com a solução analítica encontrada. Os resultados das soluções analíticas fornecem um resultado bastante próximo e podem ser utilizadas para calcular valores pertinentes conservativos.

Os resultados analíticos mostram duas componentes transitórias majoritárias que surgem nas correntes do estator e rotor devido ao curto-circuito. Além da componente de corrente contínua, uma componente oscilatória ao escorregamento surge devido ao acoplamento magnético entre estator e rotor. A interação entre as componentes alternadas transitória e permanente das correntes produz o efeito de batimento que dependerá do instante do curto e do escorregamento antes do curto-circuito. 


\section{TRABALHOS FUTUROS}

Como sugestão para próximos trabalhos, os seguintes temas podem ser estudados:

- Análise de estratégias de controle para redução da corrente de curtocircuito no circuito rotórico dos DFIGs: Desenvolvimento e teste de limitadores no sistema de excitação para melhorar a capacidade de operação desses geradores frente a curtos-circuitos

- Estudo dos aspectos construtivos do gerador de indução duplamente alimentado de grandes potências: Estudos de diferentes materiais e técnicas de fabricação para produção desses geradores.

- Estudo da estabilidade do sistema interligado brasileiro devido ao aumento de aerogeradores conectados: Estudar a influencia na estabilidade do sistema elétrico brasileiro com o aumento da quantidade desses geradores conectados ao sistema.

- Utilização de DFIGs para armazenamento de energia em volantes de inércia: Estudar armazenamento de energia sob o aspecto de volantes de inércia de grande porte espalhados pelo sistema interligado bem como pequenos conectados ao sistema de distribuição.

- Estudo e análise dos ajustes das funções de proteção paro DFIGs: Discutir a respeito das funções de proteção necessárias para esses geradores e determinar os seus ajustes. 


\section{REFERÊNCIAS}

[1] KRAUSE, P. C. Analysis of electric machinery and drive systems, $2^{\text {nd }}$ ed. New York: IEEE Press, 2002. $613 p$

[2] CONCORDIA, C. Synchronous Machines Theory and Performance, $2^{\text {nd }}$ ed. New York. John Wiley \& Sons Inc., 1951. $224 p$

[3] PARK, R.H. Two-reaction theory of synchronous machines generalized method of analysis-part I. Transactions of the American Institute of Electrical Engineers, v. 48 p 716-727, 1929.

[4] HODDER, A. Double-Fed Asynchronous Motor-Generator Equipped with a 3Level VSI Cascade. 2004. 126 p. Tese (Doutorado) - Ècole Polytechnique Fédérale de Lausane. Lausane, 2004

[5] SALLES. M. B. Modelagem e análises de geradores eólicos de velocidade variável conectados em sistemas de energia elétrica. 2009. 124 p. Tese (Doutorado) - Escola Politécnica da Universidade de São Paulo. São Paulo, 2009.

[6] ÇENGEL, Y. A., CIMBALA, J. M. Fluid Mechanics: Fundamentals and Applications, $1^{\text {st }}$ ed. New York. McGraw-Hill, 2006. 955p

[7] SALLES, M. B. Análise do desempenho dinâmico de geradores eólicos conectados em redes de distribuição de energia elétrica. 2004. 109 p. Dissertação (Mestrado) - Faculdade de Engenharia elétrica e de Computação da Universidade Estadual de Campinas. Campinas, 2004. 
[8] SAIDEL, M. A. Rotação ajustável em usinas hidrelétricas: novas premissas para o planejamento energético. 1995. 160p. Tese (Doutorado) - Escola Politécnica da Universidade de São Paulo. São Paulo, 1995.

[9] RION, J. T.; YASUYUKI, A. K. T. Model derivation of an adjustable speed generator and its excitation system. In 14th Power System Computation Conference. Sevilla, 2002.

[10] PANNATIER, Y. et al. Investigation of control strategies for variable-speed pump-turbine units by using a simplified model of the converters. IEEE Transactions on Industrial Electronics, v. 57, num.9, p.3039-3049, 2010.

[11] FOSTER, S.; LIE, X.; FOX, B. Behaviour and protection of doubly-fed induction generators during network faults. In Power \& Energy Society General Meeting, 2009. PES '09. IEEE

[12] BOCQUEL, A.; JANNING, J. Analysis of a $\mathbf{3 0 0} \mathbf{~ M W}$ variable speed drive for pump-storage plant applications. In European Conference on Power Electronics and Applications, 2005.

[13] GJENGEDAL, T. Application of adjustable speed hydro (ASH) machines in the Norwegian power system. In IEEE Porto Power Tech Conference 2001. Porto, 2001

[14] WESSELS, C; FUCHS, W. Fault ride-through of o DFIG wind turbine using a dynamic voltage restorer during symmetrical and asymmetrical grid faults. IEEE Transactions on Power Electronics, v. 26, n 3, p. 807, 2011 
[15] GONG, B.; Xu, D.; Wu, B. Cost effective method for DFIG fault ride-through during symmetrical voltage dip. In IECON 2010 - 36th Annual Conference on IEEE Industrial Electronics Society. 2010

[16] HEISING, C. et al. Doubly-fed induction generator model for analysis of fault-ride through and asymmetrical generator-side faults. In 7th Mediterranean Conference and Exhibition on Power Generation, Transmission, Distribution and Energy Conversion. 2010

[17] ARDANUY, J. et al. Variable-speed hydro generation: Operational aspects and control. IEEE Transactions on Energy Conversion, VOL. 21, NO. 2, 2006

[18] VICATOS, M. S.; TEGOPOULOS, A. Transient State Analysis of a DoublyFed Induction Generator under Three Phase Short Circuit. IEEE Transactions on Energy Conversion, v. 6, n. 1, p. 62-68, 1991.

[19] Plano Nacional de Energia 2030. Ministério de Minas e Energia; colaboração Empresa de Pesquisa Energética. Brasília : MME : EPE, 2007.

[20] SPORILD, R.; Enhanced Power System Operation by Application ofAdjustable Speed Hydro Machines. In International Conference on Electric Utility Deregulation and Restructuring and Power Technologies 2000. 2000.

[21] U.S. Energy Information Administration, International Energy Statistics, http://www.eia.gov/countries/data.cfm

[22] Califórnia ISO - Operador da rede elétrica. "Renewable Watch - Today's outlook" sitio: http://www.caiso.com/Pages/TodaysOutlook.aspx. Acessado em 201303-19 
[23] Britannica Online Encyclopedia - http://www.britannica.com, acessado em 2011-06-14

(http://www.britannica.com/EBchecked/topic/609552/turbine/45673/Pumpedstorage)

[24] ENCINA, A. S. A. Despacho Ótimo De Unidades Geradoras Em Sistemas Hidrelétricos Via Heurística Baseada Em Relaxação Lagrangeana E Programação Dinâmica. 2006. 191p. Tese (Doutorado) - Universidade Estadual de Campinas, Janeiro 2006

[25] FISHER, R. K. et al. A Comparison of Advanced Pumped Storage Equipment Drivers in the US and Europe. HydroVision 2012, July 18, 2012, Louisville, KY

[26] The Telegraph. Germany's wind power chaos should be a warning to the UK. Sitio: http://www.telegraph.co.uk/comment/9559656/Germanys-wind-powerchaos-should-be-a-warning-to-the-UK.html acessado em 2013-03-19.

[27] Institute for Energy Research. Germany's Green Energy Destabilizing Electric Grids. Sítio: http://www.instituteforenergyresearch.org/2013/01/23/germanysgreen-energy-destabilizing-electric-grids/ acessado em 2013-03-19

[28] Spiegel Online International. Energy Revolution Hiccups: Grid Instability Has Industry Scrambling for Solutions. Sitio: http://www.spiegel.de/international/germany/instability-in-power-grid-comes-athigh-cost-for-german-industry-a-850419.html acessado em 2103-03-19 


\section{ANEXO A RESOLUÇÃO DO CURTO-CIRCUITO TRIFÁSICO}

Analisando o problema fisicamente, o fluxo do estator descarrega-se quase que pela totalidade pela resistência do estator (CONCORDIA,1951). Assim, considerar a resistência do circuito do rotor nula para encontrar a resposta simplificada do fluxo do estator é uma aproximação razoável. Com essas aproximações, a equação (128) reduz-se a:

$$
\left[\begin{array}{c}
\frac{u_{q s}}{p} \\
\frac{u_{d s}}{p} \\
0 \\
0
\end{array}\right]=\left[\begin{array}{cccc}
\frac{x_{s}(p)}{\omega_{s}} & 1 & -\frac{k_{s M}}{\omega_{s}} & 0 \\
-1 & \frac{x_{s}(p)}{\omega_{s}} & 0 & -\frac{k_{s M}}{\omega_{s}} \\
0 & 0 & \frac{p}{\omega_{s}} & s \\
0 & 0 & -s & \frac{p}{\omega_{s}}
\end{array}\right]\left[\begin{array}{l}
\psi_{q s} \\
\psi_{d s} \\
\psi_{q r}^{\prime} \\
\psi_{d r}^{\prime}
\end{array}\right]
$$

A solução desse sistema é apresentada nas equações

$$
\begin{gathered}
\psi_{q s}(p)=\omega_{s} \frac{u_{q s} x_{s}(p)-u_{d s} \omega_{s}}{p\left(x_{s}(p)^{2}+\omega_{s}^{2}\right)} \\
\psi_{d s}(p)=\omega_{s} \frac{u_{d s} x_{s}(p)+u_{q s} \omega_{s}}{p\left(x_{s}(p)^{2}+\omega_{s}^{2}\right)} \\
\psi_{q r}^{\prime}(p)=0 \\
\psi_{d r}^{\prime}(p)=0
\end{gathered}
$$

Expandido as expressões (156) e (157) em frações parciais

$$
\begin{gathered}
\psi_{q s}(p)=\omega_{s} \frac{u_{q s} k_{s}-u_{d s} \omega_{s}}{p\left(k_{s}^{2}+\omega_{s}^{2}\right)}-\omega_{s} \frac{u_{q s}\left(k_{s} x_{s}(p)-\omega_{s}^{2}\right)-u_{d s}\left(x_{s}(p)+k_{s}\right) \omega_{s}}{\left(k_{s}^{2}+\omega_{s}^{2}\right)\left(x_{s}(p)^{2}+\omega_{s}^{2}\right)} \\
\psi_{d s}(p)=\omega_{s} \frac{u_{q s} k_{s}+u_{d s} \omega_{s}}{p\left(k_{s}^{2}+\omega_{s}^{2}\right)}-\omega_{s} \frac{u_{q s}\left(k_{s} x_{s}(p)-\omega_{s}^{2}\right)+u_{d s}\left(x_{s}(p)+k_{s}\right) \omega_{s}}{\left(k_{s}^{2}+\omega_{s}^{2}\right)\left(x_{s}(p)^{2}+\omega_{s}^{2}\right)} \\
\mathcal{L}^{-1}\left[\frac{(p+k) \cos \theta-\omega \operatorname{sen} \theta}{(p+k)^{2}+\omega^{2}}\right]=e^{-k t} \cos (\omega t+\theta)
\end{gathered}
$$




$$
\mathcal{L}^{-1}\left[\frac{(p+k) \operatorname{sen} \theta+\omega \cos \theta}{(p+k)^{2}+\omega^{2}}\right]=e^{-k t} \operatorname{sen}(\omega t+\theta)
$$

Considerando as anti-transformadas descritas em (162) e (163) e identidades trigonométricas, resultam as equações (164) e (165):

$$
\begin{gathered}
\psi_{q s}(t)=\omega_{s} \frac{\sqrt{u_{q s}{ }^{2}+u_{d s}{ }^{2}}}{\sqrt{k_{s}^{2}+\omega_{s}^{2}}} \operatorname{sen}\left(\theta_{U_{s}}+\theta_{k \omega}\right)+ \\
+e^{-t k_{s}} \omega_{s} \frac{\sqrt{u_{q s^{2}}{ }^{2} u_{d s}{ }^{2}}}{\sqrt{k_{s}^{2}+\omega_{s}^{2}}} \operatorname{sen}\left(\omega_{s} t-\theta_{U_{s}}-\theta_{k \omega}\right) \\
\psi_{d s}(t)=\omega_{s} \frac{\sqrt{u_{q s}^{2}+u_{d s}^{2}}}{\sqrt{k_{s}^{2}+\omega_{s}^{2}}} \cos \left(\theta_{U_{s}}+\theta_{k \omega}\right)+ \\
-e^{-t k_{s}} \omega_{s} \frac{\sqrt{u_{q s}{ }^{2}+u_{d s}^{2}}}{\sqrt{k_{s}^{2}+\omega_{s}^{2}}} \cos \left(\omega_{s} t-\theta_{U_{s}}-\theta_{k \omega}\right) \\
\theta_{U_{s}}=\operatorname{atan} 2\left(-u_{d s}, u_{q s}\right) \\
\theta_{k \omega}=\operatorname{atan} 2\left(k_{s}, \omega_{s}\right)
\end{gathered}
$$

Para resistências pequenas, é verdade que

$$
\theta_{k \omega} \cong 0
$$

$$
\frac{\omega_{s}}{\sqrt{k_{S}^{2}+\omega_{S}^{2}}} \cong 1
$$

Portanto, as equações (164) e (165) são reduzidas à:

$$
\begin{gathered}
\psi_{q s}(t)=-u_{d s}-e^{-t k_{s}} u_{d s} \cos \left(\omega_{s} t\right)-e^{-t k_{s}} u_{q s} \operatorname{sen}\left(\omega_{s} t\right) \\
\psi_{d s}(t)=u_{q s}-e^{-t k_{s}} u_{q s} \cos \left(\omega_{s} t\right)+e^{-t k_{s}} u_{d s} \operatorname{sen}\left(\omega_{s} t\right)
\end{gathered}
$$

O fluxo do rotor pode ser encontrado adotando-se uma aproximação análoga, considerando a resistências do estator nula. Assim a equação (129) reduz-se à:

$$
\left[\begin{array}{c}
\frac{u_{q s}}{p} \\
\frac{u_{d s}}{p} \\
0 \\
0
\end{array}\right]=\left[\begin{array}{cccc}
\frac{p}{\omega_{s}} & 1 & 0 & 0 \\
-1 & \frac{p}{\omega_{s}} & 0 & 0 \\
-\frac{k_{r M}}{\omega_{s}} & 0 & \frac{x_{r}(p)}{\omega_{s}} & s \\
0 & -\frac{k_{r M}}{\omega_{s}} & -s & \frac{x_{r}(p)}{\omega_{s}}
\end{array}\right]\left[\begin{array}{l}
\psi_{q s} \\
\psi_{d s} \\
\psi_{q r}^{\prime} \\
\psi_{d r}^{\prime}
\end{array}\right]
$$


Resolvendo o sistema resulta em:

$$
\begin{gathered}
\psi_{q s}(p)=-\frac{u_{d s}}{p}+\frac{u_{d s} p+u_{q s} \omega_{s}}{p^{2}+\omega_{s}^{2}} \\
\psi_{d s}(p)=\frac{u_{q s}}{p}+\frac{-u_{q s} p+u_{d s} \omega_{s}}{p^{2}+\omega_{s}^{2}} \\
\psi_{q r}^{\prime}(p)=k_{r M} \omega_{s} \frac{p x_{r}(p) u_{q s}-\left(x_{r}(p)+s p\right) u_{d s} \omega_{s}-u_{q s} s \omega_{s}^{2}}{p\left(p^{2}+\omega_{s}^{2}\right)\left(x_{r}(p)^{2}+s^{2} \omega_{s}^{2}\right)} \\
\psi_{d r}^{\prime}(p)=k_{r M} \omega_{s} \frac{p x_{r}(p) u_{d s}+\left(x_{r}(p)+s p\right) u_{q s} \omega_{s}-u_{d s} s \omega_{s}^{2}}{p\left(p^{2}+\omega_{s}^{2}\right)\left(x_{r}(p)^{2}+s^{2} \omega_{s}^{2}\right)}
\end{gathered}
$$

Observa-se que o fluxo do estator não decai com o tempo, pois a resistência do circuito do estator é considerada nula.

Expandindo os fluxos do rotor em frações parciais

$$
\begin{gathered}
\psi_{q r}^{\prime}(p)=-k_{r M} \frac{s \omega_{s} u_{q s}+k_{r} u_{d s}}{p\left(k_{r}^{2}+s^{2} \omega_{s}^{2}\right)}+ \\
+k_{r M} \frac{-u_{q s}\left(p\left(\omega_{s}-s \omega_{s}\right)-\omega_{s} k_{r}\right)+u_{d s}\left(p k_{r}+\omega_{s}\left(\omega_{s}-s \omega_{s}\right)\right)}{\left(p^{2}+\omega_{s}^{2}\right)\left(k_{r}^{2}+\left(\omega_{s}-s \omega_{s}\right)^{2}\right)}+ \\
+k_{r M} \omega_{s} u_{q s} \frac{k_{r}\left(x_{r}(p) k_{r}+s \omega_{s}\left(\omega_{s}-s \omega_{s}\right)\right)+s \omega_{s}\left(x_{r}(p)\left(\omega_{s}-s \omega_{s}\right)-s \omega_{s} k_{r}\right)}{\left(k_{r}^{2}+s^{2} \omega_{s}^{2}\right)\left(k_{r}^{2}+\left(\omega_{s}-s \omega_{s}\right)^{2}\right)\left(x_{r}(p)^{2}+s^{2} \omega_{s}^{2}\right)}+ \\
+k_{r M} \omega_{s} u_{d s} \frac{k_{r}\left(x_{r}(p)\left(\omega_{s}-s \omega_{s}\right)-s \omega_{s} k_{r}\right)-s \omega_{s}\left(x_{r}(p) k_{r}+s \omega_{s}\left(\omega_{s}-s \omega_{s}\right)\right)}{\left(k_{r}^{2}+s^{2} \omega_{s}^{2}\right)\left(k_{r}^{2}+\left(\omega_{s}-s \omega_{s}\right)^{2}\right)\left(x_{r}(p)^{2}+s^{2} \omega_{s}^{2}\right)} \\
\psi_{d r}^{\prime}(p)=k_{r M} \frac{k_{r} u_{q s}-s \omega_{s} u_{d s}}{p\left(k_{r}^{2}+s^{2} \omega_{s}^{2}\right)}+ \\
-k_{r M} \frac{u_{q s}\left(p k_{r}+\omega_{s}\left(\omega_{s}-s \omega_{s}\right)\right)+u_{d s}\left(p\left(\omega_{s}-s \omega_{s}\right)-\omega_{s} k_{r}\right)}{\left(p^{2}+\omega_{s}^{2}\right)\left(k_{r}^{2}+\left(\omega_{s}-s \omega_{s}\right)^{2}\right)}+ \\
-k_{r M} \omega_{s} u_{q s} \frac{k_{r}\left(x_{r}(p)\left(\omega_{s}-s \omega_{s}\right)-s \omega_{s} k_{r}\right)-s \omega_{s}\left(x_{r}(p) k_{r}+s \omega_{s}\left(\omega_{s}-s \omega_{s}\right)\right)}{\left(k_{r}^{2}+s^{2} \omega_{s}^{2}\right)\left(k_{r}^{2}+\left(\omega_{s}-s \omega_{s}\right)^{2}\right)\left(x_{r}(p)^{2}+s^{2} \omega_{s}^{2}\right)}+ \\
+k_{r M} \omega_{s} u_{d s} \frac{k_{r}\left(x_{r}(p) k_{r}+s \omega_{s}\left(\omega_{s}-s \omega_{s}\right)\right)+s \omega_{s}\left(x_{r}(p)\left(\omega_{s}-s \omega_{s}\right)-s \omega_{s} k_{r}\right)}{\left(k_{r}^{2}+s^{2} \omega_{s}^{2}\right)\left(k_{r}^{2}+\left(\omega_{s}-s \omega_{s}\right)^{2}\right)\left(x_{r}(p)^{2}+s^{2} \omega_{s}^{2}\right)}
\end{gathered}
$$

Aplicando as anti-transformadas de Laplace (162) e (163) e identidades trigonométricas, resulta:

$$
\psi_{q s}(t)=-u_{d s}+\sqrt{u_{q S}^{2}+u_{d s}^{2}} \operatorname{sen}\left(\omega_{s} t-\theta_{U_{s}}\right)
$$




$$
\begin{aligned}
& \psi_{d s}(t)=u_{q s}-\sqrt{u_{q s}^{2}+u_{d s}^{2}} \cos \left(\omega_{s} t-\theta_{U_{s}}\right) \\
& \psi_{q r}^{\prime}(t)=-k_{r M} \frac{\sqrt{u_{q s}^{2}+u_{d s}^{2}}}{\sqrt{k_{r}^{2}+s^{2} \omega_{s}^{2}}} \cos \left(\theta_{U_{s}}+\theta_{k 1}\right)+ \\
& -k_{r M} \frac{\sqrt{u_{q s}^{2}+u_{d s}^{2}}}{\sqrt{k_{r}^{2}+\left(\omega_{s}-s \omega_{s}\right)^{2}}} \cos \left(\omega_{s} t-\theta_{U_{s}}+\theta_{k 2}\right)+ \\
& +e^{-t k_{r}} k_{r M} \omega_{s} \frac{\sqrt{u_{q s}^{2}+u_{d s}^{2}}}{\sqrt{k_{r}^{2}+s^{2} \omega_{s}^{2}} \sqrt{k_{r}^{2}+\left(\omega_{s}-s \omega_{s}\right)^{2}}} \cos \left(s \omega_{s} t-\theta_{U_{s}}-\theta_{k 1}+\theta_{k 2}\right) \\
& \psi_{d r}^{\prime}(t)=k_{r M} \frac{\sqrt{u_{q s}^{2}+u_{d s}^{2}}}{\sqrt{k_{r}^{2}+s^{2} \omega_{s}^{2}}} \operatorname{sen}\left(\theta_{U_{S}}+\theta_{k 1}\right)+ \\
& -k_{r M} \frac{\sqrt{u_{q s}^{2}+u_{d s}^{2}}}{\sqrt{k_{r}^{2}+\left(\omega_{s}-s \omega_{s}\right)^{2}}} \operatorname{sen}\left(\omega_{s} t-\theta_{U_{s}}+\theta_{k 2}\right)+ \\
& +e^{-t k_{r}} k_{r M} \omega_{s} \frac{\sqrt{u_{q s}^{2}+u_{d s}^{2}}}{\sqrt{k_{r}^{2}+s^{2} \omega_{s}^{2}} \sqrt{k_{r}^{2}+\left(\omega_{s}-s \omega_{s}\right)^{2}}} \operatorname{sen}\left(s \omega_{s} t-\theta_{U_{s}}-\theta_{k 1}+\theta_{k 2}\right) \\
& \theta_{k 1}=\operatorname{atan} 2\left(k_{r}, s \omega_{s}\right) \\
& \theta_{k 2}=\operatorname{atan} 2\left(k_{r},\left(\omega_{s}-s \omega_{s}\right)\right)
\end{aligned}
$$

Portanto, os fluxos obtidos para uma resposta ao degrau nas coordenadas $d q 0$ da velocidade síncrona são:

$$
\begin{gathered}
\psi_{q s}(t)=-u_{d s}+e^{-t k_{s}} \sqrt{u_{q S}^{2}+u_{d s}^{2}} \operatorname{sen}\left(\omega_{s} t-\theta_{U_{s}}\right) \\
\psi_{d s}(t)=u_{q s}-e^{-t k_{s}} \sqrt{u_{q s}^{2}+u_{d s}^{2}} \cos \left(\omega_{s} t-\theta_{U_{s}}\right) \\
\psi_{q r}^{\prime}(t)=-k_{r M} \frac{\sqrt{u_{q s}^{2}+u_{d s}^{2}}}{\sqrt{k_{r}^{2}+s^{2} \omega_{s}^{2}}} \cos \left(\theta_{U_{s}}+\theta_{k 1}\right)+ \\
-e^{-t k_{s}} k_{r M} \frac{\sqrt{u_{q s}^{2}+u_{d s}^{2}}}{\sqrt{k_{r}^{2}+\left(\omega_{s}-s \omega_{s}\right)^{2}}} \cos \left(\omega_{s} t-\theta_{U_{s}}+\theta_{k 2}\right)+
\end{gathered}
$$




$$
\begin{aligned}
& +e^{-t k_{r}} k_{r M} \omega_{s} \frac{\sqrt{u_{q s}^{2}+u_{d s}^{2}}}{\sqrt{k_{r}^{2}+s^{2} \omega_{s}^{2}} \sqrt{k_{r}^{2}+\left(\omega_{s}-s \omega_{s}\right)^{2}}} \cos \left(s \omega_{s} t-\theta_{U_{s}}-\theta_{k 1}+\theta_{k 2}\right) \\
& \psi_{d r}^{\prime}(t)=k_{r M} \frac{\sqrt{u_{q S}^{2}+u_{d s}^{2}}}{\sqrt{k_{r}^{2}+s^{2} \omega_{s}^{2}}} \operatorname{sen}\left(\theta_{U_{S}}+\theta_{k 1}\right)+ \\
& -e^{-t k_{s}} k_{r M} \frac{\sqrt{u_{q S}^{2}+u_{d s}^{2}}}{\sqrt{k_{r}^{2}+\left(\omega_{s}-s \omega_{s}\right)^{2}}} \operatorname{sen}\left(\omega_{s} t-\theta_{U_{s}}+\theta_{k 2}\right)+ \\
& +e^{-t k_{r}} k_{r M} \omega_{s} \frac{\sqrt{u_{q s}^{2}+u_{d s}^{2}}}{\sqrt{k_{r}^{2}+s^{2} \omega_{s}^{2}} \sqrt{k_{r}^{2}+\left(\omega_{s}-s \omega_{s}\right)^{2}}} \operatorname{sen}\left(s \omega_{s} t-\theta_{U_{s}}-\theta_{k 1}+\theta_{k 2}\right)
\end{aligned}
$$

Esses resultados devem ser subtraídos dos fluxos em regime permanente.

Os fluxos do estator em regime permanente podem ser escritos, desprezando as resistências, como:

$$
\begin{gathered}
\psi_{q s}(t=0)=-u_{d s 0} \\
\psi_{d s}(t=0)=u_{q s 0}
\end{gathered}
$$

Resolvendo o sistema de equações em (155) desprezando as resistências do estator obtém-se a seguinte equação para os fluxos do rotor em regime permanente $(p=0)$ :

$$
\begin{aligned}
\psi_{q r}^{\prime}(t)= & \frac{\sqrt{u_{q r 0}^{\prime}{ }^{2}+u_{q r 0}^{\prime}{ }^{2}}}{\sqrt{k_{r}^{2}+s^{2} \omega_{s}^{2}}} \omega_{s} \operatorname{sen}\left(\theta_{r 0}+\theta_{e 0}+\theta_{k 1}\right)+ \\
& -k_{r M} \frac{\sqrt{u_{q s 0}^{2}+u_{d s 0}^{2}}}{\sqrt{k_{r}^{2}+s^{2} \omega_{s}^{2}}} \cos \left(\theta_{U_{s 0}}+\theta_{k 1}\right) \\
\psi_{d r}^{\prime}(t)= & \frac{\sqrt{u_{q r 0}^{\prime}{ }^{2}+u_{q r 0}^{\prime}}}{\sqrt{k_{r}^{2}+s^{2} \omega_{s}^{2}}} \omega_{s} \cos \left(\theta_{r 0}+\theta_{e 0}+\theta_{k 1}\right)+ \\
& +k_{r M} \frac{\sqrt{u_{q s 0}^{2}+u_{d s 0}^{2}}}{\sqrt{k_{r}^{2}+s^{2} \omega_{s}^{2}}} \operatorname{sen}\left(\theta_{U_{s 0}}+\theta_{k 1}\right)
\end{aligned}
$$

Portanto, os fluxos resultantes para um degrau de tensão no estator quando a máquina está em regime permanente considerando tanto a velocidade do rotor quanto a excitação constantes são: 


$$
\begin{aligned}
& \psi_{q s}(t)=-u_{d s 0}+u_{d s}-e^{-t T_{s}} \sqrt{u_{q s}^{2}+u_{d s}^{2}} \operatorname{sen}\left(\omega_{s} t-\theta_{U_{S}}\right) \\
& \psi_{d s}(t)=u_{q s 0}-u_{q s}+e^{-t T_{s}} \sqrt{u_{q s}^{2}+u_{d s}^{2}} \cos \left(\omega_{s} t-\theta_{U_{S}}\right) \\
& \psi_{q r}^{\prime}(t)=\frac{\sqrt{{u_{q r 0}^{\prime}{ }^{2}+u_{q r 0}^{\prime}}^{2}}}{\sqrt{k_{r}^{2}+s^{2} \omega_{s}^{2}}} \omega_{s} \operatorname{sen}\left(\theta_{r 0}+\theta_{e 0}+\theta_{k 1}\right)+ \\
& -k_{r M} \frac{\sqrt{u_{q s 0}^{2}+u_{d s 0}^{2}}}{\sqrt{k_{r}^{2}+s^{2} \omega_{s}^{2}}} \cos \left(\theta_{U_{s 0}}+\theta_{T 1}\right)+k_{r M} \frac{\sqrt{u_{q s}^{2}+u_{d s}^{2}}}{\sqrt{k_{r}^{2}+s^{2} \omega_{s}^{2}}} \cos \left(\theta_{U_{s}}+\theta_{k 1}\right)+ \\
& +e^{-t k_{s}} k_{r M} \frac{\sqrt{u_{q s}^{2}+u_{d s}^{2}}}{\sqrt{k_{r}^{2}+\left(\omega_{s}-s \omega_{s}\right)^{2}}} \cos \left(\omega_{s} t-\theta_{U_{s}}+\theta_{k 2}\right)+ \\
& -e^{-t k_{r}} k_{r M} \omega_{s} \frac{\sqrt{u_{q s}^{2}+u_{d s}^{2}}}{\sqrt{k_{r}^{2}+s^{2} \omega_{s}^{2}} \sqrt{k_{r}^{2}+\left(\omega_{s}-s \omega_{s}\right)^{2}}} \cos \left(s \omega_{s} t-\theta_{U_{s}}-\theta_{k 1}+\theta_{k 2}\right)
\end{aligned}
$$

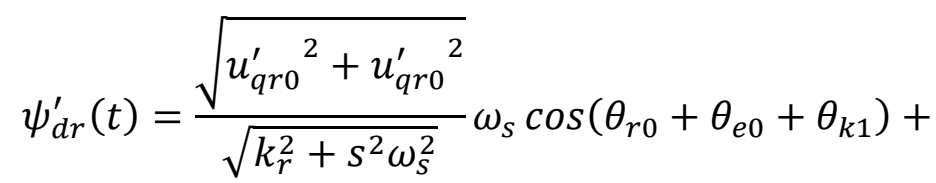

$$
\begin{aligned}
& +k_{r M} \frac{\sqrt{u_{q s 0}^{2}+u_{d s 0}^{2}}}{\sqrt{k_{r}^{2}+s^{2} \omega_{s}^{2}}} \operatorname{sen}\left(\theta_{U_{s 0}}+\theta_{T 1}\right)-k_{r M} \frac{\sqrt{u_{q s}^{2}+u_{d s}^{2}}}{\sqrt{k_{r}^{2}+s^{2} \omega_{s}^{2}}} \operatorname{sen}\left(\theta_{U_{S}}+\theta_{k 1}\right)+ \\
& +e^{-t k_{s}} k_{r M} \frac{\sqrt{u_{q s}^{2}+u_{d s}^{2}}}{\sqrt{k_{r}^{2}+\left(\omega_{s}-s \omega_{s}\right)^{2}}} \operatorname{sen}\left(\omega_{s} t-\theta_{U_{s}}+\theta_{k 2}\right)+ \\
& -e^{-t k_{r}} k_{r M} \omega_{s} \frac{\sqrt{u_{q s}^{2}+u_{d s}^{2}}}{\sqrt{k_{r}^{2}+s^{2} \omega_{s}^{2}} \sqrt{k_{r}^{2}+\left(\omega_{s}-s \omega_{s}\right)^{2}}} \operatorname{sen}\left(s \omega_{s} t-\theta_{U_{s}}-\theta_{k 1}+\theta_{k 2}\right)
\end{aligned}
$$

Nos quais os valores com subscrito "0" representam os valores antes do curtocircuito.

Nota-se que o degrau de tensão aplicado no estator considera ambas componentes "d" e "q". Isso permite analisar a sincronização da máquina na qual a tensão do estator pode ser aplicada com defasagem em relação à referência do sistema de coordenadas síncrono. 
Para uma aproximação, a parcela devida ao fluxo do estator presente no resultado do fluxo do rotor pode ser desconsiderada, pois é consideravelmente menor para valores pequenos de escorregamento. Além disso, pode-se considerar o curto-circuito trifásico brusco para simplificar ainda mais as equações, ou seja:

$$
\begin{gathered}
\theta_{U_{s}}=\theta_{U_{s 0}}=0 \\
\sqrt{u_{q s}^{2}+u_{d s}^{2}}=\sqrt{u_{q s 0}^{2}+u_{d s 0}^{2}}=1
\end{gathered}
$$

Os fluxos devido ao curto-circuito trifásico brusco ficam então:

$$
\begin{gathered}
\psi_{q s}(t)=-e^{-t k_{s}} \operatorname{sen}\left(\omega_{s} t\right) \\
\psi_{d s}(t)=e^{-t k_{s}} \cos \left(\omega_{s} t\right) \\
\psi_{q r}^{\prime}(t)=\frac{\sqrt{{u_{q r 0}^{\prime}}^{2}+u_{q r 0}^{\prime}}}{\sqrt{k_{r}^{2}+s^{2} \omega_{s}^{2}}} \omega_{s} \operatorname{sen}\left(\theta_{r 0}+\theta_{e 0}+\theta_{k 1}\right)+ \\
-\frac{e^{-t k_{r}} \omega_{s}}{\sqrt{k_{r}^{2}+s^{2} \omega_{s}^{2}}} k_{r M} \frac{1}{\sqrt{k_{r}^{2}+\left(\omega_{s}-s \omega_{s}\right)^{2}}} \cos \left(s \omega_{s} t-\theta_{k 1}+\theta_{k 2}\right) \\
\psi_{d r}^{\prime}(t)=\frac{\sqrt{{u_{q r 0}^{\prime}}^{2}+u_{q r 0}^{\prime}}}{\sqrt{k_{r}^{2}+s^{2} \omega_{s}^{2}}} \omega_{s} \cos \left(\theta_{r 0}+\theta_{e 0}+\theta_{k 1}\right)+ \\
-\frac{e^{-t k_{r}} \omega_{s}}{\sqrt{k_{r}^{2}+s^{2} \omega_{s}^{2}}} k_{r M} \frac{1}{\sqrt{k_{r}^{2}+\left(\omega_{s}-s \omega_{s}\right)^{2}}} \operatorname{sen}\left(s \omega_{s} t-\theta_{k 1}+\theta_{k 2}\right)
\end{gathered}
$$

As equações (203) a (206), obtidas a partir de (51) e (52) permitem calcular as correntes a partir dos fluxos.

$$
\begin{aligned}
i_{q s} & =\frac{x_{r r}^{\prime} \psi_{q s}-x_{M} \psi_{q r}^{\prime}}{D} \\
i_{d s} & =\frac{x_{r r}^{\prime} \psi_{d s}-x_{M} \psi_{d r}^{\prime}}{D} \\
i_{q r}^{\prime} & =\frac{-x_{M} \psi_{q s}+x_{s s} \psi_{q r}^{\prime}}{D} \\
i_{d r}^{\prime} & =\frac{-x_{M} \psi_{d s}+x_{s s} \psi_{d r}^{\prime}}{D}
\end{aligned}
$$

Portanto, as correntes nas coordenadas $d q 0$ síncrona resultam: 


$$
\begin{aligned}
& i_{q s}=-\frac{x_{r r}^{\prime}}{D} e^{-t k_{s}} \operatorname{sen}\left(\omega_{s} t\right)+ \\
& -\frac{x_{M}}{D} \frac{\sqrt{u_{q r 0}^{\prime 2}+u_{q r 0}^{\prime 2}}}{\sqrt{k_{r}^{2}+s^{2} \omega_{s}^{2}}} \omega_{s} \operatorname{sen}\left(\theta_{r 0}+\theta_{e 0}+\theta_{k 1}\right)+ \\
& +\frac{x_{M}}{D} \frac{e^{-t k_{r}} \omega_{s}}{\sqrt{k_{r}^{2}+s^{2} \omega_{s}^{2}}} \frac{k_{r M}}{\sqrt{k_{r}^{2}+\left(\omega_{s}-s \omega_{s}\right)^{2}}} \cos \left(s \omega_{s} t-\theta_{k 1}+\theta_{k 2}\right) \\
& i_{d s}=\frac{x_{r r}^{\prime}}{D} e^{-t k_{s}} \cos \left(\omega_{s} t\right)+ \\
& -\frac{x_{M}}{D} \frac{\sqrt{u_{q r 0}^{\prime 2}+u_{q r 0}^{\prime}{ }^{2}}}{\sqrt{k_{r}^{2}+s^{2} \omega_{s}^{2}}} \omega_{s} \cos \left(\theta_{r 0}+\theta_{e 0}+\theta_{k 1}\right)+ \\
& +\frac{x_{M}}{D} \frac{e^{-t k_{r}} \omega_{s}}{\sqrt{k_{r}^{2}+s^{2} \omega_{s}^{2}}} \frac{k_{r M}}{\sqrt{k_{r}^{2}+\left(\omega_{s}-s \omega_{s}\right)^{2}}} \operatorname{sen}\left(s \omega_{s} t-\theta_{k 1}+\theta_{k 2}\right) \\
& i_{q r}^{\prime}=\frac{x_{M}}{D} e^{-t k_{s}} \operatorname{sen}\left(\omega_{s} t\right)+ \\
& +\frac{x_{s s}}{D} \frac{\sqrt{u_{q r 0}^{\prime 2}+u_{q r 0}^{\prime}{ }^{2}}}{\sqrt{k_{r}^{2}+s^{2} \omega_{s}^{2}}} \omega_{s} \operatorname{sen}\left(\theta_{r 0}+\theta_{e 0}+\theta_{k 1}\right)+ \\
& -\frac{x_{s s}}{D} \frac{e^{-t k_{r}} \omega_{s}}{\sqrt{k_{r}^{2}+s^{2} \omega_{s}^{2}}} \frac{k_{r M}}{\sqrt{k_{r}^{2}+\left(\omega_{s}-s \omega_{s}\right)^{2}}} \cos \left(s \omega_{s} t-\theta_{k 1}+\theta_{k 2}\right) \\
& i_{d r}^{\prime}=-\frac{x_{M}}{D} e^{-t k_{s}} \cos \left(\omega_{s} t\right)+ \\
& +\frac{x_{s s}}{D} \frac{\sqrt{u_{q r 0}^{\prime 2}+u_{q r 0}^{\prime}{ }^{2}}}{\sqrt{k_{r}^{2}+s^{2} \omega_{s}^{2}}} \omega_{s} \cos \left(\theta_{r 0}+\theta_{e 0}+\theta_{k 1}\right)+ \\
& -\frac{x_{s S}}{D} \frac{e^{-t k_{r}} \omega_{s}}{\sqrt{k_{r}^{2}+s^{2} \omega_{s}^{2}}} \frac{k_{r M}}{\sqrt{k_{r}^{2}+\left(\omega_{s}-s \omega_{s}\right)^{2}}} \operatorname{sen}\left(s \omega_{s} t-\theta_{k 1}+\theta_{k 2}\right)
\end{aligned}
$$

As correntes para as fases "as" e "ar" nas coordenadas abc são escritas a partir das correntes no sistema de coordenadas $d q 0$ síncrono utilizando a transformação $K^{-1}$. É considerado o eixo "q" alinhado com a tensão "as"

Como $\theta_{k 2} \cong 0$, resulta então: 


$$
\begin{gathered}
i_{a s}=-\frac{x_{M}}{D} \frac{\sqrt{u_{q r 0}^{\prime}{ }^{2}+u_{q r 0}^{\prime}{ }^{2}}}{\sqrt{k_{r}^{2}+s^{2} \omega_{s}^{2}}} \omega_{s} \operatorname{sen}\left(\omega_{s} t+\theta_{r 0}+\theta_{e 0}+\theta_{k 1}\right)+ \\
\quad+\frac{x_{r r}^{\prime}}{D} e^{-t k_{s}} \operatorname{sen}\left(\theta_{s}\right)+ \\
+\frac{x_{M}}{D} \frac{e^{-t k_{r}} \omega_{s}}{\sqrt{k_{r}^{2}+s^{2} \omega_{s}^{2}}} \frac{k_{r M}}{\sqrt{k_{r}^{2}+\left(\omega_{s}-s \omega_{s}\right)^{2}}} \cos \left(\omega_{r} t+\theta_{s}+\theta_{k 1}\right) \\
i_{a r}^{\prime}=\frac{x_{s s}}{D} \frac{\sqrt{u_{q r 0}^{\prime}} \frac{{ }^{2}+u_{q r 0}^{\prime}}{\sqrt{k_{r}^{2}+s^{2} \omega_{s}^{2}}} \omega_{s} \operatorname{sen}\left(s \omega_{s} t+\theta_{e 0}+\theta_{k 1}\right)+}{+\frac{x_{M}}{D} e^{-t k_{s}} \operatorname{sen}\left(\omega_{r} t-\theta_{s}+\theta_{r 0}\right)+} \\
-\frac{x_{s s}}{D} \frac{e^{-t k_{r} \omega_{s}}}{\sqrt{k_{r}^{2}+s^{2} \omega_{s}^{2}}} \frac{k_{r M}}{\sqrt{k_{r}^{2}+\left(\omega_{s}-s \omega_{s}\right)^{2}}} \cos \left(\theta_{s}+\theta_{k 1}-\theta_{r 0}\right)
\end{gathered}
$$

Para obter as correntes das fases "bs", "cs", "br" e "cr" basta defasar as fases "as" e “ar" de $\pm \frac{2 \pi}{3}$. 


\section{ANEXO B CIRCUITOS MAGNÉTICOS}

Este anexo apresentação uma explicação sucinta de circuitos magnéticos para meIhor o entendimento do modelamento do gerador. Para isso será calculado o circuito magnético de um gerador monofásico simplificado de um par de polos.

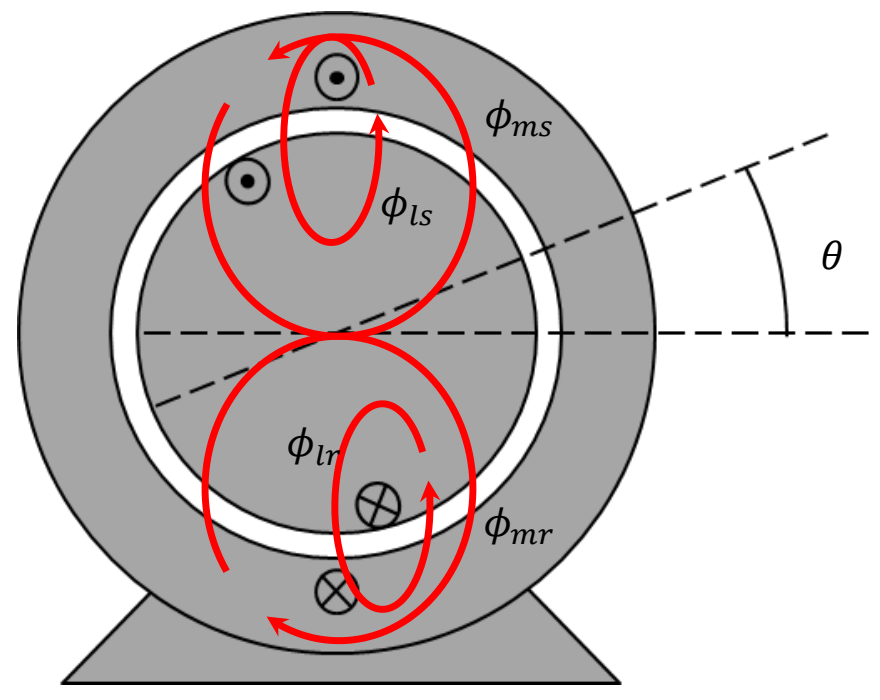

Figura 45 - Circuito magnético para uma máquina monofásica teórica de uma par de polos

Pela Lei de Ampère, o fluxo magnético depende do valor líquido de corrente que intercepta o interior no circuito fechado $\mathrm{l}$ :

$$
\oint H d l=N I
$$

Sendo $\mathrm{l}$ o comprimento do caminho magnético médio, $H=\frac{B}{\mu}$ e $B=\phi A$

$$
\begin{aligned}
& \frac{B}{\mu} l=N I \\
& \phi \mathcal{R}=N I
\end{aligned}
$$

Onde $\mathcal{R}$ é a relutância do circuito magnético médio. O fluxo é então dado como

O fluxo próprio possui uma parcela que concatena com o outro enrolamento, subscrito " $m$ ", e uma parcela que fecha em seu em enrolamento, subscrito " $l$ ":

$$
\phi_{s s}=\phi_{l s}+\phi_{m s}
$$




$$
\begin{gathered}
\phi_{l s}=\frac{N_{s} i_{s}}{\mathcal{R}_{l s}} \\
\phi_{m s}=\frac{N_{s} i_{s}}{\mathcal{R}_{m s}} \\
\phi_{r r}=\phi_{l r}+\phi_{m r} \\
\phi_{l r}=\frac{N_{r} i_{r}}{\mathcal{R}_{l r}} \\
\phi_{m r}=\frac{N_{r} i_{r}}{\mathcal{R}_{m r}}
\end{gathered}
$$

Observa-se que, como o caminho magnético é essencialmente o mesmo, a relutância de magnetização é a mesma para ambos os fluxos. Além disso, vale esclarecer que fluxo de dispersão não depende da posição angular. A figura apresentada é apenas uma representação extremamente simplificada.

O fluxo concatenado por enrolamento dependerá no número de voltas, ou seja:

$$
\lambda=N \phi
$$

Assim, o fluxo concatenado do enrolamento do estator é dado como:

$$
\begin{gathered}
\lambda_{s}=N_{s} \phi_{s}=N_{s} \phi_{s s}+N_{s} \phi_{s r} \\
\lambda_{r}=N_{r} \phi_{r}=N_{r} \phi_{r r}+N_{s} \phi_{r s} \\
\lambda_{s}=\frac{N_{s}^{2} i_{s}}{\mathcal{R}_{l s}}+\frac{N_{s}^{2} i_{s}}{\mathcal{R}_{m}}+\frac{N_{s} N_{r} i_{r}}{\mathcal{R}_{m}} \cos \theta \\
\lambda_{r}=\frac{N_{r}^{2} i_{r}}{\mathcal{R}_{l r}}+\frac{N_{r}^{2} i_{r}}{\mathcal{R}_{m}}+\frac{N_{r} N_{s} i_{s}}{\mathcal{R}_{m}} \cos \theta
\end{gathered}
$$

Colocando as indutâncias equivalentes

$$
\begin{gathered}
\lambda_{s}=L_{l s} i_{s}+L_{m s} i_{s}+L_{s r} i_{r} \cos \theta \\
\lambda_{r}=L_{l r} i_{r}+L_{m r} i_{r}+L_{r s} i_{s} \cos \theta \\
\lambda_{s}=L_{s s} i_{s}+L_{s r} i_{r} \cos \theta \\
\lambda_{r}=L_{r r} i_{r}+L_{r s} i_{s} \cos \theta
\end{gathered}
$$

Entretanto, pelas equações anteriores: 


$$
\begin{gathered}
L_{m r}=L_{m s}\left(\frac{N_{s}}{N_{r}}\right)^{2} \\
L_{s r}=L_{r s}=L_{m 1} \frac{N_{r}}{N_{s}}=L_{m r} \frac{N_{s}}{N_{r}}
\end{gathered}
$$

Refletindo as grandezas do rotor para o estator tem-se:

$$
\begin{gathered}
L_{l r}^{\prime}=L_{l r}\left(\frac{N_{s}}{N_{r}}\right)^{2} \\
i_{r}^{\prime}=i_{r} \frac{N_{r}}{N_{s}} \\
u_{r}^{\prime}=u_{r} \frac{N_{s}}{N_{r}}
\end{gathered}
$$

Portanto, desprezando-se a resistência dos enrolamentos, pode-se escrever referenciando para o estator:

$$
\begin{gathered}
{\left[\begin{array}{l}
u_{s} \\
u_{r}
\end{array}\right]=\frac{d}{d t}\left[\begin{array}{ll}
L_{s s} & L_{s r} \\
L_{r s} & L_{r r}
\end{array}\right]\left[\begin{array}{l}
i_{s} \\
i_{r}
\end{array}\right]} \\
{\left[\begin{array}{l}
u_{s} \\
u_{r}
\end{array}\right]=\frac{d}{d t}\left[\begin{array}{cc}
L_{l s}+L_{m s} & L_{m s} \frac{N_{r}}{N_{s}} \cos \theta \\
L_{m s} \frac{N_{r}}{N_{s}} \cos \theta & L_{l r}+L_{m r}
\end{array}\right]\left[\begin{array}{l}
i_{s} \\
i_{r}
\end{array}\right]} \\
{\left[\begin{array}{c}
u_{s} \\
u_{r}^{\prime} \frac{N_{s}}{N_{s}}
\end{array}\right]=\frac{d}{d t}\left[\begin{array}{cc}
L_{l s}+L_{m s} & L_{m s} \frac{N_{r}}{N_{s}} \cos \theta \\
L_{m s} \frac{N_{r}}{N_{s}} \cos \theta & \left(\frac{N_{r}}{N_{s}}\right)^{2}\left(L_{l r}^{\prime}+L_{m s}\right)
\end{array}\right]\left[\begin{array}{c}
i_{s} \\
i_{r}^{\prime} \frac{N_{s}}{N_{r}}
\end{array}\right]} \\
{\left[\begin{array}{l}
u_{s} \\
u_{r}^{\prime}
\end{array}\right]=\frac{d}{d t}\left[\begin{array}{cc}
L_{l s}+L_{m s} & L_{m s} \cos \theta \\
\frac{N_{s}}{N_{r}} L_{m s} \cos \theta & L_{l r}^{\prime}+L_{m s}
\end{array}\right]\left[\begin{array}{l}
i_{s} \\
i_{r}^{\prime}
\end{array}\right]}
\end{gathered}
$$

Para os casos especiais $\theta=120^{\circ} \mathrm{e} \theta=240^{\circ}$ tem-se

$$
\left[\begin{array}{l}
u_{s} \\
u_{r}^{\prime}
\end{array}\right]=\frac{d}{d t}\left[\begin{array}{cc}
L_{l s}+L_{m s} & -\frac{1}{2} L_{m s} \\
-\frac{1}{2} L_{m s} & L_{l r}^{\prime}+L_{m s}
\end{array}\right]\left[\begin{array}{l}
i_{s} \\
i_{r}^{\prime}
\end{array}\right]
$$

Deve-se notar que para enrolamentos estatóricos defasados de $\theta$ a conclusão é análoga. 